\title{
Exploring a connection to nature and pro-environmental behaviours in a New Zealand business context
}

\author{
Michelle Ruiling Goh \\ A thesis submitted to Victoria University of Wellington \\ in partial fulfilment of the requirements for the degree of \\ Master of Science in Ecology and Biodiversity
}

2021 



\section{Acknowledgements}

First and foremost, I would like to thank my primary supervisor Dr Danielle Shanahan who has provided endless support and encouragement throughout this thesis. Thank you for your invaluable and incredibly speedy feedback on chapter drafts. You were always available to bounce ideas, listen to my rambles, and guide me throughout this thesis. I would also like to thank my secondary supervisor Dr Nicola Nelson for her encouragement during this thesis and for welcoming me into her lab group.

I would like to acknowledge the Nelson lab group (FixIt) for their on-going support. Our weekly catch-ups were a nice break away from desk life, filled with valuable conversations, and delicious snacks that have made this journey enjoyable. A special thank you to Lisa Casasanto for your early support in this research and for accompanying me to a business networking event. I would also like to express my appreciation to the School of Biological Sciences administrative team, particularly Mary Murray and Mark Stephen for their administrative support and friendly corridor smiles. Additional thanks go to the University's Scholarships Office for awarding me with a Masters by thesis Scholarship, and the Human Ethics Committee (\#0000028328) for approving this research.

This research would not have been possible without the business leaders and business networks who shared, participated, and showed enthusiasm for my research. I would like to express my sincere gratitude and a very big thank you for all of your contributions. A notable acknowledgement must be extended to the 10 business leaders who took the time to be interviewed in this research. Your responses form the findings in Chapter 3, and for that, I am extremely appreciative for all that you shared during the interviews.

I am so grateful for my friends who reminded me that there is life beyond university walls. I thoroughly enjoyed going out for food and walks, playing board games, and going to quiz nights. Your friendships have helped me stay positive throughout this research. To my Taekwondo family, thank you for providing an outlet to literally kick away stress during all of my studies. 
To Martin Markwitz, thank you for helping me get through the most difficult parts of this thesis and for celebrating even the smallest of achievements along this journey. Your unwavering confidence in me has contributed to the successful completion of this thesis.

The final thanks belong to my incredibly supportive family. Thank you for making life in Tawa comfortable and wholesome during my studies. To my parents, Molly and Michael, thank you for believing in me and encouraging me to pursue my passions. Your enduing love and support-both emotional and financial, have made the last six years of university education possible, and for that, I am forever grateful. 


\begin{abstract}
Business leaders are likely to have a key role in driving pro-environmental behaviours in their businesses as they continue to face increasing political, social, and economic pressures to become environmentally responsible. While research has shown that a connection to nature is associated with pro-environmental behaviour uptake in a non-business context, there is limited research that explores how a connection to nature relates to proenvironmental behaviours in businesses. This study investigates how New Zealand business leaders perceive their connection to nature in a business context, and how this relates to the pro-environmental behaviours undertaken within their business now and their plans for the future. Specifically, this study aims to: 1) assess how business leaders perceive their current connection to nature; 2) identify the pro-environmental behaviours that business leaders currently report their business undertakes and the barriers to undertaking these behaviours; and 3) evaluate what environmental and business aspirations business leaders hold for the future.
\end{abstract}

This study follows a mixed methods approach to gain an in-depth and broad perspective on these key aims. In Chapter 2, a quantitative online survey was used to gather information from 216 individual business leaders from small to medium-sized businesses from across New Zealand. The survey collected information on the business leaders' individual demographics and connection to nature, business characteristics and pro-environmental behaviours, and perceived barriers to undertaking pro-environmental behaviours. Cluster analysis and independent samples t-tests were used to explore how these characteristics were associated and their significance. The results showed that business leaders who more frequently undertake pro-environmental behaviours have a significantly higher connection to nature and perceive less frequent barriers to adopting pro-environmental behaviours in their businesses. Recycling, purchasing of sustainable products, and conserving electricity were the most frequently undertaken pro-environmental behaviours.

In Chapter 3, qualitative semi-structured interviews were conducted with 10 business leaders who had previously participated in the survey. The interviews examined concepts from the quantitative survey in further detail and explored future aspirations of the business 
leader. Thematic analysis was used to uncover emerging themes and patterns from the business leaders' responses. The results indicated that business leaders perceive a connection to nature and express this through a variety of different pro-environmental behaviours that were not captured in the quantitative survey, such as sourcing local ingredients for products and utilising virtual teams. Both Chapters 2 and 3 indicate that business leaders currently undertake pro-environmental behaviours that may not have direct effects on conserving biodiversity, instead, they can be associated with 'sustainability' more generally. These commonly undertaken pro-environmental behaviours have previously been classified as individual lifestyle behaviours as opposed to conservation behaviours. Business leaders hold aspirations for contributing positively to environmental and biodiversity outcomes, as well as aspirations for New Zealand to further realise its clean, green image. Across both studies, not enough time, the current relationship between businesses and the economy, and costs associated with pro-environmental behaviours were the most commonly identified barriers.

In this research, I show that a greater connection to nature in New Zealand business leaders is associated with more frequent undertaking of pro-environmental behaviours in their business. Findings from this research could inform interventions that support business leaders in growing their connection to nature, potentially leading to more widespread adoption of pro-environmental behaviours in the business community. Findings might be beneficial for organisations that support businesses to become more sustainable because they may be able to anticipate some of the barriers preventing pro-environmental behaviours, and provide targeted materials to assist business leaders on their sustainability journey. Further research is still required to identify how barriers to proenvironmental behaviours can be reduced to enable business leaders to undertake as much as they aspire to for the environment. 


\section{Table of Contents}

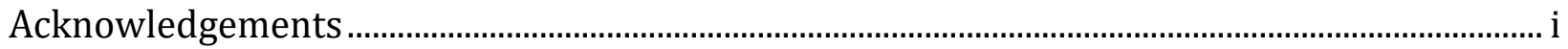

Abstract.............................................................................................................................ii

Chapter 1: General introduction ............................................................................... 1

1.1 Affective connection to nature ................................................................................................

1.2 Cognitive connection to nature............................................................................................... 4

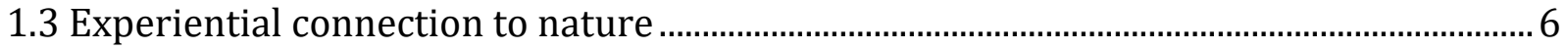

1.4 The connection to nature and businesses .............................................................................

1.5 Importance of conducting research …………………...................................................... 10

1.6 Key questions and thesis outline....................................................................................... 10

Chapter 2: The association between business leaders' connection to nature and pro-

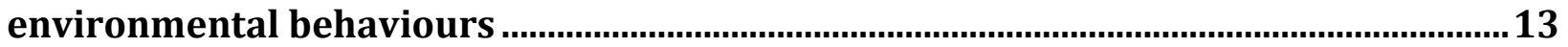

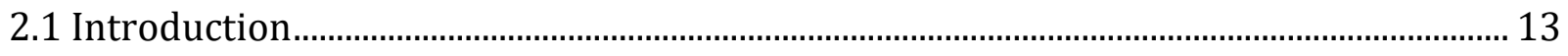

2.2 Methodology

2.2.1 Survey design ........................................................................................................... 16

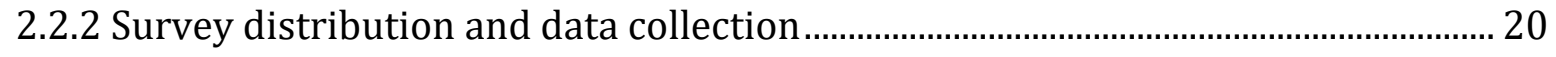

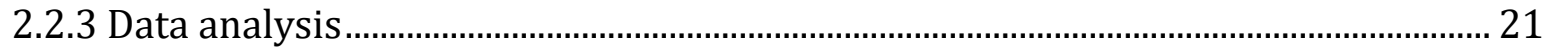

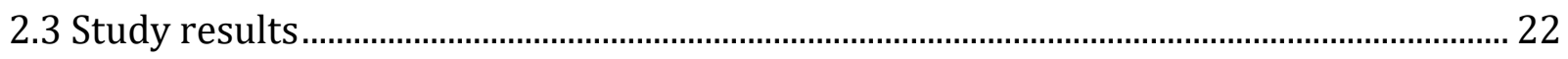

2.3.1 Pro-environmental behaviours ............................................................................... 24

2.3.2 Barriers to undertaking pro-environmental behaviours ........................................... 25

2.3.3 Cluster analysis results.............................................................................................. 26

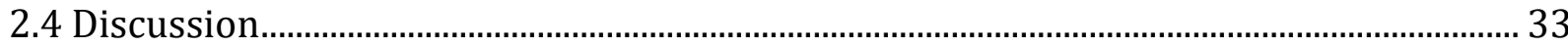

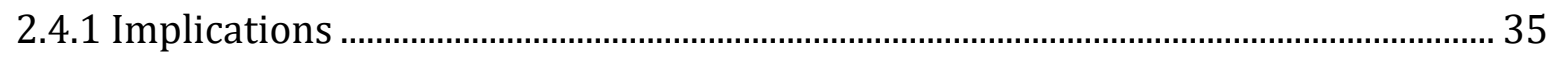

2.4.2 Limitations and future research ………………………………………………....... 36

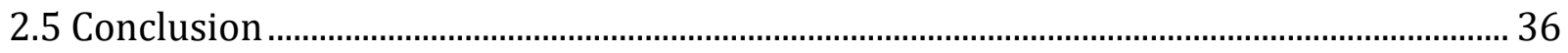

Chapter 3: The role of business leaders' connection to nature in fostering pro-

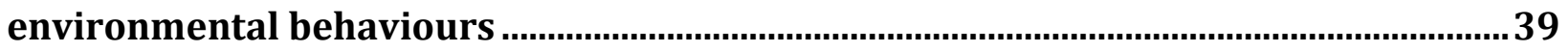

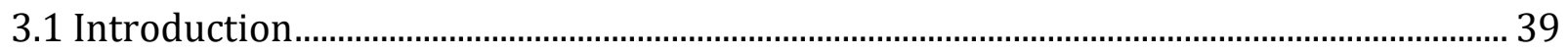

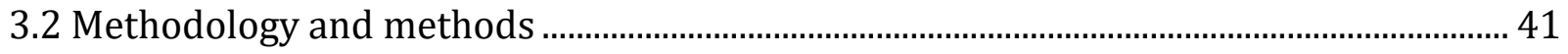

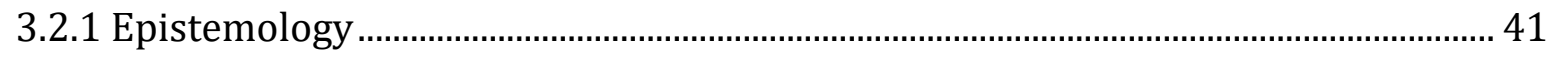

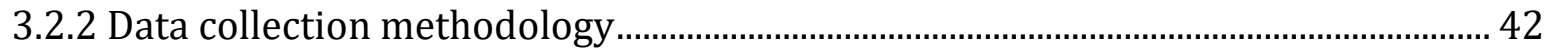




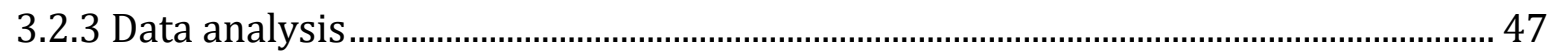

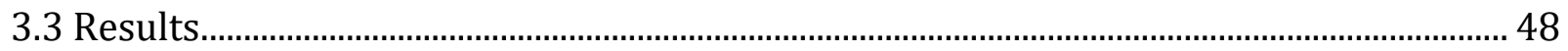

3.3.1 Participants ............................................................................................................ 48

3.3.2 Theme one: connection to nature.................................................................................. 48

3.3.3 Theme two: sustainability journey ………………………………………………...... 53

3.3.4 Theme three: aspirations and barriers ......................................................................... 59

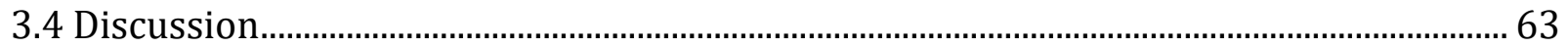

3.4.1 Connection to nature and pro-environmental behaviour............................................ 63

3.4.2 Future aspirations of business leaders .......................................................................... 64

3.4.3 Barriers to pro-environmental behaviours .................................................................. 64

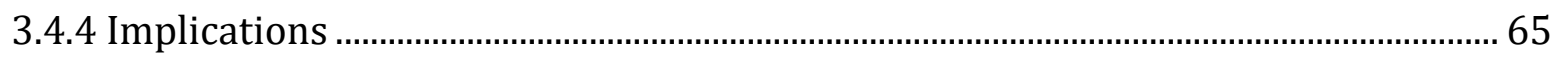

3.4.5 Limitations and future research ................................................................................. 67

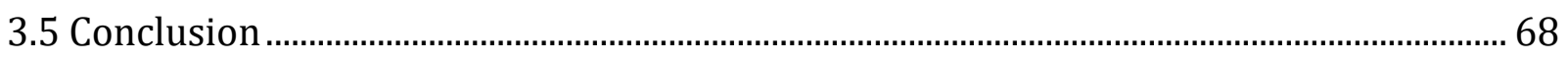

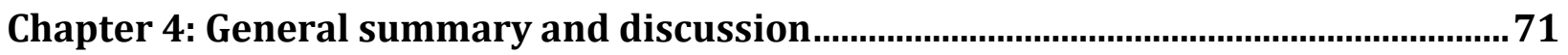

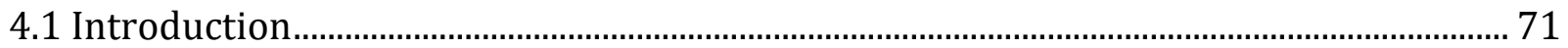

4.2 Overview of findings by chapter...…………………………………………………….... 72

4.2.1 Chapter 2: The association between business leaders' connection to nature and pro-environmental behaviours......................................................................................... 72

4.2.2 Chapter 3: The role of business leaders' connection to nature in fostering proenvironmental behaviours ................................................................................................ 73

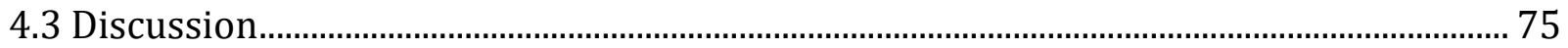

4.3.1 Connection to nature in a business context................................................................. 75

4.3.2 Pro-environmental behaviours in a business context................................................. 76

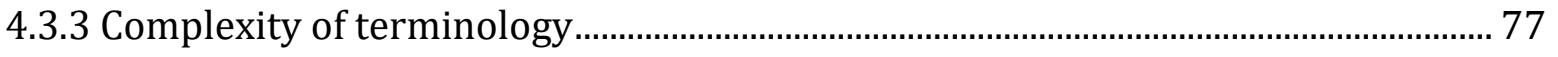

4.3.4 Value of a mixed methods approach ……………………………………………….... 78

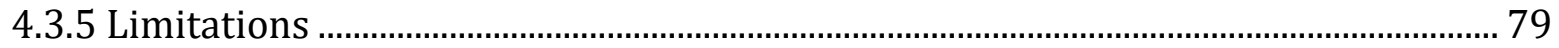

4.3.6 Future research directions......................................................................................... 81

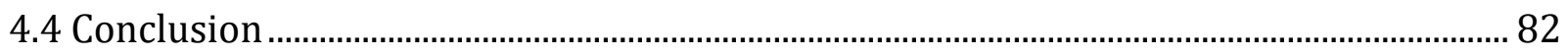

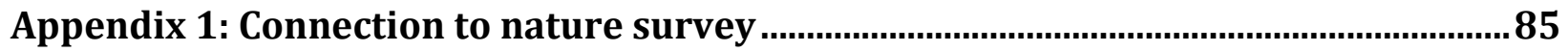

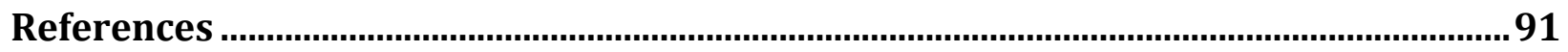




\section{Chapter 1: General introduction}

People's affective, cognitive, and experiential connections to nature are useful dimensions to describe various types of human-nature relationships (Nisbet et al. 2009), and they also have varying links to pro-environmental behaviours. Pro-environmental behaviours can be defined as behaviours which aim to reduce the negative impacts of people's actions on the natural world (Stern, 2000). This chapter focusses on these three dimensions to explore how a connection to nature is relevant to individuals in a business context, and how that might relate to pro-environmental behaviours. Exploring this is important because there are potentially significant outcomes that could be achieved for businesses and the environment when a connection to nature leads to pro-environmental behaviours.

The first three sections of this chapter explore how the science literature describes connection to nature, examine how connection to nature is relevant in a business context, and outlines the relationship between connection to nature and pro-environmental behaviour. The final section explores businesses and connection to nature through explaining the interactions of connection to nature, discussing how businesses benefit from adopting pro-environmental behaviours, and exploring the role of businesses in achieving environmental outcomes. The aim of this chapter is to summarise the current literature on connection to nature and to extend our understanding on connection to nature through incorporating a business lens.

\subsection{Affective connection to nature}

An affective connection to nature can be defined as a positive conscious relationship with nature that is experienced at the emotional or subjective level of the individual (Kals, 2014). The construct of affective connection in environmental psychology has only recently started to gain attention in the empirical literature (Ives et al., 2017). Research has explored the importance of affective connections to the natural environment under a variety of different terms such as emotional affinity (Kals et al., 1999), love of nature (Gebhard, 1994), the nature relatedness spirituality dimension (Nisbet et al., 2009), and inclusion of nature in self (Schultz, 2001). 
Emotional interactions with the natural environment are shown to stem from two mental faculties: 1) attention - the ability to be captivated by natural stimuli, and 2) empathy - the ability to emotively associate with different life forms (Barbiero, 2011; Gruen, 2009). These faculties along with an individual's past and present exposure to the natural environment are shown to influence an affective connection to nature (Müller et al., 2009).

An affective connection to nature is closely related to the creation of an environmental identity (Hinds \& Sparks, 2008). An environmental identity describes how humans perceive their relationship with the natural world (Clayton, 2003). Studies have shown that individuals who hold strong environmental identities perceive themselves as being emotionally connected, or inseparable from nature (Dutcher et al., 2007; Mayer, 2004; Nisbet et al., 2009). Environmental identities are unique because people feel and experience nature in different ways (Kals, 2014).

\subsubsection{Affective connection to nature in a business context}

Only in the last decade has the literature really begun to explore the role of an affective connection to nature in a business context (Wang et al., 2019). Research has predominantly focussed on the inclusion of the natural environment into business concepts such as corporate identity (Handelman, 2006; Heikkurunen, 2010; Otubanjo, 2013) and stakeholder management (Balmer \& Fukukawa, 2007; Garvare \& Johansson, 2010; Madsen \& Ulhøi, 2001).

Every business has a corporate identity that defines what the organisation is to itself and its stakeholders (Balmer, 1995; Zinkhan et al., 2001). Corporate identities are dynamic and describe how companies perceive the social space in which they coexist with other societal actors-organisations, consumers, and natural spaces (Handelman, 2006). There are clear similarities between an environmental identity and corporate identity; both are unique and based on relationship perceptions (Gray \& Balmer, 1998; Kals, 2014). If a business has a positive conscious relationship with nature, then the corporate identityincluding activities and status, are likely to reflect an affective connection (Brown \& Dacin, 1997). 
In the development of a corporate identity, environmental values will have differing levels of importance dependent on the company's stakeholder management perspective (Heikkurinen, 2010). Companies that perceive the natural environment as a stakeholder are more likely to embed environmental values into their identities (Philips \& Reichart, 2000; Starik, 1995). In contrast, companies that perceive the natural environment as external to the corporate identity are more likely to adopt environmental values superficially at the corporate image level, in response to stakeholder pressures (Crane, 2000; Heikkurinen, 2010).

\subsubsection{Affective connection and pro-environmental behaviour in business}

Several studies have shown that an affective connection to the natural environment predicts pro-environmental behaviour (Hinds \& Spark, 2008; Mayer \& Frantz, 2004; Pereira \& Forster, 2015). Such behaviours include, for example, using public transport and joining environmental organisations (Kals et al., 1999), purchasing environmentally-friendly products and conserving water and energy (Schultz \& Zelezny, 1998), and participating in green initiatives such as solar electricity programmes (Clark et al., 2003). These behaviours may well be expressed in the workplace, and ultimately this could have significant implications for businesses particularly where business leaders embrace the outcomes. For example, a company leadership that implements solar panels may both reduce the environmental footprint of an organisation and receive financial benefits through reduced electricity costs.

Despite the potentially significant implications for businesses, there are very few studies that examine the direct role of affect in pro-environmental behaviour in the workplace (Russell \& Griffiths, 2008). However, the few studies that do exist indicate that a key challenge for engaging employees in pro-environmental behaviours is developing a workplace culture where employees feel committed to sustainable practices (Rezapouraghdam et al., 2018). It has been demonstrated that businesses that incorporate environmental values in their corporate identity have employees who feel more encouraged to participate in pro-environmental behaviours (Goldsmith, 1997; Zientara \& Zamojska, 2016). Further research is required in this area because employee pro-environmental 
behaviours are likely to contribute significantly to an organisation's environmental achievements (Blok et al., 2015).

\subsection{Cognitive connection to nature}

A cognitive connection to nature is shaped by pre-conceived attitudes, values, and beliefs (Nisbet et al., 2009). Environmental attitudes have been described in the literature as predispositions towards environmentally-related situations or issues (Buijs, 2007). Additionally, environmental values and beliefs have been described as being nature-related views that guide what is moral, just, or desirable for the natural environment (Kempton et

al., 1995). Research into nature connection has predominantly focussed on exploring a cognitive connection to nature (Ives et al., 2017).

Schultz et al. (2004), claims that connection to nature is inherently cognitive. There is extensive research that explores how a cognitive connection to nature is conceptualised under different values including: biospheric, egoistic, and altruistic (Stern et al., 1995), intrinsic (Chan et al., 2016), and utilitarian, naturalistic, and moralistic (Lumbar, 2017). A cognitive connection to nature has been found to have similar characteristics to personality traits: being different for individuals and groups, relatively consistent over time and in different situations, and having the ability to change (Mayer \& Frantz, 2004; Nisbet et al., 2009).

\subsubsection{Cognitive connection to nature in a business context}

In the business literature, a cognitive connection to nature has been investigated using environmental management concepts. Environmental management covers broad areas of concern including: resource management, pollution, and environmental impact (Kirk, 1995). Early environmental management research focussed on improving financial performance (Klassen \& McLaughlin, 1996), reducing business functions that cause pollution (Khanna et al., 2009), and meeting changing government pressures and regulations (Berry \& Rondinelli, 1998). More recent research has looked at incorporating environmental values into corporate strategy (Sugiarto et al., 2019), and communicating sustainable environmental actions (Amaladoss \& Manohar, 2011). 
Businesses are often considered to have a moral and civic duty to respond to environmental issues (Lent \& Wells, 1992). One way businesses have responded to this obligation is by incorporating sustainable business models and frameworks into their corporate strategy (Ekwueme et al., 2013). Since the 1980s, Corporate Social Responsibility has been a model utilised by businesses to guide environmental, social, and ethical practices (Utting, 2007). Businesses that incorporate such models are likely to have a cognitive connection to nature because environmental values are embedded within the company's leadership, culture, and environmental capability (Chen et al., 2012).

\subsubsection{Cognitive connection to nature and pro-environmental behaviour in business}

When businesses include considerations about the natural environment in their corporate strategies, they are shown to improve environmental performance, particularly when employees are involved in the creation of the strategies (Borial, 2005). When employees are not involved in the strategy creation, it has been shown by Jones et al. (2012) and Tudor et al. (2008) that employees need to be made aware of the strategies through training or visual cues before they are shown to act sustainably. Barriers to adopting environmental actions include time, finances, and a lack of environmental knowledge and skills (Gerstenfeld \& Roberts, 2000).

Research investigating how a cognitive connection to nature affects proenvironmental behaviours have mostly used questionnaire scales to measure self-reported behaviours, behavioural intentions, and other concerns for the environment (Dietz et al., 2005). Findings from these studies suggest that cognitive dimensions including attitudes, values, morals, and beliefs influence pro-environmental behaviours such as recycling, energy usage, transportation choice, and purchasing behaviour (Diekmann \& Preisendörfer, 1998; Milfont \& Duckitt, 2010). Additionally, Howell et al. (2011), claims that individuals who have positive life attitudes and a higher connection to nature engage with more proenvironmental behaviours, while Van Birgelen et al. (2009), suggest that greater knowledge about environmental issues also influences pro-environmental behaviour. 
Recent research has indicated that there is growing interest around how to incorporate pro-environmental behaviours in the workplace through culture change and influencing employee perceptions and attitudes of the business (Blok et al., 2015; Lukas et al., 2008). Robertson and Barling (2012), found that environmental leadership and proenvironmental behaviour needs to start with a company's top management, while Daily et al. (2008), concluded that employee attitudes and behaviour are critically impacted by the middle management. Assessing how a cognitive connection to nature leads to proenvironmental behaviour in a business context is difficult due to the complex structure of businesses (Hargreaves, 2011).

\subsection{Experiential connection to nature}

An experiential connection to nature can be defined as an individual's physical interactions with the natural environment (Ives et al., 2017). Furthermore, Nisbet et al. (2009), describes an experiential connection to nature as an individual's familiarity and attraction to the natural environment. Physical interactions with the natural environment are shown to influence positive environmental attitudes (Rosa \& Collado, 2019), environmental knowledge (Bögeholz, 2006), and environmental beliefs (Ewert et al., 2005).

An experiential connection has been explored to understand the interactions between an individual's experiences and local natural areas (Cosquer et al., 2012), health benefits of nature exposure (Shanahan et al., 2015), and the causes and consequences of an experiential connection to nature (Ives et al., 2018). Research has also started to examine the 'extinction of experience' as humans become more dissociated from the natural environment (Colléony et al., 2017; Schuttler et al., 2018; Soga \& Gaston, 2016).

In addition to this research, new research around 'reconnecting to nature' is emerging from a range of disciplines including environmental education, conservation biology, sustainability science, and environmental psychology (Ives et al., 2018). Research on the experiential connection to nature is of interest because there is significant evidence which demonstrates the importance of this connection on wellbeing (Shanahan et al., 2015), cognition (Berman et al., 2008), and mood (Ryan et al., 2010). 


\subsubsection{Experiential connection to nature in a business context}

In the business literature, there are many studies looking at how the workplace environment can be changed to improve employee wellbeing, cognition, and mood (Kalliath et al., 2012; Shibata \& Suzuki, 2004). However, there are few studies that directly link these improvements to an experiential connection to nature. Despite the research gap, research about workplace environments is important because many people spend majority of their working time indoors (Dravigne et al., 2008).

Research has mostly focussed on improving workplace environments with the addition of, or exposure to natural environmental features. For example, Chang and Chen (2005), found that natural window views improved employee health by reducing nervousness and anxiousness. In a study by Dravigne et al. (2008), employees who owned interior office plants reported better job satisfaction and a better quality-of-life score. While Miller et al. (2009), concluded that exposure to natural sunlight in the office improved work productivity of employees. Businesses that positively influence their employees' physical interactions with the natural environment are shown to have improved business functionality due to the benefits associated with an experiential connection to nature.

While there is resounding evidence for the inclusion of natural features in the workplace, there is little research directly linking these practices to an improved experiential connection to nature. Research that looks at the impacts of biodiversity in the workplace are also limited (Snep et al., 2011). It is important to broaden the scope of research into these areas because urban environments provide an opportunity to reconcile humans to nature where they already exist (Miller, 2006).

\subsubsection{Experiential connection and pro-environmental behaviour in business}

There is significant evidence in the literature which suggests that an experiential connection to nature influences pro-environmental behaviour. Pro-environmental behaviours that have been associated with an experiential connection to nature include signing environmental protection petitions, recycling, choosing to use public transport (Finger, 1994), spending time outdoors, donating money to environmental organisations, and green consumerism 
(Nord et al., 1998). Findings in the literature suggest that people are reconnecting with nature through gardening (Kiesling \& Manning, 2010), having plants indoors (Bringslimark et al., 2009), and choosing to participate in outdoor recreational activities such as hiking and bird watching (Karkoff, 2003).

Individuals can improve their experiential connection to nature relatively easily through their behaviour choices; however, there are many factors that influence behaviour choices in a workplace environment (Hargreaves, 2011). In a business context, the adoption and commitment to pro-environmental behaviours depends on the involvement of other employees and the environmental friendliness of the business (Boiral, 2009; Saifulina \& Carballo-Penela, 2017).

There is little research in the business literature that focusses on how sustainable buildings or green environments affect pro-environmental behaviour in the workplace. One study by McCunn \& Gifford (2012), showed that green workplaces were not associated with a direct effect on employee pro-environmental behaviours. This contradicted their hypothesis that exposure to green workplaces would be positively associated with proenvironmental behaviours. Further research is needed to determine how green environments might influence workplace pro-environmental behaviours, considering how exposure to nature has been shown to predict pro-environmental behaviour in other studies (Pensini et al., 2016; Whitburn et al., 2019).

\subsection{The connection to nature and businesses}

Affective, cognitive, and experiential connections to nature interact (Ives et al., 2018). For example, Lin et al. (2004) demonstrated that people who held a positive psychological perception of nature (emotional and cognitive connections) were more inclined to visit nature reserves and parks (experiential connection). Similarly, Cheng and Munroe (2010), concluded that a child's emotional connection to nature-sense of oneness and empathy for creatures, influenced how they participated in future nature-based activities (experiential connection). In another study, Koenig-Lewis et al. (2014), showed that purchasing intention 
of green packaging by individuals was influenced by their concerns for the environment (cognitive connection) and positive and negative emotions (emotional connection).

From a theoretical perspective, it is evident that a connection to nature is complex and multifaceted. While understanding each dimension separately is important, it is crucial to acknowledge that these dimensions interact with each other to form an individual's or business's connection to nature. Affective, cognitive, and experiential dimensions in combination are shown to influence pro-environmental behaviours.

\subsubsection{Business benefits of pro-environmental behaviours}

In practice, businesses that integrate environmental values within the company's culture and pro-environmental behaviours are more likely to achieve better operational and marketing performance (Fraj et al., 2010). Additionally, businesses that communicate their proenvironmental behaviours to employees, consumers, and stakeholders also have benefits such as more satisfied and loyal customers (Menon \& Menon, 1997), enhancement of environmental reputation (Miles \& Covin, 2000), access to green partnerships (Sadovnikova \& Pujari, 2017), entry into new markets (Weber, 2008), and ultimately increased revenue (Malik, 2015). There is resounding evidence in the literature which suggests that embedding environmental values that lead to pro-environmental behaviours in a business creates competitive advantage (York, 2009).

\subsubsection{Potential role of businesses to achieve environmental outcomes}

When businesses engage in pro-environmental behaviours, they are able to achieve impactful environmental outcomes. For example, businesses that provide environmental education and awareness training are shown to influence the many daily decisions and actions of employees which accumulate to large improvements for the organisation's environmental impact (Perron et al., 2006). Furthermore, the sheer size and distribution of organisations means that they are well placed to contribute resources and time to achieve environmental outcomes, compared to any other group (Studer et al., 2006). Large businesses also have the ability to influence environmental policy and regulations (Child \& Tsai, 2005). When businesses adopt pro-environmental behaviours, they have the potential 
to conserve finite resources and improve environmental conditions globally (Rondinelli \& Berry, 2000).

\subsection{Importance of conducting research}

Extending our knowledge of connection to nature through a business lens is important because it is becoming apparent that businesses can achieve significant environmental outcomes while benefiting from adapting their current primary business operations to include pro-environmental behaviours. While this is becoming clear in practice, there are knowledge gaps in the literature that could be explored to promote further connection to nature and pro-environmental behaviour in businesses. The affective, cognitive, and experiential dimensions identified by Nisbet et al. (2009) provide a useful construct for understanding connection to nature and pro-environmental behaviour of individuals, and this can be translated in theory into a business context as demonstrated throughout this chapter. However, there is very limited literature that examines this issue explicitly. Further research is necessary to understand the existing connection to nature of individuals in businesses to promote future pro-environmental behaviours in the workplace due to the significant outcomes that could be realised when businesses are shown to adopt proenvironmental behaviours.

\subsection{Key questions and thesis outline}

This thesis explores how New Zealand business leaders perceive their connection to nature in a business context, and how they currently, and may in the future, contribute positively to environmental outcomes. Specifically, this thesis aims to:

1. assess how business leaders perceive their current connection to nature;

2. identify the pro-environmental behaviours that business leaders currently report their business undertakes, and the barriers to undertaking these behaviours; and

3. evaluate what environmental and business aspirations business leaders hold for the future. 
This thesis consists of two stand-alone manuscripts formatted for publication in peerreviewed journals. Chapter 2 follows quantitative methods with the aim to measure associations between business leaders' connection to nature, pro-environmental behaviours, and barriers to adopting pro-environmental behaviours. Assessing these factors in conjunction provides insight into how New Zealand business leaders currently connect to nature and how this is associated with their businesses' pro-environmental behaviours. Chapter 3 utilises qualitative methods with the aims of investigating how business leaders individually express their connection to nature in their businesses and exploring their future aspirations. Evaluating how connection to nature is expressed in current businesses reveals how business leaders may contribute to current and future positive environmental outcomes. Chapter 4 provides a general discussion regarding findings from the previous two data chapters and outlines future research directions. 


\section{Chapter 2: The association between business leaders' connection to nature and pro-environmental behaviours}

\subsection{Introduction}

New Zealand is promoted internationally as clean and green, and New Zealand businesses often trade off this branding (Bell, 2008). Additionally, New Zealanders perceive a connection with the land as a central crux to their identity as a nation (Brown, 2008). Despite the natural environment shaping our identity, there is limited research that explores how this connection to nature translates into pro-environmental behaviours in a business setting.

Business and nature are inherently connected in an interactive system-whereby energy and materials continuously cycle in a feedback loop of nature and industry (Rosen, 2005). Research aimed at understanding this connection, and people's role in it, is important because businesses play a crucial role in the achievement of sustainable development goals including responsible consumption and production, promoting inclusive and sustainable economic growth, and fostering sustainable industrialisation and innovation (OECD, 2017). Previous research has focussed on large firms, where environmental and economic reporting are more easily accessible in annual reports (Collins et al., 2007); fewer, more recent studies are beginning to examine the environmental role of small to medium-sized businesses. Blundel et al. (2013), claim that small to medium-sized businesses have an important role in addressing current environmental challenges. In New Zealand, there is a significant opportunity for this group to play a key role in addressing environmental challenges because they make up $97 \%$ of all classified businesses and employ more than 630,000 people, or $29 \%$ of all New Zealand employees ("Supporting SME's," 2020). When looking internationally, small to medium-sized businesses are a substantial group that could contribute to positive environmental outcomes considering that they make up 99\% of all businesses across the Organisation for Economic Co-operation and Development (OECD, 2019). While by definition these businesses are small, their numbers ensure that together they have a significant impact on environmental outcomes. 
The expression of pro-environmental behaviours in a New Zealand business setting is increasing, and takes many forms. In a longitudinal survey study by Collins et al. (2010), the average number of companies in New Zealand adopting pro-environmental behaviours increased by $10 \%$ over a three-year period, with the most common behaviour being recycling programmes. In another survey study, Lewis and Cassells (2010), found that a group of small to medium-sized businesses in the New Zealand manufacturing industry were most actively engaged in waste management practices when compared to other proenvironmental behaviours including operational practices, design for the environment, and environmental management. These commonly adopted pro-environmental behaviours are the ones that make good business sense because they are relatively easy to adopt while simultaneously improving organisational efficiency and producing some positive environmental results (Benn et al., 2014).

Many factors may influence whether a small to medium-sized business engages in pro-environmental behaviours. For example, there is a strong connection between how a business values nature and its environmental performance (Vazquez \& Liston-Heyes, 2008). Some research concludes that an individual business leader's values and beliefs are significant motivating factors for adopting environmental responsibility and proenvironmental behaviours within their business (Cambra-Fierro et al., 2008; Hemingway \& Maclagan, 2004). However, this area of research is still understudied and consists of mostly informal analysis, and I am aware of no studies addressing this knowledge gap in New Zealand. More commonly, research has investigated barriers that business leaders' encounter when trying to implement pro-environmental behaviours in their businesses. In such research, small business owners often characterise a lack of time as one of the most common reasons for not engaging with pro-environmental behaviours (Lepoutre \& Heene, 2006). Other common barriers for small business owners include a lack of awareness of environmental legislation (Stokes \& Rutherfoord, 2000), lack of human and financial resources (Rutherfoord et al., 2000), and limited managerial expertise (Vernon et al., 2003).

Not all pro-environmental behaviours are equal in how they affect the natural environment. Previous studies have classified pro-environmental behaviours into distinct 
categories, specifically 'individual lifestyle behaviours' and 'conservation behaviours' (Cooper et al., 2015; McMullin et al., 2007). Conservation behaviours such as habitat restoration or volunteering for conservation have been defined as being able to alter ecosystems or influence the availability of natural resources (Stern, 2000). These types of pro-environmental behaviours are shown to have direct effects on biodiversity conservation (Veríssimo, 2013). In contrast, individual lifestyle behaviours such as reducing electricity usage and waste minimisation may only have limited effects on environmental quality (Poortinga et al., 2004). Ceballos et al. (2017), claims that people need to start engaging in pro-environmental behaviours that actively support the restoration of biodiversity, both flora and fauna. This is reflected in Te Mana o te Taiao-Aotearoa New Zealand Biodiversity Strategy 2020, whereby everyone-whānau, hapū, iwi, Māori communities, organisations, environmental non-governmental organisations, central and local government, businesses, industry, and every individual needs to be actively involved in actions that protect and restore biodiversity.

While studies have looked at a connection to nature, pro-environmental behaviours, and barriers in isolation, or in some combination, there is a need for research that investigates how these factors interact together in a business context. Further research is needed to understand how a business leader's connection to nature influences their proenvironmental behaviours to inform decision-making across multiple areas which include pro-environmental behaviours that deliver positive biodiversity outcomes, corporate social responsibility goals in businesses, policy making in government, and encouraging further research and social awareness in this area.

In this chapter, I aim to investigate the New Zealand small to medium-sized business landscape to examine whether and how a connection to nature is related to proenvironmental behaviour in a business setting. This study examines the association between business leaders' connection to nature and their businesses' pro-environmental behaviours, while considering characteristics and barriers that may influence pro-environmental behaviour uptake. Specifically, this quantitative data chapter aims to: 
1. identify what and how often businesses are currently undertaking proenvironmental behaviours;

2. analyse the different types of pro-environmental behaviours-conservation versus individual lifestyle, engaged businesses are taking, and determine whether there are different groups within this environmentally engaged community; and

3. examine the extent to which pro-environmental behaviours within businesses are associated with the connection to nature of their business leaders.

\subsection{Methodology}

\subsubsection{Survey design}

A survey was designed and deployed to target individuals who are small to medium-sized business leaders from across New Zealand who are likely to already be involved in some sort of environmental action. The survey was designed with the goal of collecting information on business leaders' individual demographics and connection to nature, business characteristics and pro-environmental behaviours, and perceived barriers to undertaking pro-environmental behaviours. This work was carried out under the Victoria University of Wellington Human Ethics approval number \#0000028328.

The survey was created in Qualtrics Survey Software. To encourage responses and reduce non-response bias, the survey included brief and succinct questions with no jargon, limited/ optional open-ended textboxes, and utilised drop box and ticking measures to capture answers. The survey was also kept to under 10 minutes to reduce respondent fatigue. The survey content outline is shown below in Table 2.1 and a full copy of the survey can be found in Appendix 1. 
Table 2.1: Variables included in the survey, measures for each variable, and rationale for including the variable.

\begin{tabular}{|c|c|c|}
\hline Variable name & Measure & Description/ rationale \\
\hline Business leader & $\begin{array}{l}\text { Yes (respondent is a business leader)- } \\
\text { survey continues; No (respondent is not a } \\
\text { business leader)-survey terminates }\end{array}$ & $\begin{array}{l}\text { Determines whether the respondent can } \\
\text { make decisions in a New Zealand business. }\end{array}$ \\
\hline Industry type & $\begin{array}{l}\text { Respondent selects the most relevant from } \\
\text { same categories as those used in the New } \\
\text { Zealand Census: Agriculture, forestry and } \\
\text { fishing; Mining; Manufacturing; electricity, } \\
\text { gas, water and waste services; } \\
\text { Construction; Wholesale trade; Retail trade } \\
\text { and accommodation; Transport, postal and } \\
\text { warehousing; Information media and } \\
\text { telecommunications; Financial and } \\
\text { insurance services; Rental, hiring and real } \\
\text { estate services; Professional, scientific, } \\
\text { technical, administrative and support } \\
\text { services; Public administration and safety; } \\
\text { Education and training; Health care and } \\
\text { social assistance; Arts, recreation and other } \\
\text { services; Other (please mention) } \\
\text { Categories from the New Zealand Census } \\
\text { Classification Categories }\end{array}$ & $\begin{array}{l}\text { Industry type may have an important } \\
\text { influence on pro-environmental behaviour } \\
\text { because industry-specific conditions } \\
\text { influence an organisation's ability to engage } \\
\text { in environmental practices (Aragón-Correa } \\
\text { et al., 2008). Certain industries have better } \\
\text { plausibility and capability for corporate } \\
\text { social responsibility activities (Porter \& } \\
\text { Kramer, 2006). }\end{array}$ \\
\hline $\begin{array}{l}\text { Postcode for } \\
\text { business location }\end{array}$ & Open ended textbox & $\begin{array}{l}\text { Determines whether the business is located } \\
\text { in New Zealand (i.e. relevant to the study). }\end{array}$ \\
\hline $\begin{array}{l}\text { Number of } \\
\text { employees }\end{array}$ & $\begin{array}{l}\text { Category selected from those identified in } \\
\text { the Ministry of Business, Innovation and } \\
\text { Employment Small Business Factsheet, and } \\
\text { include: } 1-5 ; 6-19 ; 20-49 ; 50-99 ; 100+ \\
\text { Categories from Ministry of Business, } \\
\text { Innovation and Employment Small } \\
\text { Business Factsheet }\end{array}$ & $\begin{array}{l}\text { The size of an organisation may have an } \\
\text { important influence on pro-environmental } \\
\text { behaviour. While there has been less } \\
\text { research into small to medium-sized } \\
\text { businesses, larger firms have been shown } \\
\text { to contribute proportionately more funds } \\
\text { into social and environmental interests } \\
\text { (Adams \& Hardwick, 1998; Hoogendoorn et } \\
\text { al., 2015). }\end{array}$ \\
\hline $\begin{array}{l}\text { Organisation } \\
\text { structure }\end{array}$ & $\begin{array}{l}\text { Category selected from those identified in } \\
\text { business.govt.nz: Sole trader; Company; } \\
\text { Partnership; Other, please detail } \\
\text { Categories from business.govt.nz }\end{array}$ & $\begin{array}{l}\text { Organisation structure may have an } \\
\text { important influence on pro-environmental } \\
\text { behaviour because it outlines the co- } \\
\text { ordination of activities to achieve an } \\
\text { organisation's objectives and goals } \\
\text { (Maduenyi et al., 2015). }\end{array}$ \\
\hline Years of operation & $\begin{array}{l}\text { Category selected from: Less than } 1 \text { year; } \\
1-5 \text { years; } 6-10 \text { years; More than } 10 \text { years }\end{array}$ & $\begin{array}{l}\text { How long a business has been operating } \\
\text { may have an important influence on pro- } \\
\text { environmental behaviour as new } \\
\text { organisations have been found to more } \\
\text { easily adopt environmental practices } \\
\text { (Schick et al., 2002). }\end{array}$ \\
\hline $\begin{array}{l}\text { Affiliations with a } \\
\text { business network }\end{array}$ & Yes, please list; No & $\begin{array}{l}\text { An affiliation to a business network may } \\
\text { have an important influence on pro- } \\
\text { environmental behaviour because inter- } \\
\text { company relationships are shown to } \\
\text { influence a company's policies and } \\
\text { environmental practices (Wagner \& } \\
\text { Svensson, 2014). }\end{array}$ \\
\hline
\end{tabular}




\begin{tabular}{|c|c|c|}
\hline $\begin{array}{l}\text { Accreditations or } \\
\text { certificates related } \\
\text { to protecting the } \\
\text { environment }\end{array}$ & As above. & $\begin{array}{l}\text { Accreditations or certificates related to } \\
\text { protecting the environment may be } \\
\text { influenced by a leader's connection to } \\
\text { nature and/or influence a leader's access to } \\
\text { information and social networks that } \\
\text { support pro-environmental behaviour. }\end{array}$ \\
\hline $\begin{array}{l}\text { Nature } \\
\text { relatedness scale }\end{array}$ & $\begin{array}{l}\text { Five-point Likert agreement scale against } \\
21 \text { items developed by Nisbet, et al. (2009). }\end{array}$ & $\begin{array}{l}\text { Measures the affective, cognitive, and } \\
\text { experiential aspects of an individual's } \\
\text { connection to nature. }\end{array}$ \\
\hline $\begin{array}{l}\text { Pro- } \\
\text { environmental } \\
\text { behaviours }\end{array}$ & $\begin{array}{l}\text { Five-point Likert scale measuring } \\
\text { importance and option of 'don't know'. } \\
\text { Types of behaviours outlined below in } \\
\text { section 2.2.2.1 }\end{array}$ & $\begin{array}{l}\text { Identifies what type of behaviours are } \\
\text { currently being undertaken in businesses } \\
\text { and how frequently. }\end{array}$ \\
\hline Barriers & $\begin{array}{l}\text { Five-point Likert scale measuring } \\
\text { importance and option of 'don't know'. } \\
\text { Barriers outlined below in section 2.2.2.2 }\end{array}$ & $\begin{array}{l}\text { Identifies key barriers preventing business } \\
\text { leaders from undertaking as much as they } \\
\text { would like to for the environment. }\end{array}$ \\
\hline Age & $\begin{array}{l}\text { Category selected from those used in the } \\
\text { New Zealand Census Classification } \\
\text { Categories. Measured in (years): less than } \\
20 ; 20-24 ; 25-29 ; 30-34 ; 35-39 ; 40-44 ; \\
45-49 ; 50-54 ; 55-59 ; \text { more than } 60 \\
\text { Categories from the New Zealand Census } \\
\text { Classification Categories }\end{array}$ & $\begin{array}{l}\text { This variable was included because it has } \\
\text { been shown to influence pro-environmental } \\
\text { behaviour and has been linked to a } \\
\text { connection to nature (Allen \& Spialek, } \\
\text { 2017; Dean et al., 2018). }\end{array}$ \\
\hline Gender & $\begin{array}{l}\text { Category selected from those used in the } \\
\text { New Zealand Census Classification } \\
\text { Categories: Female; Male; Other; Prefer not } \\
\text { to say } \\
\text { Categories from the New Zealand Census } \\
\text { Classification Categories }\end{array}$ & As above. \\
\hline Further comments & Open answer textbox & $\begin{array}{l}\text { Opportunity for additional information } \\
\text { about connection to nature, or pro- } \\
\text { environmental behaviours. }\end{array}$ \\
\hline Interview interest & $\begin{array}{l}\text { Name and contact details (phone and } \\
\text { email) provided where relevant. Yes; No }\end{array}$ & $\begin{array}{l}\text { People were invited to indicate interest in } \\
\text { participation in further research. }\end{array}$ \\
\hline
\end{tabular}

\subsubsection{Pro-environmental behaviours}

The survey provided a list of 17 pro-environmental behaviours adapted from McMullin et al. (2007) and Cooper et al. (2015), and requested respondents to indicate how frequently they undertook the behaviour on a 5-point Likert scale (never, rarely, occasionally, often, and very often). This expands on previous studies which have predominantly focussed on individual lifestyle behaviours that only have a small effect on environmental qualities, while overlooking conservation behaviours that alter ecosystems, or change resource availability (Poortinga, et al., 2004; Stern, 2000). When constructing the list of pro-environmental behaviours, I chose to include both individual lifestyle behaviours: 
- recycling,

- using public transport,

- conserving water,

- conserving electricity,

- green purchasing,

- composting,

- supporting green policies,

- picking up litter,

- green supply chain,

and conservation behaviours:

- pest control,

- volunteering for conservation,

- donating to conservation,

- contacting government agencies about environmental issues,

- reading and watching material related to protecting the environment,

- growing native plants,

- habitat enhancement,

- joining environmental groups.

\subsubsection{Barriers to pro-environmental behaviours}

The survey examined the importance of six barriers to pro-environmental behaviours for the business leaders, which were adapted from Blake (1999). Both internal and external factors influence behaviour (Kollmuss \& Agyeman, 2002); therefore, it is important to acknowledge both types of barriers when trying to understand why people may or may not undertake proenvironmental behaviours. Barriers included were internal:

- availability of time,

- lack of resources,

- lack of interest, 
and external:

- lack of opportunity,

- lack of encouragement,

- lack of information.

Respondents were requested to indicate how frequently these six barriers to proenvironmental behaviours affected them in their business based on a 5-point Likert scale (never, rarely, occasionally, often, and very often). Respondents could also identify and rank their own barriers through an open-ended textbox.

\subsubsection{Survey distribution and data collection}

Initially, I contacted 15 different New Zealand business networks via email asking them to share my survey link with their members. Following this email, I rang leaders of the different networks asking if they could share my survey with their members. Both distribution methods varied in success; some business networks forwarded the survey link directly to their members via email, others added the survey link to their newsletters, some shared the survey link on their social media platforms, and a few declined my request to share the survey link. One network invited me to share my research/ survey during a networking lunch.

When survey responses from the business networks started to slow down, I began to contact (email and phone) different organisations who may have been interested in distributing the survey. I also shared the survey more broadly on Facebook in different community groups. As a final method of collecting responses, I contacted businesses directly via email asking them to complete my survey.

All complete and incomplete survey responses were recorded in a secure online Qualtrics file.

Respondents who were not business leaders were removed from the survey response pool, and respondents from outside New Zealand as indicated by the postcode were also 
excluded. Where respondents had provided 'other' responses, these were read and recategorised into an existing category if appropriate, or a new category was created where necessary.

\subsubsection{Data analysis}

Data for nature relatedness measures (affective, cognitive, and experiential) were calculated into scores for each respondent following the method from Nisbet et al. (2009). Four new variables were created: NR Self, NR Perspective, NR Experience, and Overall NR.

Response validity was tested through two measures. Firstly, common method variance was tested using Harman's single factor in IBM SPSS Statistics (version 26.0) (Podsakoff \& Organ, 1986). Common method variance represents the spurious association between variables that are generated by using the same method (i.e. self-reported survey) to measure each variable (Jakobsen \& Jensen, 2015). Harman's single factor test is used to identify if the variance from the survey variables are below the recommended $50 \%$ threshold (Tehseen et al., 2017). Secondly, non-response bias occurs when there is a difference between respondents and non-respondents (Berg, 2005). To test non-response bias, variables from early respondents can be compared against late respondents to determine any differences (Armstrong \& Overton, 1977). The study dataset was divided into thirds based on survey completion date, then an independent samples t-test was conducted between the first and last responses to test if there was a significant difference between scale variables.

After checking the validity of the data, frequencies and cross-tabulations of variables were first explored in Microsoft Excel, before using cluster analysis in SPSS to group respondents based on their pro-environmental behaviours. Cluster analysis was the chosen analysis because it addresses the aims of this chapter by being able to identify and classify different groups of business leaders based on the type of pro-environmental behaviours they undertake, connection to nature, individual demographics, and businesses characteristics.

Cluster analysis is a collection of different multivariate statistical methods that structures similar sets or groups based on observations in a dataset (Ketchen \& Shook, 
1996). Two-step cluster analysis is one method that sorts natural groups within a dataset based on pre-clustering followed by hierarchical methods (Wendler \& Gröttrup, 2016). Twostep clustering was chosen over other clustering techniques because it: 1) works well with large datasets, 2) determines the optimal number of clusters automatically and, 3) identifies the predictor importance of variables in the cluster solution (Tkaczynsk, 2017). Clustering techniques can be used in conjunction with other statistical methods to test cluster validity and reliability of results (Ketchen \& Shook, 1996).

When considering variables to use in cluster analysis, it is important to carefully consider including variables with a low predictor importance rating ( 0.02 or below) in the final solution (Tkaczynsk, 2017). Any pro-environmental behaviour variables that had a predictor importance rating of below 0.02 were removed.

Specifically, the first aim of this chapter was answered by calculating total percentages for each pro-environmental behaviour to show the frequency at which the proenvironmental behaviour was being undertaken by businesses. Secondly, cluster analysis was used to analyse individual demographics, business characteristics, connection to nature, and perceived barriers to determine whether there are different groups of business leaders. SPSS results were overlaid to compare the different business leader groups. Finally, independent samples t-tests were conducted, where appropriate, to confirm the cluster results and examine the extent to which pro-environmental behaviours within businesses are associated with the connection to nature of their business leaders.

\subsection{Study results}

A total of 320 responses were recorded over a three-month period. Of these responses, 216 were complete and valid (Table 2.2), 69 were incomplete, and 35 did not meet the first criterion of being a business leader in New Zealand. 
Table 2.2: The number of respondents and the equivalent percentage of survey responses for each business and individual characteristic question. Responses for each variable are ordered from the most frequent to the least frequent.

\begin{tabular}{|c|c|c|c|c|c|}
\hline \multicolumn{6}{|l|}{ Business Characteristics } \\
\hline Structure & $\mathbf{N}$ & $\%$ & Operation time & $\mathbf{N}$ & $\%$ \\
\hline Company & 176 & 81.5 & 5 years or more & 173 & 80.1 \\
\hline Sole trader & 18 & 8.3 & 4 years & 17 & 7.9 \\
\hline Partnership & 8 & 3.7 & 2 years & 13 & 6.0 \\
\hline Charitable Trust & 7 & 3.2 & 3 years & 8 & 3.7 \\
\hline Not-For-Profit & 4 & 1.9 & 1 year or less & 5 & 2.3 \\
\hline Other, please detail & 3 & 1.4 & & & \\
\hline \multicolumn{3}{|l|}{ Industry } & \multicolumn{3}{|l|}{ Number of employees } \\
\hline $\begin{array}{l}\text { Professional, Scientific, Technical, Administrative } \\
\text { and Support Services }\end{array}$ & & 270 & 15 & 100 & 463 \\
\hline Retail Trade and Accommodation & 33 & $\begin{array}{l}21.8 \\
15.3\end{array}$ & $\begin{array}{l}1-5 \\
6-19\end{array}$ & 56 & 25.9 \\
\hline Manufacturing & 18 & 8.3 & $20-49$ & 25 & 11.6 \\
\hline Construction & 17 & 7.9 & $100+$ & 24 & 11.1 \\
\hline Arts, Recreation and Other Services & 13 & 6.0 & $50-99$ & 11 & 5.1 \\
\hline Financial and Insurance Services & 13 & 6.0 & & & \\
\hline Information Media and Telecommunications & 13 & 6.0 & & & \\
\hline Education and Training & 12 & 5.6 & Network & & \\
\hline Agriculture, Forestry and Fishing & 11 & 5.1 & Yes & 118 & 54.6 \\
\hline Tourism & 8 & 3.7 & No & 98 & 45.4 \\
\hline Health Care and Social Assistance & 7 & 3.2 & & & \\
\hline Transport, Postal and Warehousing & 5 & 2.3 & \multicolumn{3}{|l|}{ Accreditation or certificates } \\
\hline Wholesale Trade & 4 & 1.9 & No & 153 & 70.8 \\
\hline Rental, Hiring and Real Estate Services & 2 & 0.9 & Yes & 63 & 29.2 \\
\hline \multicolumn{6}{|l|}{ Individual Characteristics } \\
\hline Age & $\mathbf{N}$ & $\%$ & Gender & $\mathbf{N}$ & $\%$ \\
\hline $45-49$ years & 39 & 18.1 & Male & 117 & 54.2 \\
\hline $40-44$ years & 35 & 16.2 & Female & 96 & 44.4 \\
\hline more than 60 years & 35 & 16.2 & Prefer not to say & 3 & 1.4 \\
\hline 50 - 54 years & 31 & 14.4 & & & \\
\hline 55 - 59 years & 31 & 14.4 & & & \\
\hline 35 - 39 years & 20 & 9.3 & & & \\
\hline 25 - 29 years & 12 & 5.6 & & & \\
\hline $30-34$ years & 10 & 4.6 & & & \\
\hline $20-24$ years & 3 & 1.4 & & & \\
\hline
\end{tabular}

There was no indication that non-response bias was a problem in this dataset based on the independent samples t-tests (Table 2.3) which indicates no statistically significant difference in the mean nature relatedness measures between first-third and last-third of all respondents based on response time. 
Table 2.3: Results from the independent samples t-test results for non-response bias between first, second, and last third of respondents.

\begin{tabular}{lllll}
\hline Variable & n & t-value & p-value & \\
\hline Overall NR & 142 & -1.20 & .233 & \\
NR Self & 142 & -1.00 & .317 & \\
NR Perspective & 142 & 0.64 & .522 & \\
NR Experience & 142 & -1.75 & .083 & $\mathrm{p}<0.05$
\end{tabular}

The results from Harman's single factor test extracted 27 factors, with the first factor accounting for $26.11 \%$ of the total variance. Based on these results, common method variance is assumed not to be an issue in this dataset because the total variance from the first factor is less than the recommended $50 \%$ threshold.

\subsubsection{Pro-environmental behaviours}

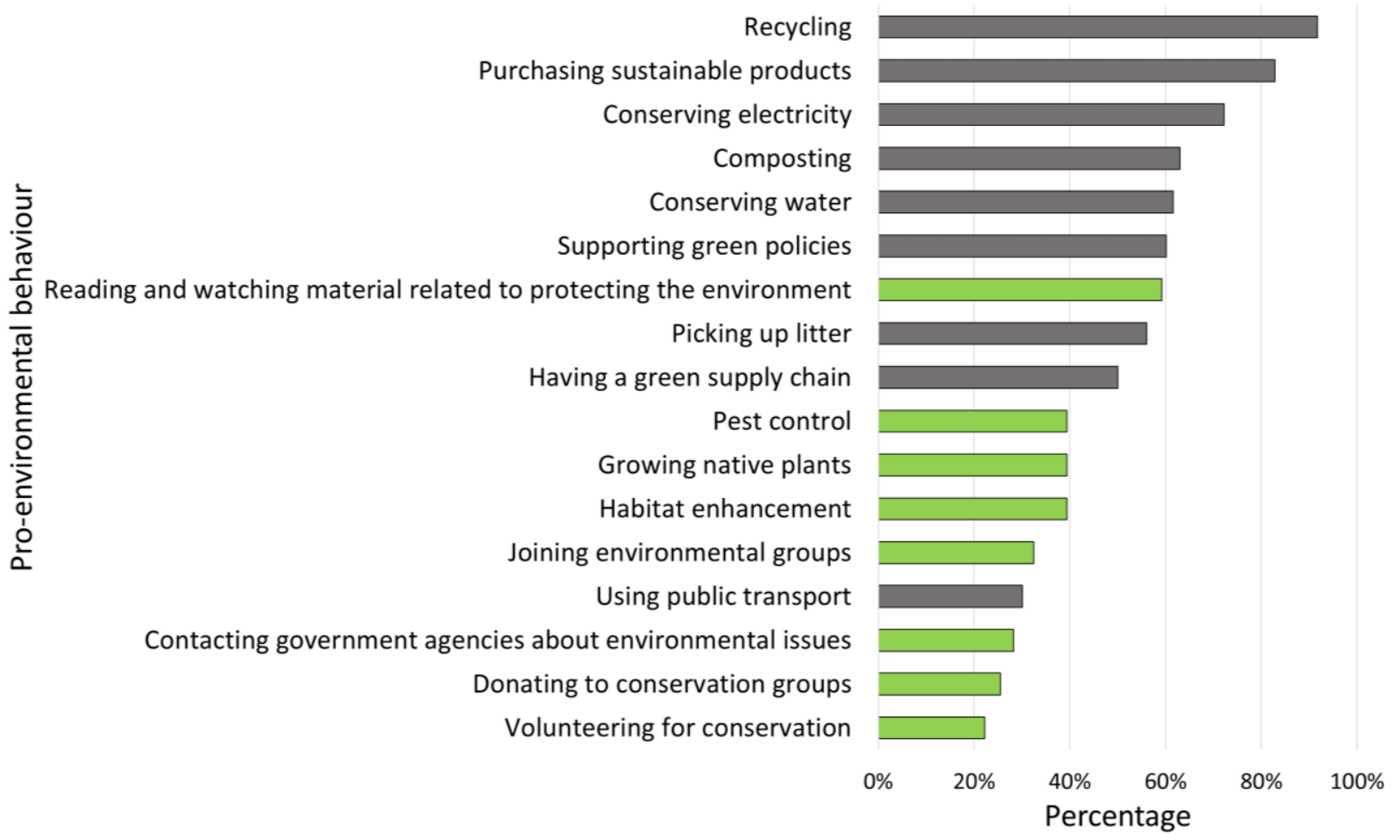

Figure 2.1: Grey bars represent individual lifestyle behaviours while green bars represent conservation behaviours. The total percentage of respondents who chose 'often' or 'very often' for each pro-environmental behaviour are shown as total percentages for each pro-environmental behaviour.

The most frequently undertaken pro-environmental behaviours were recycling (92\%), purchasing sustainable products (83\%), and conserving electricity (72\%) (Figure 2.1). These three most frequently undertaken behaviours were classified as individual lifestyle 
behaviours. The most frequently undertaken conservation behaviour is reading and watching material related to protecting the environment, with $59 \%$ of respondents selecting 'often' or 'very often' (Figure 2.1). The most frequently undertaken conservation behaviour appears as the seventh most frequently undertaken pro-environmental behaviour.

The least frequently undertaken pro-environmental behaviours were volunteering for conservation (22\%), donating to conservation groups (25\%), and contacting government agencies about environmental issues (28\%) (Figure 2.1). These three least frequently undertaken behaviours were all classified as conservation behaviours.

Other pro-environmental behaviours reported by business leaders included choosing sustainable transport options (electric vehicles and bikes), carbon offsetting, reducing landfill waste, avoiding excess travel through working remotely and using technology, and becoming plastic free.

\subsubsection{Barriers to undertaking pro-environmental behaviours}

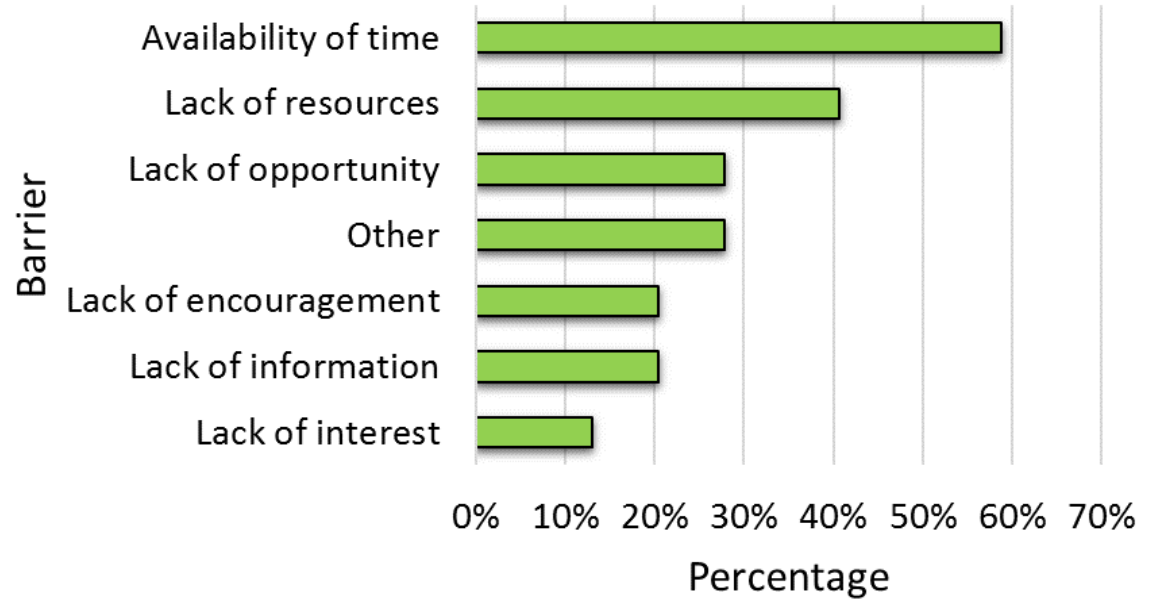

Figure 2.2: The total percentage of respondents who chose 'often' or 'very often' for the barrier are shown as total percentages for each barrier.

The reported barriers for all respondents were primarily lack of available time (59\%), lack of resources (41\%), lack of opportunity (28\%), other barriers (28\%), lack of encouragement (20\%), lack of information (20\%), and finally lack of interest (13\%) (Figure 2.2). The biggest 
two barriers identified were both internal barriers while the third biggest barrier of lack of opportunity was an external barrier.

Other reported barriers included legislative barriers, commercial pressures, public perception, lack of relevance to business, and difficulties around co-ordination of focus and direction.

\subsubsection{Cluster analysis results}

In an initial two-step analysis, 14 of the 17 pro-environmental behaviours had a significant predictor importance of above 0.02 . Conserving water, having a green supply chain, and pest control had a predictor importance below 0.02 , so were removed before conducting a final two-step cluster analysis. This two-step cluster analysis of 14 pro-environmental behaviours produced two clusters. Cluster one had 117 respondents (60.9\%), and cluster two had 75 respondents (39.1\%). 


\subsubsection{Cluster characteristics}

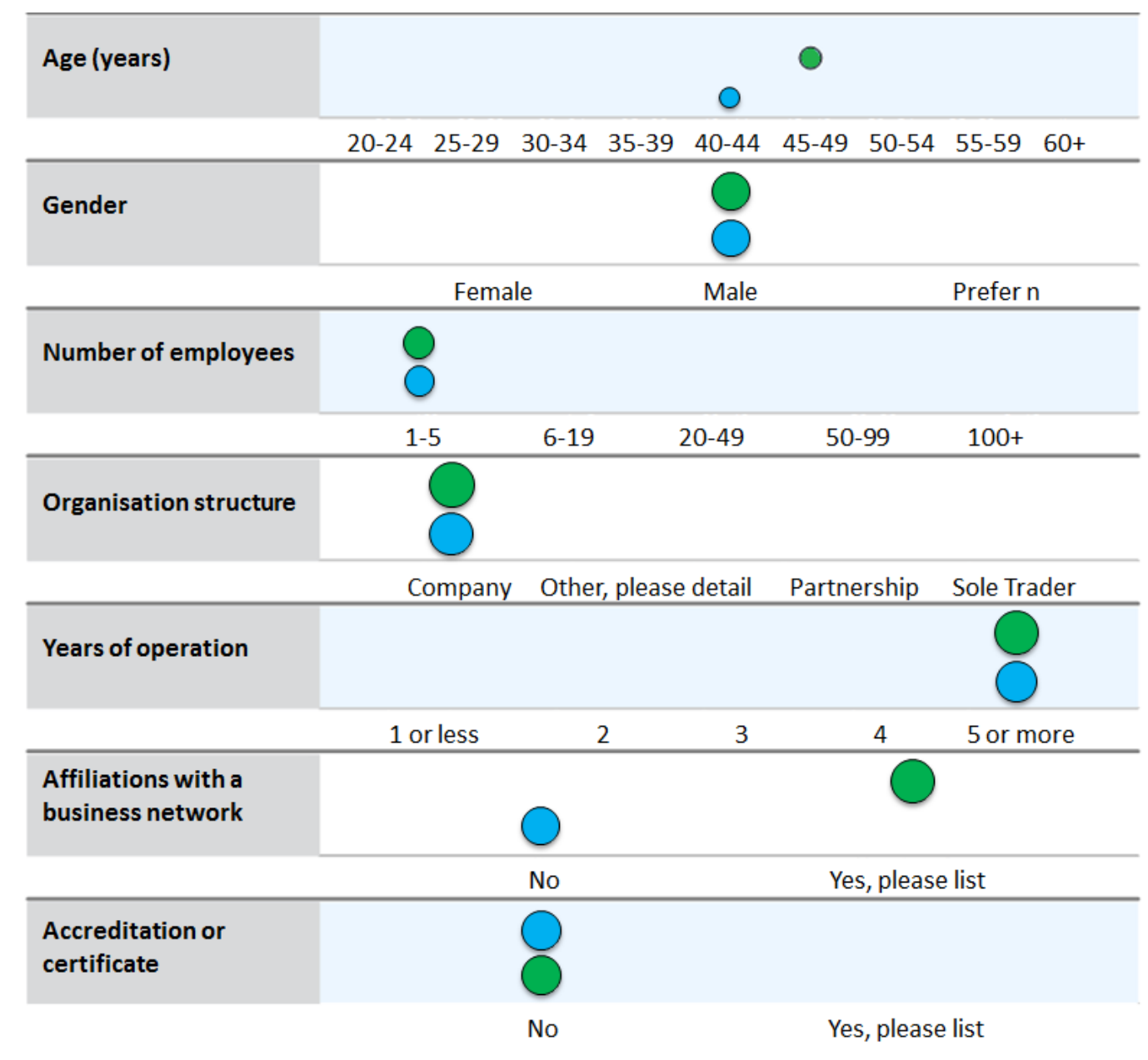

Key

Figure 2.3: Depiction of differences between clusters of business leader survey responses showing the most frequently chosen respondent characteristics. Cluster one is represented by the green circle and cluster two is represented by the blue circle. The size of the circle for each cluster is indicative of the mode size.

Based on cluster modes, both clusters were predominantly characterised as having a company organisation structure, being of male gender, five years or more operation time, no accreditation or certificate related to protecting the environment, and one to five employees (Figure 2.3).

There were very limited demographic differences between clusters; cluster one was slightly older, but both were predominantly male. Cluster characteristics differed based on age and being a member of a business network. Based on modes, cluster one was aged between 45 and 49 years (18.8\%), with business network associations (66.7\%). While 
cluster two was aged between 40 and 44 years (22.7\%), with no business network association (65.3\%).

Conducting an independent samples t-test showed no statistically significant age difference between the two clusters; $\mathrm{t}(190)=0.43, \mathrm{p}=.664$. 


\subsubsection{Cluster pro-environmental behaviours}

\begin{tabular}{|c|c|c|c|c|c|c|}
\hline & Never & Rarely & Occasionally & Often & Very often & \multirow{2}{*}{$\begin{array}{l}\text { Key } \\
\text { Cluster } 1 \\
\text { Cluster } 2\end{array}$} \\
\hline Conserving energy & & & & & & \\
\hline \multicolumn{6}{|l|}{$\begin{array}{l}\text { Purchasing } \\
\text { sustainable products }\end{array}$} & \\
\hline \multicolumn{6}{|l|}{ Public transport } & \\
\hline \multicolumn{6}{|l|}{$\begin{array}{l}\text { Growing native } \\
\text { plants }\end{array}$} & \\
\hline \multicolumn{6}{|l|}{$\begin{array}{l}\text { Reading and watching } \\
\text { material }\end{array}$} & \\
\hline \multicolumn{7}{|l|}{$\begin{array}{l}\text { Habitat } \\
\text { enhancement }\end{array}$} \\
\hline \multicolumn{6}{|l|}{$\begin{array}{l}\text { Supporting green } \\
\text { policies }\end{array}$} & \\
\hline \multicolumn{6}{|l|}{$\begin{array}{l}\text { Joining environmental } \\
\text { groups }\end{array}$} & \\
\hline \multicolumn{6}{|l|}{$\begin{array}{l}\text { Volunteering for } \\
\text { conservation }\end{array}$} & \\
\hline \multicolumn{6}{|l|}{ Picking up litter } & \\
\hline \multicolumn{6}{|l|}{$\begin{array}{l}\text { Contacting } \\
\text { government agencies }\end{array}$} & \\
\hline \multicolumn{6}{|l|}{ Composting } & \\
\hline $\begin{array}{l}\text { Donating to } \\
\text { conservation groups }\end{array}$ & & & $?$ & & & \\
\hline Recycling & & & & & & \\
\hline & Never & Rarely & Occasionally & Often & Very often & \\
\hline
\end{tabular}

Figure 2.4: Depiction of differences between clusters of business leader respondents, showing the most frequently undertaken behaviours. Cluster one is represented by the green circle and cluster two is represented by the blue circle. The size of the circle for each cluster is indicative of the mode size. The further right the circle, the more frequent the behaviour. 
Based on cluster modes, cluster one business leaders undertake the pro-environmental behaviours at the same or higher frequency than cluster two (Figure 2.4). The two proenvironmental behaviours where cluster one and cluster two business leaders undertake at the same frequency were: donating to conservation groups (occasionally) and recycling (very often).

Cluster one business leaders reported 'very often' to six pro-environmental behaviours: conserving energy, purchasing sustainable products, composting, enhancing habitats, supporting green policies, and joining environmental groups. Additionally, they reported 'often' to public transport, and volunteering for conservation. The minimum proenvironmental behaviour frequency was recorded as 'occasionally'.

In comparison, cluster two business leaders only reported 'very often' to one proenvironmental behaviour which was recycling, and 'often' to habitat enhancement. Cluster two business leaders report 'never' to undertaking four pro-environmental behaviours: growing native plants, reading and watching material related to protecting the environment, contacting government agencies, and picking up litter.

Business leaders from both clusters undertake a mixture of conservation behaviours and individual lifestyle behaviours. Cluster one business leaders report more frequently undertaking conservation behaviours than cluster two. Business leaders in cluster one, reported 'very often' to undertaking three conservation behaviours: habitat enhancement, supporting green policies, and joining environmental groups. However, cluster two business leaders only reported 'often' to one conservation behaviour which was habitat enhancement. Both clusters of business leaders did not have pro-environmental behaviours modes marked as 'rarely' being undertaken. 


\subsubsection{Cluster barriers}

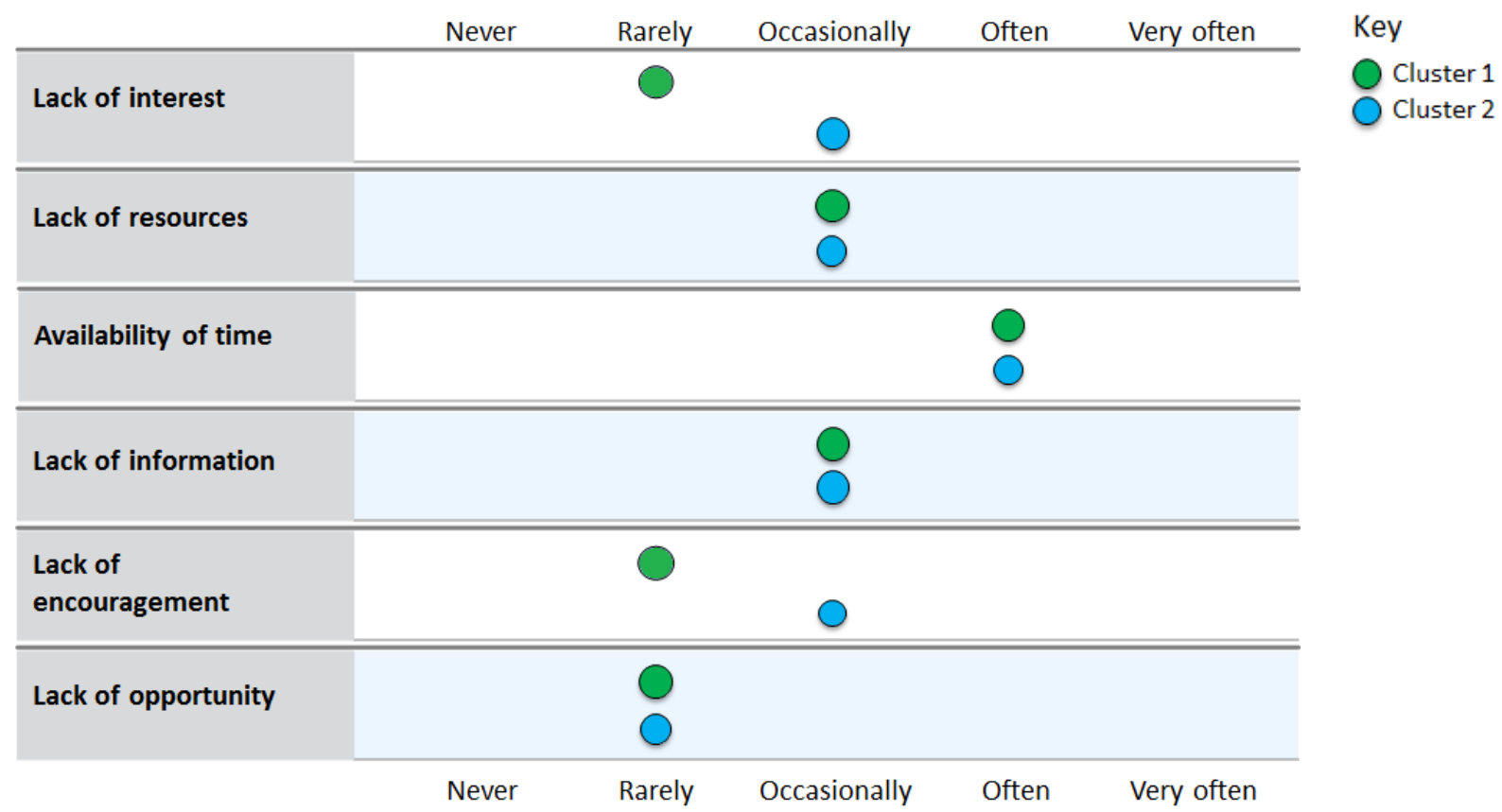

Figure 2.5: Depiction of differences between clusters of business leader respondents, showing the most frequent barriers. Cluster one is represented by the green circle and cluster two is represented by the blue circle. The size of the circle for each cluster is indicative of mode size. The further right the circle, the more frequent the barrier.

Business leaders from both clusters identified the internal barrier of availability of time as the most frequent barrier preventing them from undertaking as much as they would like for the environment (Figure 2.5).

Cluster one reported a lack of resources and lack of information as occasionally being a barrier while cluster two also reported a lack of encouragement and lack of interest as also being an occasional barrier. While cluster one reported a lack of interest, lack of encouragement, and lack of opportunity as rarely being a barrier, cluster two business leaders only identified lack of opportunity as 'rarely' being a barrier. None of the six barriers were identified as 'never' or 'very often'.

Overall, cluster two identified the barriers as being more frequent in preventing them from undertaking as many pro-environmental behaviours as they would like to compared to cluster one. 


\subsubsection{Nature relatedness of respondents within clusters}

Table 2.4: Independent sample t-test results comparing both clusters on overall nature relatedness, nature relatedness self, and nature relatedness experience. Significant results are indicated by an asterisk above the $p$ value.

\begin{tabular}{llll}
\hline Variable & n & t-value & p-value \\
\hline Overall NR & 190 & 2.38 & $.018^{*}$ \\
NR Self & 190 & 2.19 & $.030^{*}$ \\
NR Perspective & 190 & -0.16 & .876 \\
NR Experience & 190 & 2.38 & $.019^{*}$ \\
\hline
\end{tabular}

Cluster one had a significantly higher Overall NR, NR Self, and NR Experience score compared to cluster two (Table 2.4). These results show that business leaders who perform proenvironmental behaviours more often tend to have a higher nature relatedness across most dimensions of its measurement.

However, the NR Perspective measure was not significantly different between cluster two and cluster one (Table 2.4). This result shows that there is no perspective nature relatedness score difference between business leaders who undertake pro-environmental behaviours more or less frequently in their businesses.

Figure 2.6 below illustrates these findings.
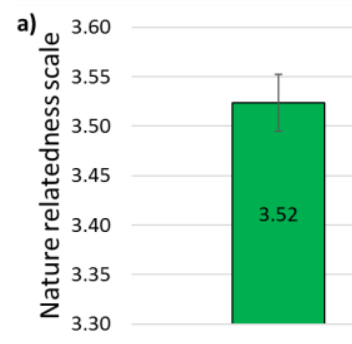

1

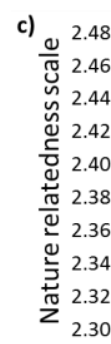

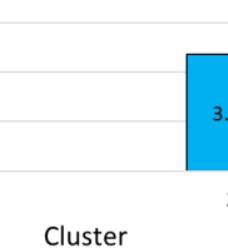

Cluster
2
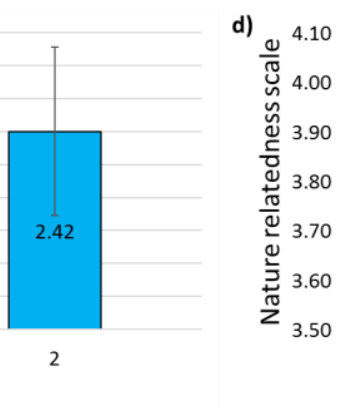

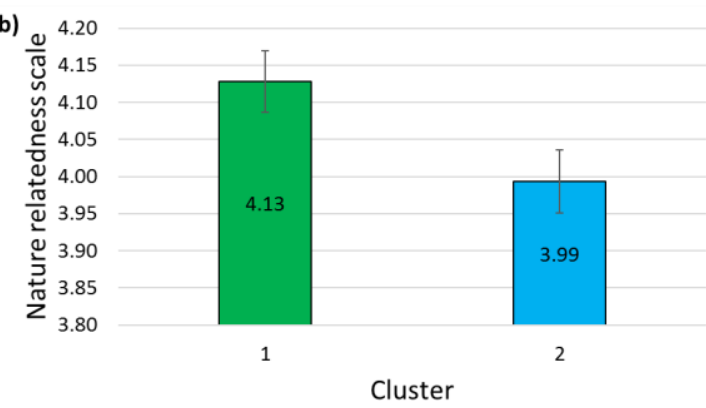

Cluster

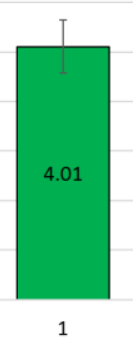

Figure 2.6: Means of nature relatedness for two clusters of survey respondents. Graphs show a) overall nature relatedness, b) nature relatedness self, c) nature relatedness perspective, and d) nature relatedness experience. Error bars represent standard error of proportion. 


\subsection{Discussion}

This chapter explores the relationship between New Zealand business leaders' connection to nature and pro-environmental behaviours in a business setting. Here, I have shown that there is a positive association between a connection to nature and the uptake of proenvironmental behaviours in a New Zealand business context. Specifically, business leaders who reported performing pro-environmental behaviours more often were found to have significantly higher overall nature relatedness, nature relatedness self and, nature relatedness experience scores compared to business leaders who reported less frequent proenvironmental behaviour uptake. This positive association between a connection to nature and pro-environmental behaviour is consistent with findings in the literature (Mayer \& Frantz., 2004; Nisbet et al., 2009; Tam, 2013).

This research identified two distinct clusters of business leaders, with cluster one business leaders being shown to more frequently partake in conservation behaviours. Business leaders who more frequently undertake conservation behaviours such as habitat enhancement, supporting green policies, and joining environmental groups demonstrated a higher connection to nature. Cluster analysis indicated that there were limited differences between clusters based on individual demographics and business characteristics, except for business leaders in cluster one generally being slightly older and members of a business network. Based on these limited differences, there are likely to be other important reasons that drive business leaders to partake in pro-environmental behaviours. Cluster results for barriers to undertaking pro-environmental behaviours showed that cluster one perceived the barriers as less frequently preventing them from undertaking further pro-environmental behaviours. Cluster analysis was beneficial for determining different groups within the business leaders and analysing their pro-environmental behaviours and perceived barriers to undertaking further pro-environmental behaviours.

Business leaders who reported a higher connection to nature self dimension may participate in more pro-environmental behaviours because emotions and beliefs have been

found as influential drivers of environmental attitudes that lead to environmental action (Pooley \& O'Connor, 2000). Another explanation is that people who have a greater affective 
connection with the natural environment have greater intentions to engage with it (Hinds \& Spark, 2008). In my study, business leaders who more frequently undertake proenvironmental behaviours reported rarely facing the barriers of a lack of interest, lack of encouragement, or lack of opportunity. This suggests that business leaders who undertake more frequent pro-environmental behaviours are aware of opportunities for environmental action, are interested in being involved in pro-environmental behaviours, and receive the encouragement needed to partake in as much as they can to protect the natural environment. Findings from this study support existing evidence in the literature that a stronger affective connection to nature influences pro-environmental behaviour uptake (Hinds \& Spark, 2008; Mayer \& Frantz, 2004; Pereira \& Forster, 2015).

This chapter also shows that business leaders who reported higher experiential nature relatedness scores more frequently undertake pro-environmental behaviours that have an experiential element, such as growing native plants, habitat enhancement, volunteering for conservation, and composting-notably these are mostly conservation behaviours. Rosa and Collado (2019), list several reasons which may explain why a higher experiential connection to nature influences pro-environmental behaviours including: higher biocentric values (Larson et al., 2011), a greater sense of place attachment (Lawrence, 2012), and increased justice towards the environment (Hahn \& Garrett, 2017). An experiential connection to nature defines an individual's physical interactions with the natural environment (Ives et al., 2017); therefore, it seems logical that business leaders who are already interacting and connecting with their natural environments would partake in more pro-environmental behaviours in this study.

Both clusters had near identical nature relatedness perspective scores (which reflects the cognitive dimension of connection to nature). This suggests that they both share similar pre-conceived attitudes, values, and beliefs about the natural environment (Nisbet et al., 2009). Many theoretical frameworks have tried to close the gap between environmental knowledge and environmental awareness, and performing environmental behaviours, however, there are still no conclusive answers (Kollmuss \& Agyeman, 2002). My study shows that a cognitive connection to nature is not a differentiating factor for increased pro- 
environmental behaviour uptake in business leaders. These results align with findings from Carmi et al. (2015), where solely cognitive dimensions of a connection to nature were not enough to demonstrate pro-environmental motivation. When looking at the types of barriers facing business leaders in this study, they both report occasionally lacking the knowledge needed to engage in actions for the environment. Other influences-affective and experiential connections, may be more significant in influencing pro-environmental behaviour (Pooley \& O'Connor, 2000; Rosa \& Collado, 2019). It would be beneficial to conduct further research investigating the strength of such a linkage between a cognitive connection to nature and environmental action.

\subsubsection{Implications}

This chapter provides new insight into the relationship between a connection to nature and pro-environmental behaviour through sampling small business leaders-an understudied population in this research area. Previous research has found associations between a connection to nature and participation in pro-environmental behaviours in university students (Mackay \& Schmitt, 2019), landowners (Dutcher et al., 2007), employees (Wesselink et al., 2015), and children (Cheng \& Monroe, 2010). Results from this study add breadth to the literature demonstrating that business leaders who partake in proenvironmental behaviours more frequently appear to have a greater connection to nature than business leaders who partake in pro-environmental behaviours less frequently.

Findings from this study are valuable because they suggest that further uptake of proenvironmental behaviours in the workplace may be encouraged by connecting business leaders to nature through an emotional or experiential approach. Businesses can build upon these findings to promote work environments where employees can connect to nature during their normal working day. Studies have shown benefits such as improved productivity from having lunch breaks outside (Loder, 2014), walking meetings (Clayton et al., 2015), and accessing workplace green spaces (Lottrup et al., 2013). Facilitating a connection to nature in the workplace may also have benefits for promoting further proenvironmental behaviour uptake in businesses. 


\subsubsection{Limitations and future research}

Although this study reports important findings concerning the association between a connection to nature and pro-environmental behaviour in New Zealand business leaders, two key limitations must be acknowledged.

The methodological choice of conducting a survey presents limitations. Bias is a potential issue in surveys because answers rely on the self-assessment of participants (Cassells \& Lewis, 2011). Following this, participants may interpret, and therefore, answer questions differently to the intended purpose of the question. While steps were taken to reduce and test for bias, and improve the interpretability of questions, findings are likely to still be influenced by some bias. Future research might consider a different methodology to confirm the findings in this research. An experiential study could explore how a connection to nature is actually realised as pro-environmental behaviours in New Zealand businesses as opposed to reported pro-environmental behaviours in a survey.

It is beyond the scope of this study to conclude causation or relationship directionality between a connection to nature and pro-environmental behaviour, instead the research focusses on associations between the two variables to describe existing relationships in an understudied sample. Future research may test the directionality of a connection to nature and pro-environmental behaviour in business leaders to confirm whether participation in workplace pro-environmental behaviours fosters a greater connection to nature or vice versa.

\subsection{Conclusion}

This chapter shows that New Zealand business leaders who undertake more frequent proenvironmental behaviours demonstrate higher levels of a connection to nature than business leaders who do not frequently undertake pro-environmental behaviours. Between the two clusters of business leaders there are some differences, most notable are 1) the frequency at which pro-environmental behaviours are undertaken, 2) the rate at which barriers prevent them from engaging in as much as they would like to for the environment, and 3) their overall connection to nature dimensions. These findings capture a snapshot of how business leaders 
currently connect to nature and how this relates to their businesses pro-environmental behaviours. To encourage further pro-environmental behaviour uptake, especially conservation behaviours, my study suggests it may be most effective to promote affective and experiential connection to nature. Means of recognising and removing barriers to proenvironmental behaviour are also needed to promote further pro-environmental behaviour. 


\section{Chapter 3: The role of business leaders' connection to nature in fostering pro-environmental behaviours}

\subsection{Introduction}

Businesses are considered an important part of the solution for environmental crises (Ristovska, 2010). Consequently, the business sector faces increasing political, social, and economic pressures to become environmentally responsible (Baughn et al., 2007). According to DesJardins (1998), environmental responsibility should address two key points: 1) the prevention of environmental and ecological degradation caused by decision-making in business, and 2) it should impact business policy. Business leaders play a significant role in realising environmental responsibility in the business sector because they have the ability to react to external pressures and make decisions on behalf of their businesses (Hollender \& Breen, 2010; Zu, 2019).

The theoretical constructs that explore the purpose of business in modern society provide an important framework for the role of business in solving environmental and social challenges (Ashrafi et al., 2020; Montiel, 2008). Following a classical view, businesses exist solely to convert their resources into financial profitability and to engage in activities that serve profit-making-goals that benefit stakeholders (Metcalfe, 1998; Orts \& Strudler, 2002). In contrast, a moral or normative view is that businesses exist as social institutions with social, environmental, and economic responsibilities (Lozano, 2015; Vermeulen \& Witjes, 2016). Recently, the normative view has become prevalent in the literature and in the business sector as leaders become more aware of the interconnections between economic, environmental, and social factors (Elkington, 2005).

Existing research into business and the natural environment commonly focusses on 'businesses' as the unit of measure (Headd \& Saade, 2008). For example, significant bodies of research broadly focus on why and how businesses adopt environmental management models such as Corporate Social Responsibility (Babiak \& Trendafilova, 2011; Kudłak \& Low, 2015), Triple Bottom Line (Glavas \& Mish, 2015; Hidayati, 2011), and environmental reporting (Hahn \& Kühnen, 2013; Sharma, 2002). Additionally, research explores the effects 
of incorporating such environmental management models based on environmental outcomes (Ammenberg et al., 2002; Nawrocka \& Parker, 2009), financial performance (Albertini, 2013; Montabon et al., 2007), and social benefits (Salzmann et al., 2005; Stubbs \& Cocklin, 2008). While there is a breadth of research focussing on businesses as a whole and the natural environment, little attention has been given to the role of individual business leaders as key influencers in business activity. This is important because business leaders are the drivers for change in business and are likely to influence pro-environmental behaviour uptake that will have positive impacts on the natural environment (Ferdig, 2010).

There is a growing body of research investigating how an individual's environmental values influence their engagement with pro-environmental behaviours, and this is likely to be highly relevant when considering the role of individual business leaders for informing pro-environmental action. According to Dunlap et al. (2000), individuals who demonstrate concern for the natural environment are more likely to partake in pro-environmental behaviours. Personal beliefs and an affective, cognitive, and experiential connection to nature have also been shown to predict a variety of different pro-environmental behaviours (Nisbet et al., 2009; Stern, 2000). Existing research indicates that there is a positive relationship between individual values and pro-environmental behaviours in a non-business context (Kals et al., 1999; Nisbet et al., 2009; Schultz, 2001).

Of the research that does exist, there are some studies which have examined individual values, factors that influence business leaders, and barriers to adopting proenvironmental barriers. However, further research is still needed to fully understand individual connection to nature and pro-environmental behaviour in a business context. Hemingway and Maclagan (2004), suggest that a business leader's values and beliefs are persuading factors for adopting environmental behaviours. Similarly, Wilson (2002) claims that personal values and interests can influence the adoption of corporate social responsibility in business. While individual values, beliefs, and interests are shown to motivate business leaders, there are numerous external factors that vie for their attention, such as financial, social, legal, and ethical considerations (Baughn et al., 2007; Clegg, 2011). Additionally, common barriers including limited time, finances, and environmental 
knowledge are also shown to affect business leaders when trying to undertake proenvironmental behaviours (Gerstenfeld \& Roberts, 2000).

In this qualitative study, I specifically focus on how New Zealand business leaders connect with nature, and how this influences their businesses pro-environmental behaviours. Further, I examine barriers and enablers that support the realisation of business leader's pro-environmental aspirations in their business. Through studying the personal values, perspectives, and stories shared by business leaders, the relationship between a connection to nature, business, and pro-environmental behaviours can be explored in depths that the previous quantitative chapter cannot measure. My overarching aim is to provide an in-depth analysis on how business leaders translate their connection to nature into the running of their businesses, which could inform how uptake of further pro-environmental behaviour might be realised in other settings. Specifically, this qualitative data chapter aims to:

1. understand how business leaders currently express a connection to nature in their businesses;

2. explore the relationship between a connection to nature and pro-environmental behaviours in business;

3. determine what environmental aspirations business leaders hold for the future; and

4. identify what barriers business leaders face in their businesses.

\subsection{Methodology and methods}

\subsubsection{Epistemology}

Epistemology is a theory of knowledge that evaluates what knowledge is acceptable in a field of study (Bryman, 2016; Saunders et al., 2009). Additionally, epistemology explores relationships between the researcher and the participant, or vice versa (Guba \& Lincoln, 1994; Lee, 2012). It is important to disclose the epistemology undertaken in a qualitative study because it can influence what knowledge constitutes as acceptable, and therefore, has impacts on the final results (Ambert et al., 1995). 
This research adopts a constructivist epistemology which assumes that there are multiple realities which can be constructed (Guba \& Lincoln, 1994). A constructivist approach focusses on what participants think and feel, how they communicate, and aims to illustrate why participants have different experiences (Bahari, 2010). As the researcher, I interpret meaning from my interactions with the participants. The construction of knowledge through interacting with participants supports the development of answers to the chapter aims.

\subsubsection{Theoretical perspective}

A theoretical perspective influences which methodology should be taken and provides a lens for conducting analysis (Malterud, 2016). The constructivist epistemology outlined above is associated with an interpretative theoretical perspective (Schwandt, 1994). An interpretative theoretical perspective claims that reality needs to be interpreted and that individual perspectives can be thought of as 'truth'. Interpretivism has different approaches which can be used to emphasise how people interact with the world (Chowdhury, 2014).

This research follows a hermeneutics approach because it concerns the practice of interpretation to form understanding (Bernstein, 1983; Bleicher, 1980). According to Gadamer (1989), hermeneutic philosophy emphasises language and writing as the means for understanding to be exchanged. In a research context, understanding is achieved through open dialogue between the researcher and the participant (Koch, 1999). Data is collected from interviews and observations for inductive analysis to identify common themes (Paterson \& Higgs, 2005). A hermeneutics approach is appropriate for this study because it allows for interpretation of multiple perspectives to form understanding on how business leaders connect with nature and how that influences their businesses' pro-environmental behaviours.

\subsubsection{Data collection methodology}

This chapter uses qualitative methodology, in line with a constructivist epistemology, to develop an in-depth understanding on how New Zealand business leaders currently connect with nature and how that influences their businesses' pro-environmental behaviours. 
Qualitative methodology can be used to explore new study areas and focusses on understanding concepts, opinions, or experiences through collecting and analysing nonnumerical data (Creswell \& Poth, 2016).

The qualitative methodology used in this study follows grounded theory which considers words as data elements that can be organised into themes (McCaffery et al., 2012). This theory aims to explain specific research phenomena through interviews or focus groups (Sutton \& Austin, 2015). Considering the epistemology and methodology described above, and the aims of this research, I chose to use individual semi-structured interviews to collect data. Semi-structured interviews consist of several questions that outline key topics to be discussed with the interviewee. I followed general interview guidelines when conducting interviews (DiCicco-Bloom \& Crabtree, 2006; Gill et al., 2008; Jamshed, 2014). The method of semi-structured interviews was chosen because they have the benefit of allowing the interviewer to diverge into ideas or responses bought up by the interviewee. Interviews of this nature usually last between 30-60 minutes (DiCicco-Bloom \& Crabtree, 2006). Further, they are an appropriate method to answer the aims of this research because I will be able to prompt business leaders to talk about their businesses, connection to nature, proenvironmental behaviours, and barriers while being able to diverge and explore individual responses provided by each business leader.

\subsubsection{Data collection}

The data collection methods in this chapter were approved under the Victoria University of Wellington Human Ethics number \#0000028328.

From the quantitative survey in Chapter 2, 50 business leaders showed an interest in participating in the research further by providing their contact details. From this list, I used a random number generator to select business leaders to call until I had 10 business leaders who agreed to an interview. Following the phone call, I immediately emailed the consent to interview form, information sheet for participants, interview guide, and a summary of the phone call to the business leaders. A URL link to an online consent form built in Qualtrics was also included in the email, for electronic consent if the business leader preferred. 


\subsubsection{Interview methods}

Ten semi-structured interviews were conducted either in-person or via video-conferencing based on the business leader's preference. Where in-person interviews were held, they were carried out in locations familiar to the business leader to create an atmosphere where they felt comfortable to share their views, experiences, and perceptions (Longhurst, 2003). Three interviews were conducted in-person in Wellington and seven interviews were conducted online via Zoom - a videotelephony software program. The in-person interviews were held at a local café or in an office meeting room. I followed the thematic interview guide structure below to conduct the interviews (Table 3.1). 
Table 3.1: Thematic interview guide with broad themes, main questions, and subtopics outlined.

\begin{tabular}{|c|c|c|}
\hline Broad Theme & Main questions & Subtopics \\
\hline \multirow[t]{2}{*}{$\begin{array}{l}\text { Gathering information about the } \\
\text { interviewee }\end{array}$} & \multirow[t]{2}{*}{$\begin{array}{l}\text { Tell me about yourself and your } \\
\text { business. }\end{array}$} & $\begin{array}{l}\text { Interviewee information e.g. name, } \\
\text { reason for interview, expectations } \\
\text { of the interview, general survey/ } \\
\text { interview comments etc. }\end{array}$ \\
\hline & & $\begin{array}{l}\text { Business information e.g. name, } \\
\text { size of business, location, type, } \\
\text { purpose etc. }\end{array}$ \\
\hline \multirow[t]{3}{*}{ Connection to nature } & \multirow[t]{3}{*}{$\begin{array}{l}\text { Can you tell me about how your } \\
\text { business connects with nature? }\end{array}$} & $\begin{array}{l}\text { Thoughts around nature } \\
\text { connection to self: environmental/ } \\
\text { corporate identity, stakeholder } \\
\text { management }\end{array}$ \\
\hline & & $\begin{array}{l}\text { Thoughts around nature } \\
\text { connection to perspective: } \\
\text { environmental management } \\
\text { practices, corporate strategy }\end{array}$ \\
\hline & & $\begin{array}{l}\text { Thoughts around nature } \\
\text { connection to experience: } \\
\text { workplace environment, green } \\
\text { initiatives }\end{array}$ \\
\hline \multirow[t]{4}{*}{$\begin{array}{l}\text { Current pro-environmental } \\
\text { behaviours }\end{array}$} & \multirow{4}{*}{$\begin{array}{l}\text { Can you tell me about the pro- } \\
\text { environmental behaviours that } \\
\text { your business currently } \\
\text { undertakes? }\end{array}$} & $\begin{array}{l}\text { Experiences related to business } \\
\text { leaders' behaviours }\end{array}$ \\
\hline & & $\begin{array}{l}\text { Experiences related to individual } \\
\text { employee behaviours }\end{array}$ \\
\hline & & $\begin{array}{l}\text { Experiences related to } \\
\text { organisational behaviours }\end{array}$ \\
\hline & & $\begin{array}{l}\text { Perceived benefits of undertaking } \\
\text { these behaviours }\end{array}$ \\
\hline \multirow[t]{3}{*}{$\begin{array}{l}\text { Future pro-environmental } \\
\text { behaviours }\end{array}$} & \multirow{3}{*}{$\begin{array}{l}\text { Can you tell me about the pro- } \\
\text { environmental behaviours that } \\
\text { you would like to undertake in } \\
\text { your business? }\end{array}$} & $\begin{array}{l}\text { Thoughts around what future pro- } \\
\text { environmental behaviours they } \\
\text { would like to undertake }\end{array}$ \\
\hline & & $\begin{array}{l}\text { Reasoning for adopting these pro- } \\
\text { environmental behaviours }\end{array}$ \\
\hline & & $\begin{array}{l}\text { Thoughts on what the future of a } \\
\text { green business looks like }\end{array}$ \\
\hline \multirow{2}{*}{$\begin{array}{l}\text { Barriers to pro-environmental } \\
\text { behaviours }\end{array}$} & \multirow{2}{*}{$\begin{array}{l}\text { Can you tell me about the barriers } \\
\text { that are stopping you from } \\
\text { achieving the pro-environmental } \\
\text { behaviours that you have shared? }\end{array}$} & Exploring the barriers \\
\hline & & How to overcome the barriers \\
\hline \multirow[t]{2}{*}{ Feedback and thank you } & \multirow[t]{2}{*}{$\begin{array}{l}\text { Do you have any comments or } \\
\text { questions based on your } \\
\text { participation in the survey and } \\
\text { interview? }\end{array}$} & $\begin{array}{l}\text { Comments around how } \\
\text { respondent would like to be } \\
\text { referred to as in thesis } \\
\text { (e.g. retail manager Bob) }\end{array}$ \\
\hline & & Explore respondents' answers \\
\hline
\end{tabular}

At the start of each interview, I introduced myself, outlined how the interview would proceed, and provided background for the research. I reiterated that all answers would be confidential and that the utmost care would be taken to ensure not to disclose any information that would identify them in the report. Participants were informed that the 
interview would be audio-recorded either via the record feature on Zoom or by the voice recording application on my cellphone. Audio-recording allowed me to focus on listening and responding to the interviewee, without the need to write verbatim (Stuckey, 2014). According to Green and Thorogood (2018), audio-recording is recommended for interviews because it produces the most accurate and reliable transcripts. Prior to asking the first question, I ensured that all concerns or questions held by the business leader were addressed.

During the interview, I adjusted the thematic interview guide structure based on the conversation with each business leader and asked open-ended follow-up questions. This allowed interviewees to respond using their own words and motivated them to share as much or as little as they would like to answer the question (Corbin \& Morse, 2003). Openended questions along with encouraging signals from the interviewer, prompted interviewees to share their opinions, feelings, and thoughts freely (Albudaiwi, 2017). Encouraging signals include both verbal cues and visual gestures such as nodding, smiling, and affirmative sounds (Prior, 2018). Rich, highly individualised data can be gathered in this manner (Kurasaki, 2000).

At the conclusion of the interview, I answered any questions that the interviewee had before thanking them for their time and letting them know that I would send a transcript of the interview, summary and/or the audio-recording (if they had requested this in the consent form) for their review. All audio-recordings were stored securely on password protected servers and computers to ensure security.

\subsubsection{Transcription}

Transcripts of each interview were created using Otter.ai software-a free online speech to text transcription application. Generated transcripts were downloaded into a word processing format and manually checked for accuracy against the original audio-recording. Transcribing is the first step of interpreting the data, therefore care must be taken to transfer the intended spoken meaning into written text (Stuckey, 2014). As per best practice, I carried out all the transcription as the interviewer (Easton et al., 2000). 
Interviewees who indicated they would like to see the transcripts were provided copies for comment if they had any, and these were then finalised. All electronic transcripts and audio-recordings were stored in password protected files without identifiers, and where hard copies existed they were stored in a locked filing cabinet.

\subsubsection{Data analysis}

Thematic analysis was used to analyse the data. Thematic analysis is used to uncover emerging themes in data to understand a specific context or phenomena (Attride-Stirling, 2001). This method of analysis is appropriate for this study because it can help to identify patterns within a group of individual business leaders. This analysis aligns with grounded theory described in section 3.2.2.

Data analysis in this study follows the six thematic analysis phases outlined by Braun and Clarke (2006) (Table 3.2).

Table 3.2: The data analysis process used in this study was developed based on the six thematic analysis phases outlined by Braun and Clarke (2006).

\begin{tabular}{|cl|l|}
\hline \multicolumn{2}{|l|}{ Phase } & Description of the process \\
\hline $\begin{array}{r}\text { 1. } \\
\text { with the data }\end{array}$ & $\begin{array}{l}\text { After all the interviews were transcribed, each transcript was read multiple } \\
\text { times to familiarise myself with the data. Initial ideas were noted while } \\
\text { reading. }\end{array}$ \\
\hline $\begin{array}{r}\text { 2. } \\
\text { codes }\end{array}$ & $\begin{array}{l}\text { Searching for } \\
\text { themes }\end{array}$ & $\begin{array}{l}\text { All transcripts were read systematically while freely creating codes across the } \\
\text { whole dataset. Relevant data was collated together. }\end{array}$ \\
\hline 4. & Reviewing themes & $\begin{array}{l}\text { Fodes, along with the data points, were grouped into potential themes. } \\
\text { emerging themes. Secondly, the themes were reviewed against the whole data } \\
\text { set. Finally, a thematic map of the analysis was created. }\end{array}$ \\
\hline 5. & $\begin{array}{l}\text { Defining and } \\
\text { naming themes }\end{array}$ & $\begin{array}{l}\text { The specifics of each theme were analysed and changed to generate clear } \\
\text { names and definitions for each theme. On-going review shaped the overall } \\
\text { story of the data. }\end{array}$ \\
\hline 6. & Writing the report & $\begin{array}{l}\text { Powerful and compelling extracts were selected to be included in the final } \\
\text { results section. Analysis at this stage also ensured that the selected extracts } \\
\text { were relevant to the aims of the research and general literature. }\end{array}$ \\
\hline \multicolumn{2}{|l}{} \\
\hline
\end{tabular}

To ensure anonymity of survey participants, pseudonyms alongside the business leaders' generalised industries were used to describe the results, and any other potentially identifiable information was removed. 


\subsection{Results}

\subsubsection{Participants}

On average, interviews were 44 minutes and ranged from 35 minutes to 1 hour and 6 minutes. Completing the interviews and analysing the responses from business leaders resulted in three overarching themes, specifically: 1) connection to nature, 2) sustainability journey, and 3) aspirations and barriers. Participants were from a range of different industries (Table 3.3).

Table 3.3: The table below outlines the pseudonyms used in this chapter and the general industry of the business leader.

\begin{tabular}{|l|l|}
\hline Pseudonym & Industry \\
\hline Ben & Healthcare \\
\hline Craig & Building \\
\hline Daniel & Education \\
\hline David & Technology \\
\hline Fiona & Sales \\
\hline Grace & Content creation \\
\hline Penny & Marketing \\
\hline Shaun & Manufacturing \\
\hline Tina & Education \\
\hline William & Agriculture \\
\hline & \\
\hline
\end{tabular}

\subsubsection{Theme one: connection to nature}

All participants described some affective, cognitive, or experiential connection to nature. There were similarities and differences in how business leaders described their connection to nature which are outlined here. Interview questions related to a connection to nature elicited responses about childhood memories, changing life circumstances, and increasing environmental awareness. Responses also showed how business leaders try to incorporate their connection to nature into their businesses' values, purposes, and, behaviours.

Half of the participants referenced their childhood nature experiences as a key reason that influenced their choice of profession. For example, Daniel and Tina recalled fond memories of being in nature as a child and wanted to share this connection to nature with future generations through their chosen careers in education. Daniel also mentioned that he didn't want to be cooped up in a job from 9 am to 5 pm, and wanted to find work that allowed 
him to be mostly outdoors. Their responses described affective and experiential connections to nature. For Daniel, who runs a business leading students in sustainability and enterprise, the experiential and affective connection to nature also acted as a driver towards a cognitive connection to nature:

I grew up on the Coromandel, in a small little town, where nature is a big part of living because obviously, we don't have many activities that relate to different environments, no movies, shops, etc., so you create your fun with what you've got there. So obviously beautiful beaches, nice bush, and that sort of stuff. So obviously, that's had a big impact on my development and that was basically the main driver alongside just being a bit of a nerd, and a bit of a science person to go down a sort of environmental science, conservation, career path. (Daniel, education)

For Tina, her childhood experiential connection to nature resulted in cognitive connections which influence how she runs her business. Tina's business aims to provide children the opportunity to experience nature the way she did growing up.

I think probably my biggest memories about being engaged in nature would be from very young. We would kind of go out on a day and just collect everyone from up the road, take a picnic, and go and play in the stream for several hours... I'm a 70's child. And I think back then our upbringing was very much in nature... So, I guess part of what I wanted to bring into our business was that children could have some of those freedoms that they didn't have perhaps naturally or easily in their own home. (Tina, education)

For other business leaders, a connection to nature was not explicitly tied back to their childhood experiences in nature but rather to changing circumstances later on in life. An interviewee who exemplified this is David, whose main reason for getting involved with a sustainable business was his cognitive connection to nature as he became more aware of environmental issues. Moving back to New Zealand was the nudge he needed to work in a job that better aligned with his values. 
I spent some time in the UK, working for a large American corporate-it was everything I thought it was going to be and everything I sort of hated, making money for a giant American company. I suppose it really wasn't values aligned. My awareness of the climate crisis had been growing and I'd definitely become more sustainable and environmental myself, and then coming back to New Zealand, I wanted to put my skills to use with a business that was a New Zealand company that was doing good and wanted to make the world a better place. (David, technology)

\subsubsection{A connection to nature as an influence on work practices}

Interviews with the business leaders revealed that their connection to nature influences their workplace practices. For Grace, who runs a content creation business, her affective and experiential connection grew when she moved to New Zealand where nature was so easily accessible and safe to access. Her connection to nature has had positive influences on her ability to work as a self-employed business leader and has influenced how she makes decisions in her business.

Personally, I love to go walking. It really helps me in business as well-just clears my head and helps me to reconnect... I love being able to go out in nature and take photos, when I can take product shots outside, I prefer that as well. It's much easier in studio lighting conditions to be honest, but I prefer when I can to shoot outside. I find that using nature, natural light, shooting outdoors generally puts me in a better mood. (Grace, content creation)

For Penny, having a connection to nature influences workplace practices because working in or with nature adds value for her business and her clients' businesses. An important theme here is that nature is valuable in business because the effects of physically being in nature can be regenerative.

It's quite incidental that we work with a number of clients that operate and work in the natural world, who work with wildlife, and with the sea, and with water, and with nature, what you and I would call nature. The outdoors, the great 
outdoors, the wonderful New Zealand coastlines, and our bush, and mountains, and our beaches, and things... Somewhere in there is the impact of taking a human being into the bush, or the sea, or the surf, or the snow, or whatever, and having them connect with nature when it's not in their usual routine... And that experience of nature is regenerative and can be very positive, and that can create a better world. (Penny, marketing)

The link between a business leader's personal connection to nature as an influencing force on business decisions was a notable theme for Grace and Penny. In contrast, for Fiona, who works mostly indoors in sales, going outside was more of a personal choice that she made during her workday. She noticed that during the New Zealand COVID-19 2020 Level Four lockdown, more people in her neighbourhood were also going out for walks. Her comments share a similar sentiment as Penny's comment on the regenerative effects of being in nature.

Because I work from home, I usually try to schedule a time to go out for a walk during the day. When I go out for my walks, I get really distracted because I'm like, "oh there's more tūi up there" and I'm looking around going "oh wow, so cool"... If I go out at lunchtime, I'm seeing loads of people out for walks and I know a lot of people in the neighbourhood are not fully back into the office yet... And so, it's been really interesting. It's almost like a reset where people have started to prioritise different activities. (Fiona, sales)

\subsubsection{Connection to nature and environment-based businesses}

For some business leaders, establishing and running environment-based businesses was a way for them to contribute to environmental solutions. Craig reflected on his values rooted in his Māori heritage when he described recently pursuing his next business venture in building.

Wairuatanga is the understanding that there is a spiritual essence additional to the physical world. And that is we've got to be connected spiritually to our environment; the Wairua of a person is nourished by their environment... [My 
next business] is all about working as a collective creating sustainability, but also creating a better way of life. That's very grandiose. But I'm going to do it. (Craig, building)

While Craig's connection to nature appears spiritual and stems from an affective connection to nature, Shaun and Ben's connection to nature appear more cognitively in their businesses' purpose and values. Both business leaders see environment-based businesses as a way of achieving a more environmentally-friendly and sustainable future. For Shaun, after being involved in work practices which he describes as being 'not very good for the environment', he had the realisation that harmful environmental practices could no longer continue in his own business.

[My wife and I] believe that business has to become sustainable, otherwise, there won't be a world left to do business in and so that's our thing. Sustainability is right throughout the company, not just recycling... Our generation has to step up and show the way, you know, and to a certain degree, have to put some money in to pay for the things that we've done wrong, whether we knew that they were wrong at the time or not... It's not until we get a little older that we realise that the world is a finite place. (Shaun, manufacturing)

When business leader Ben started his new business venture, he looked to solve an existing environmental issue based on his personal environmental beliefs. Ben established his business to help solve the root causes of plastic waste caused by healthcare products. Similar to Shaun, Ben wanted his business to be a part of solving wider environmental issues.

My sustainability comes from my own beliefs, not from an educational background... This particular business started because we wanted to reduce plastic, so it wasn't started because of, "oh what a great business opportunity", it was actually to make a difference, which is probably different to other people who have started a business and then adapted to being a responsible corporate. Mine comes from the other way around. The whole business is about 
sustainability. We've chosen to educate people on refusing to use plastics, not about reuse or recycle, but basically refuse. (Ben, healthcare)

This theme highlights how business leaders have personal connections to nature that not only impact their individual decisions but have flow on effects into their businesses. For some business leaders, connecting to nature is ingrained from their childhood, while others became more connected to nature as their perspectives changed throughout adulthood. The responses show that there is an intrinsic relationship between the personal beliefs of the business leader and how their business is connected to nature. Based on this relationship, businesses become connected to nature when business leaders themselves have a personal connection to nature.

\subsubsection{Theme two: sustainability journey}

Business leaders described being on a sustainability journey where they adopted proenvironmental behaviours that align with their personal values and businesses' purpose. The importance of aligned values, being a role model, educating staff members, and encouraging people to join on the sustainability journey were also key insights that business leaders shared.

For some business leaders, having a connection to nature was a key driver in being involved with pro-environmental behaviours. Daniel and Tina considered that it was important to have a personal connection to nature for them to make decisions and take action for the environment in their businesses. They both described how people need to have a connection to nature in order to care and partake in actions to protect it.

It comes down to the fact that you can't protect what you don't love. I try to get people thinking about why they enjoy the natural world, rather than seeing the natural world as a resource, as a reason to protect it. (Daniel, education)

I think the more you can be in nature, the more you can appreciate it, care for it, and have concern for it. (Tina, education) 
Shaun provided a personal anecdote that exemplified how his own connection to nature influenced his behaviour. After seeing the effects of climate change on a childhood holiday location, Shaun became aware of his ability to make sustainable changes in his business.

[With my children] we'd go to places where I'd been as a child and things would be completely different. Just going down to the Franz Josef Glacier, and it's receded by four or five hundred metres from when I was a kid, and I go "man, it didn't look like this". It all started to just fit together and I realised that we've got to do something about this. (Shaun, manufacturing)

The excerpts above demonstrate how having an affinity to nature can influence the type of business individuals establish, and business practices.

\subsubsection{Pro-environmental behaviours in a business setting}

The business leaders in this study shared a wide variety of pro-environmental behaviours which they undertake in their businesses (as shown in Figure 3.1).

\begin{tabular}{ll}
\multicolumn{2}{c}{ composting } \\
$\begin{array}{ll}\text { participating in environmental initiatives } & \text { encouraging technological solutions } \\
\text { e.g. plastic-free July and Veganuary } & \text { e.g. limited printing and video-calling } \\
\text { lobbying againstunsustainable practices }\end{array}$
\end{tabular}

educating clients, customers, and employees

using reusable cups

growing plants

recycling

utilising virtual teams

waste management systems

practicing zero-waste

trapping pests

reducing electricity usage

running lean

offsetting carbon from travel

managing a green supply-chain

green transport options

e.g. public transport and bicycling

researching environmental issues 
Figure 3.1: The word cloud indicates the types of pro-environmental behaviours business leaders undertake in their business, as reported by 10 business leaders in New Zealand. The text size indicates the number of business leaders who mentioned the behaviour during the interview. More commonly mentioned pro-environmental behaviours are shown in a larger font size.

The conversations around the different ways that business leaders promote and enforce pro-environmental behaviours in their businesses covered a range of topics especially in the context of dealing with employees, suppliers, or customers.

To begin with, business leaders who hire or work with employees discussed how in some way their employees shared similar values and beliefs for working in the business or partaking in pro-environmental behaviours. Business leaders mentioned fostering a workplace culture where employees feel empowered to express their own connection to nature. Penny noted that everyone in her team, as well as client base, hold a key value which unites them together in their purpose:

[Sustainability] is one of the unifying themes across our team and our client base... The consultants in our team have all demonstrated a commitment to sustainability through their work, through their career choices, and through their lifestyle choices. So that's what aligns us. We've all had big business experience and now we believe that through our work we can be a force for good to encourage the sort of businesses we want to see prosper. (Penny, marketing)

Tina encourages her employees to take these core values and the sustainability thinking beyond the workplace. This indicates that for Tina, pro-environmental behaviours are not only something that should be done while being authorised at work, but something that should be upheld independently.

We do lots of little things within our team to try and keep us sustained together, sustained in our thinking, sustained in our drive and motivation of what we're trying to achieve... So, this isn't something that we just want our employees to be practicing at work, we want them to go home and think twice about what they're doing at home to. For example, could they think of a different bin system? 
Perhaps their neighbours have chickens and they could give them the scraps? So really encouraging the thinking to go beyond just our space. (Tina, education)

With regards to enforcing pro-environmental behaviours, business leaders had different approaches to encouraging and managing pro-environmental behaviours in their businesses. Some business leaders strictly enforced their employees to undertake proenvironmental behaviours. For Shaun, if his employees were not following the business's protocols around sustainability, then that was enough of a reason for him to end their contract.

It's part of our agreement for our employees, that they follow sustainable practices or they don't work here. And you know, we have terminated people that wouldn't follow the practices. But most people accept our policies, and the ones that make a stand about them don't really fit in with our company culture. (Shaun, manufacturing)

For David, the way pro-environmental behaviours were enforced in his business were the opposite of Shaun's business. Employees in David's business undertake the proenvironmental behaviours that they see align with their own values.

Nothing is enforced. I think the whole thing about our business is that we let people work off their own values and what they care about... So, it's like, everyone sort of has their own piece that they work with. So being a small company, I suppose we've just got flexibility to let people do what they want. There's nothing really enforced but I'd say majority of us take public transport or electric vehicles to work, and yeah, definitely sustainably focussed. (David, technology)

Additionally, if employees do not undertake what might be considered the most proenvironmental behaviours, they are not criticised or pressured. David believes that the best way to enforce pro-environmental behaviours is to create positive associations with the behaviours rather than through strict enforcement. 
I suppose we don't put too much pressure on ourselves and not much pressure in the office. If you ate meat or had a plastic coffee cup from Starbucks, or whatever, no one's gonna grill you for it. It's definitely about trying to take people on that same path with you and there's definitely a nice way of doing it. (David, technology)

\subsubsection{The influence of the business setting on employees}

Shaun discussed how educating his staff prompted his employees to perform workplace proenvironmental behaviours at home. He gave an anecdote about a staff member who got into the habit of turning the lights off. Shaun shows how educating staff and changing behaviours at work can influence positive behaviour changes outside of the workplace.

We try and educate our staff on things like energy consumption. Employees say that they get into the habit of turning off the light when they go home. And that when they see their kids leaving the lights on, they'll get into their kids about it. So, once they get into a habit at work, then they get into it elsewhere. (Shaun, manufacturing)

When communicating and encouraging pro-environmental behaviours to employees, clients, and customers, business leaders often stressed the importance of being a role model. For Shaun, being a leader involves modelling pro-environmental behaviours so that his employees understand what behaviours are acceptable in the workplace.

You have to practice what you preach; you have to lead by example and that is one thing that I have always believed. That is what I was taught by my old bosses. That, and never ever ask someone to do something that you would never do. And so, I never ask someone to do something that I won't do, and if I don't recycle, then why would they recycle? (Shaun, manufacturing)

For Fiona and Ben, they believe that being a role model is about acting on their beliefs and taking small steps where they're able to. David suggests that these small steps contribute 
to a 'collective community' where individual small efforts can add up to meaningful outcomes.

A lot of people just go "the problem is too big, it's a global problem which I can't fix". But my actions can fix it for me and for my world. So, every little step comes to a final, hopefully, fingers-crossed, result that is a good result for us all. (Fiona, sales)

We planted a massive garden, deployed beehives, and made [the back] look nice. It's an industrial area here, it's the only plants around that are flowering all year around and the bees are pretty happy. We're trying to create a great environment as well. So, you know, we don't have many staff, but still you've got to live and breathe what you stand for. (Ben, healthcare)

For other business leaders, being a role model was about supporting other people to go in the right direction on their sustainability journeys. Similar to Shaun, they achieve this through leading by example.

All businesses are somewhere on a sustainability pathway. Some of them are going in the wrong direction and don't realise it... We don't actually have conversations with our clients about values but we like our actions to speak louder than words. (Penny, marketing)

Responses from the business leaders indicate how being a role model does not necessarily imply performing every pro-environmental behaviour perfectly from the beginning of their businesses, but rather acknowledging that something must be done and then partaking in the behaviours that align with their values. Craig made the analogy that being on a sustainability journey is like becoming more health conscious.

There's got to be some compromises, and this is like when you're trying to change the way you eat, it's really hard to do it in one hit. But ifyou work on it every day, suddenly in a year, you're eating a lot healthier, you might still have a way to go, but it's a journey, rather than a final destination. (Craig, building) 
This theme reveals how business leaders adopt pro-environmental behaviours in their businesses that align with their values. For some business leaders, their connection to nature was a key driver for performing pro-environmental behaviours in their businesses. Business leaders in this study described role modelling, but also communicating and enforcing pro-environmental behaviours to encourage their staff members, customers, and clients to join them on a sustainability journey.

\title{
3.3.4 Theme three: aspirations and barriers
}

This theme explores the future aspirations business leaders have for adopting proenvironmental behaviours in their business, achieving a 'clean and green' New Zealand, and provides insight about future generations and business. This theme also highlights some of the barriers encountered when trying to achieve these aspirations.

In the interviews, some business leaders acknowledged that they do not undertake as much as they would like to for the environment. Grace and Craig revealed aspirations for performing more pro-environmental behaviours in their businesses, however, encounter barriers when trying to pursue them. For Grace, she discussed how "every solution has a pollution" and how she finds it difficult to achieve a balance for this dilemma. Her comments indicate how there can be conflict between values, business decisions, and the environment.

\begin{abstract}
My personal values are our environments very important. I don't think I do enough to reflect that... I would love to find companies, technological solutions that don't rely on planned obsolescence, that don't rely on components that are really bad for the environment, and really bad for the people mining the components. It's tricky. I'm not sure. But by the same token, because of those components, I'm able to deliver everything online. So, it's a balance. (Grace, content creation)
\end{abstract}

For Craig, he shared how he would like to do more for the environment but struggles to find environmental solutions for some aspects of his business. Craig also mentions how cost can be a barrier for adopting pro-environmental behaviours. 
Connecting to the environment at the moment is more of where I want to head, not so much where I am now. I mean, obviously, I have a recycling bin and I do the basics that most people do, but I'd like to do more. The thing is, it's so hard to do more. For example, moving to an electric car at the moment is still too costly. At the moment for my business, I'll need to have a truck that can tow 3,500 kilos and there's no electric solution for that. So, that will be a petrol solution probably, or diesel. (Craig, building)

While these excerpts show how Grace and Craig would like to personally do more for the environment, other business leaders discussed how New Zealand as a country could be doing a lot more to protect the natural environment. New Zealand's 'clean and green' image came up in these conversations and highlight how as a nation, we might not be doing as much for the environment as we claim to be, as noted by Fiona.

Our lovely clean, green image is only really an image, it's not actually real. I think that there are parts of the country where it's not bad, and then there are other parts of the country where it's really crappy. (Fiona, sales)

\subsubsection{Sustainability as a generational issue}

Consideration about the future generation was common when discussing future aspirations. Business leaders expressed hope in the younger generations as they become more involved in business. Ben acknowledged how current and future generations are being brought up in a world where environmental issues are becoming a priority, so is optimistic that future businesses will have an interest in solving these issues at their core.

I hope other businesses will come from a different perspective in the future of start-ups, thinking about an environmental policy that is the heart of the business from the start... I really hope the younger people, the people coming up starting businesses that it'll be a part of their DNA. They are bought up in a world where environmental issues are top of mind... I have a real hope and belief that all start-ups will have that as an important part of their decision-making. (Ben, healthcare) 
Grace also shared her hope in future generations, highlighting that current business leaders must embrace environmental values and practices in their businesses or become irrelevant.

I have a lot of hope in the younger generations because they already are thinking differently. They're not going to tolerate the same things-even my generation, we're not going to tolerate it, and they're not going to tolerate it... It's the future so you better embrace it, especially in business. I think you have to embrace it, or you'll be facing down your own irrelevancy in a pretty short period of time and trying to find your way out of it, and that's a scary proposition. (Grace, content creation)

\subsubsection{Economic and social drivers as barriers and enablers of pro- environmental behaviours}

Economic drivers were an important consideration noted by interviewees that could act as a barrier to pro-environmental behaviours in business. Grace believes that there are issues around the economy and protecting the natural environment, however, she believes that this can be changed without too much difficulty.

I do believe that we can change. We've developed this economic system; we can redesign it. I think there's a lot of solutions that we could be looking at. And quickly to, like, I don't think it takes a huge, bloodless revolution to make these things happen. I think it means we just all need to start thinking differently. (Grace, content creation)

In relation to thinking differently about pro-environmental behaviours, Ben references the governments ban on single-use plastic shopping bags in 2019 to highlight how quickly society's attitudes and behaviours can change, especially when policy is involved. At the time, business leaders would have also had to adapt their businesses' practices to comply with the change in policy. 
Have you ever spoken to people about when they changed from plastic bags at the supermarket? How many people bitched and complained about how difficult it was? And now do you hear anything? No. You might hear about how it's a bit annoying that they left their reusable bag at home and need to get another one, but it's just so, so easy to change, there is no problem. (Ben, healthcare)

Where policy and government has not come through, business leaders have initiated change themselves. When discussing carbon emission reporting, David demonstrates how his business is involved in monitoring everyday carbon emissions using technology, regardless of having existing policy that supports this:

Hopefully policy comes in as well because we have sugar content, right? So why not carbon emissions? Or how far something has travelled? Or the water involved? I think it should come and hopefully it does. I think policy could definitely help, but again, we've tried with government, we're not waiting for them. We're sort of running it ourselves. (David, Technology)

For Shaun, the business sector has accountability for creating a greener future and he envisions that a lot of green initiatives will become mandated in the future.

I believe that the business sector has got a responsibility to drive it, you know... I think people are certainly becoming more aware about ethical investment. People are starting to say "I don't want to invest in oil, I don't want to invest in tobacco, or invest in coal". With the internet and the connectivity that is in the world now, I think that consumers are much more aware and businesses can only get away with greenwash for so long. (Shaun, manufacturing)

This theme explores the future aspirations that business leaders possess for performing pro-environmental behaviours in their own business, future businesses, and New Zealand. For some business leaders, they revealed that they would like to personally do more to connect with nature and partake in more pro-environmental behaviours. Other business leaders communicated generally about their aspirations and showed how New Zealand, in their view, could be doing more to protect the environment. When looking at 
future businesses, business leaders carried hope in future generations to start environmentally focussed businesses. The relationship between the economy and environment, and changing behaviours were barriers mentioned in the interviews, however, business leaders indicated how change can occur with new thinking, policy, and pressure from society.

\subsection{Discussion}

\subsubsection{Connection to nature and pro-environmental behaviour}

This research reveals a clear link between individual connection to nature and proenvironmental behaviours in a business context. The results indicate that all the business leaders interviewed described some form of connection to nature that has impacted their businesses. Business leaders described affective, cognitive, and experiential connections to nature which have influenced them to perform a variety of different workplace proenvironmental behaviours. This study supports and extends existing connection to nature theories (Mayer \& Frantz, 2004; Nisbet et al., 2009; Pereira \& Forster, 2015) that have shown a business leader's connection to nature influences their business's pro-environmental behaviours.

The most commonly mentioned pro-environmental behaviours were similar to those that have been observed in the literature including recycling (Milfont \& Duckitt, 2010), conserving water and energy (Schultz \& Zelezny, 1998), and choosing greener transportation options (Diekmann \& Preisendörfer, 1998). The connection to nature of business leaders in this study was reflected not only in the performance of proenvironmental behaviours themselves, but also through the encouragement and enforcement of these behaviours for employees, customers, and suppliers. Business leaders shared how it was important for them to model the types of behaviours that they expected their employees to perform. Business leaders facilitated connection to nature and encouraged pro-environmental behaviours in their businesses through supporting a green workplace culture, enhancing their natural workplace environments, and empowering employees to follow their own environmental passions through flexible workplace practices. 
These findings align with existing literature which suggests that managers and supervisors play important roles when influencing employees to adopt pro-environmental behaviours, and as such this may be an important area of focus for future sustainability initiatives (Boiral et al., 2015; Yaffe \& Kark, 2011). If business leaders adopt pro-environmental behaviours that are shown to have direct conservation outcomes, then their employees are likely to act in accordance with the behaviours being undertaken which may lead to greater benefits for the natural environment.

\subsubsection{Future aspirations of business leaders}

The business leaders interviewed held a normative view of business, claiming that they have environmental, social, and economic responsibilities. When business leaders discussed future aspirations, a key aspect of their responses focussed on future business leaders and the purpose of future businesses. Business leaders expressed hope that the next generation of business leaders would start businesses that would focus on solving environmental issues at their core. This aspiration is captured in the emerging literary field of 'ecopreneurship'. Ecopreneurship is a combination of the words 'entrepreneurship' and 'ecological', and describes businesses that are based on the principles of sustainability (Kirkwood \& Walton, 2014; Schaltegger, 2002). Ecopreneurship is likely to be an important part of a sustainable future because it involves innovation and environmentally conscious perspectives in business that help to maintain ecosystems, conserve biodiversity, reverse climate change, and reduce environmental degradation (Dean \& McMullen, 2007; McEwen, 2013). While business leaders did not use the term 'ecopreneurship' in their responses, a few did describe this concept sharing how they have started and run sustainable businesses to help solve current environmental issues and protect the natural environment. Current business leaders aspire for future business leaders to do the same.

\subsubsection{Barriers to pro-environmental behaviours}

The business leaders in this study noted a range of different barriers when trying to do as much as they can for the environment. Barriers shared included economic and social factors influencing business, changing behaviours, costs associated with pro-environmental 
behaviours, and environmental solutions not yet existing for specific industry needs. With the exception of cost, these barriers add to those commonly identified in the literature, which includes a lack of time, resources, customer demand, awareness of environmental legislation, and reasons to confront environmental issues (Lepoutre \& Heene, 2006; Lewis \& Cassells, 2010; Rutherfoord et al., 2000). The added barriers identified highlight the value of taking a qualitative approach to this research, as much of the existing research into proenvironmental barriers has been quantitative. Following a quantitative approach can limit the richness, diversity, and nuances of responses because answer-options are selected by the researcher and questions are often closed-ended (McCusker \& Gunaydin, 2015). Through using qualitative methodology, business leaders were able to openly explain the types of barriers that they face in their personal business circumstances. As a result, business leaders predominantly shared barriers that were specific to their business. The results of this study suggest that business leaders are aware and have reasons to address environmental issues, however, face specific barriers in their businesses to achieve as much as they would like to for the natural environment.

\subsubsection{Implications}

When business leaders express their connection to nature in the running of their businesses, the evidence in this chapter suggests they can achieve environmental outcomes as well as advantageous business benefits. According to Lozano (2015), businesses that are motivated to engage in environmental initiatives can reduce costs while improving processes and minimising waste, avoid fines and penalties related to environmental regulations, enhance their business and brand reputation, create a more unified workforce, and improve relations with stakeholders, suppliers, and customers. Additionally, business leaders might secure a competitive advantage, improve risk management, and foster innovation (Whelan \& Fink, 2016). Business leaders in my study reported realising many of these benefits in their businesses through undertaking pro-environmental behaviours that were already a key part of, or related to, their businesses. Given this, when encouraging pro-environmental behaviour uptake in businesses, promoting both environmental outcomes and business benefits may help to motivate business leaders to engage in pro-environmental behaviours. 
Businesses are a part of a larger network comprised of multiple stakeholdersgovernment, councils, suppliers, distributers, consumers, and others, and as such it is important to acknowledge business leaders are only one key player in protecting the environment (Lozano, 2015; Zu, 2019). Several studies have concluded that it requires a collaborative effort to generate significant environmental outcomes (Amel et al., 2017; Doh \& Benischke, 2019; Viswanathan \& Varghese, 2018). Stakeholders play different roles in achieving these outcomes-for example, governments establish and enforce environmental policies and regulations (Viswanathan \& Varghese, 2018), consumers demand goods and services that align with their environmental values (Kalamas et al., 2014), and suppliers continue to improve their performance on environmental issues (Lee \& Klassen, 2008). Findings from this chapter provide insights into how business leaders are contributing to protecting the environment through undertaking various pro-environmental behaviours in their businesses. Real change for environmental outcomes can be realised when business leaders collaborate and support others who are a part of their network and vice versa.

Understanding the future aspirations business leaders hold for their businesses and the environment can support advancements in achieving positive environmental outcomes (Hanelt et al., 2016). Currently there is very limited literature exploring the environmental aspirations of business leaders and how to support them in realising these, though the research that does exist has examined environmental aspirations such as climate change targets (Dahlmann et al., 2019; Maas \& Rosendaal, 2016), and the adoption of green strategies (McCullough \& Cunningham, 2010; Olson, 2008). In this chapter, business leaders shared environmental aspirations for their own businesses, future business leaders, and for the fulfilment of New Zealand's clean, green image. When business leaders discussed the aspirations of their businesses, they were specific to the context of their business or industry and personal values. This suggests that when programmes are created to support environmental sustainability in business, the most effective initiatives might be those that are appropriate and specifically relevant to the particular business or industry (Lee, 2008). Recognising future aspirations of business leaders, along with reducing industry specific barriers, will be important if business leaders are to engage further in actions that contribute to positive environmental outcomes (Gardner \& Stern, 2002). 


\subsubsection{Limitations and future research}

While business leaders in this study adopt a variety of pro-environmental behaviours in their businesses, there is no clear indication that all of these behaviours have direct effects on positive biodiversity outcomes-a subset of environmental outcomes. Achieving positive biodiversity outcomes broadly means supporting the variety of life on earth-including ecosystems and genes (Biodiversity, 2019). The types of pro-environmental behaviours that are most commonly undertaken by business leaders in this study relate to environmental best practices, which do result in some positive environmental outcomes; for example, the reduction of waste, efficient consumption of energy, and minimisation of carbon emissions. However, positive biodiversity outcomes may not be directly realised through these kinds of commonly reported practices. Pro-environmental behaviours mentioned that do have direct effects on biodiversity included habitat restoration, pest control, and growing native plants. While some business leaders did partake in these behaviours, future research could investigate how to further educate and encourage business leaders to adopt proenvironmental behaviours in their businesses that do have direct biodiversity outcomes.

In relation to the qualitative methodology used, this study holds several strengths; however, this approach does have limitations. First, the findings have limited generalisability (Alsaawi, 2014). To mitigate against this issue, quotes were used extensively throughout the results and rich descriptions of the data were included to support the transfer of findings in different contexts. While qualitative methodology was the appropriate method to answer the research aims of this study, future research could expand on the concepts discovered here through quantitative methods.

Second, the method of conducting interviews presents limitations around bias which influence validity and reliability (Smith \& Noble, 2014). While numerous steps were taken to ensure the validity and reliability of this study (including clearly describing the epistemology and approach taken in this research, asking open-ended questions during the interviews, providing interviewees the opportunity to review their transcripts after the interview, and including different interviewee perspectives in the results section to present different views), potential biases including recall, observation, or confirmation bias may still 
remain (Noble \& Smith, 2015). To overcome this limitation, future research would be valuable to support or refute our findings through different methods.

Finally, a limitation of this study is that it relied on self-report of pro-environmental behaviours. The responses from interviewees may not accurately reflect the truth because of recall bias, which occurs when participants do not remember past experiences or events correctly or exclude details (Kvale, 1994). This is an issue because findings are dependent on the responses of the interviewees being valid and reliable. Additionally, unconscious bias may be an issue, whereby interviewees have preconceived expectations of 'correct' answers that the interviewer is trying to collect (Kvale, 1994). An observational study would, therefore, be useful to examine how interview responses from business leaders are realised in their everyday workplace practices. Furthermore, a longitudinal study might add additional insight about the sustainability journey that business leaders described in this study. Future research into the relationship between nature connection and business leaders is needed to extend understanding in this field and encourage future business leaders to adopt pro-environmental behaviours that lead to positive environmental-as well as biodiversity outcomes.

\subsection{Conclusion}

Based on a qualitative analysis, this chapter illustrates that New Zealand business leaders have an affective, cognitive, and experiential connection to nature that is expressed through pro-environmental behaviours in their businesses. Business leaders hold environmental aspirations for their businesses, future business leaders, and for the country; however, face a number of barriers in realising these aspirations on their sustainability journey. Findings from this chapter support and extend existing theories in the literature that an individual's connection to nature influences their pro-environmental behaviours. Due to the qualitative methodology, results from this study are not generalisable for all business leaders. Despite this, the findings are relevant for providing a rich, in-depth account of how this sample of business leaders connect to nature and how that influences their businesses. The results are important because they reveal that pro-environmental behaviours in business are driven by the connection to nature that business leaders hold. To fully understand the implications of 
this study, future research is needed to analyse how business leaders can contribute directly to biodiversity outcomes in their businesses. 


\section{Chapter 4: General summary and discussion}

\subsection{Introduction}

The importance of an individual's connection to nature, and how this might relate to proenvironmental behaviours in a business context has received limited attention in the literature, despite the business sector continuing to face increasing pressures to become more environmentally responsible (Baughn et al., 2007). Previous findings have shown that a connection to nature is associated with pro-environmental behaviour uptake in a nonbusiness context (Nisbet et al., 2009; Stern, 2000). Findings have also demonstrated that individuals who show concern for the natural environment perform pro-environmental behaviours more willingly (Dunlap et al., 2000). Exploring whether, and how, these concepts extend into a business context will provide important insights into how businesses can contribute to positive environmental outcomes while still realising their primary business objectives.

This thesis explored how New Zealand business leaders perceive their connection to nature in a business context, and how they currently, and may in the future, contribute positively to environmental outcomes. I aimed to:

1. assess how business leaders perceive their current connection to nature;

2. identify the pro-environmental behaviours that business leaders currently report their business undertakes and the barriers to undertaking these behaviours; and

3. evaluate what environmental and business aspirations business leaders hold for the future.

This research followed a mixed methods approach to gain an in-depth and broad perspective on these aims. Chapter 2 utilised quantitative methods to determine the association between business leaders' connection to nature and pro-environmental behaviours. Chapter 3 followed qualitative methods to investigate the role of business leaders' connection to nature in fostering pro-environmental behaviours. Key findings from these chapters as well as notable future research directions are discussed in this chapter. 


\subsection{Overview of findings by chapter}

\subsubsection{Chapter 2: The association between business leaders' connection to nature and pro-environmental behaviours}

In this chapter, I aimed to measure associations between business leaders' connection to nature, pro-environmental behaviours, and barriers to adopting pro-environmental behaviours. I carried out a quantitative survey focussing on business leaders across New Zealand to understand what pro-environmental behaviours they undertook in a business setting, and identify what barriers prevent pro-environmental behaviours from occurring. Further, I examined the extent to which these reflect the business leaders' affective, cognitive, or experiential dimensions of connection to nature.

Business leaders who had a higher overall connection to nature (measured by the nature relatedness score; Nisbet et al., 2009) were shown to partake more frequently in proenvironmental behaviours compared to business leaders who reported a lower overall nature relatedness score. Additionally, business leaders who reported undertaking proenvironmental behaviours more frequently showed a significantly higher affective and experiential connection to nature. This indicates that there is a relationship between a connection to nature and the uptake of pro-environmental behaviours in a New Zealand business context. This reinforces previous research findings that have also shown a positive relationship between a connection to nature and pro-environmental behaviours in nonbusiness contexts (Kals et al., 1999; Nisbet et al., 2009; Schultz, 2001).

Recycling, purchasing sustainable products, and conserving electricity were the most frequently undertaken pro-environmental behaviours by all business leaders surveyed. These behaviours are classified as individual lifestyle behaviours (Cooper et al., 2015; McMullin et al., 2007) which may not have direct effects on biodiversity outcomes. Business leaders who showed a higher connection to nature, more frequently reported undertaking behaviours that were likely to more directly affect biodiversity conservation outcomes, such as habitat enhancement, supporting green policies, and joining environmental groups. 
Business leaders reported availability of time as the biggest barrier preventing them from undertaking as much as they would like for the environment. Business leaders who are already partaking in more frequent pro-environmental behaviours reported facing fewer barriers than business leaders less frequently partaking in pro-environmental behaviours.

This chapter shows that New Zealand business leaders with greater feelings of connection to nature are associated with higher uptake of pro-environmental behaviours in their businesses, but it is also associated with a lower perception of barriers. Findings from this chapter indicate that facilitating the development of business leaders' connection to nature could be a viable strategy to support further implementation of pro-environmental behaviours in a business context. Additionally, enabling a stronger connection to nature may encourage business leaders to perceive fewer barriers, and therefore, promote them to undertake further pro-environmental behaviours.

\subsubsection{Chapter 3: The role of business leaders' connection to nature in fostering pro-environmental behaviours}

While Chapter 2 establishes that there is a relationship between connection to nature and pro-environmental behaviours in business, this chapter extends the discovery by taking an in-depth exploration of business leaders' perceptions following qualitative methods. Understanding how and why business leaders currently express their connection to nature in their businesses could provide insights into how further pro-environmental behaviours might be encouraged. I conducted semi-structured interviews with 10 New Zealand business leaders to take a comprehensive look at their perceptions regarding how their connection to nature is expressed in their businesses, and whether (and what) their aspirations might be for extending this.

All the business leaders interviewed expressed some affective, cognitive, or experiential connection to nature that were related to performing pro-environmental behaviours in their businesses. Business leaders referenced their up-bringing, changes in lifestyle, and values as reasons for their feelings of connection to nature. They broadly reported that having a connection to nature influenced the sustainability journey in their 
businesses where they educate, enable, and encourage others to perform pro-environmental behaviours, while still achieving their primary business objectives. Recycling, reducing electricity usage, and green transport options were some of the most commonly reported pro-environmental behaviours adopted by business leaders.

Business leaders shared aspirations related to undertaking more pro-environmental behaviours in their own businesses, as well as thoughts on the broader business community including how future business leaders should run environmentally focussed businesses, and how New Zealand's clean, green image needs to be realised in practice. There were a number of barriers identified in achieving these aspirations including economic and social factors influencing the business sector, costs associated with pro-environmental behaviours, and environmental solutions not yet existing for specific industry needs.

Findings from this chapter show that business leaders have an affective, cognitive, and experiential connection to nature that is expressed through pro-environmental behaviours in their businesses. Further, they show that business leaders undertake proenvironmental behaviours that are relevant to their businesses and aligned with their personal connection to nature. This is a particularly important finding as it suggests efforts to promote pro-environmental behaviours in business might be most effective where they focus on activities that have some connection to the business itself. Findings from this chapter also showed that business leaders have aspirations to partake in more proenvironmental behaviours in their businesses; however, they perceive a number of barriers when trying to achieve these aspirations. This suggests that approaches that support businesses in understanding and overcoming real and perceived barriers could support further uptake of pro-environmental behaviours. Significant advancements for the natural environment could be achieved if business leaders were able to fully express their connection to nature and undertake the pro-environmental behaviours that they aspire to perform in their businesses. 


\subsection{Discussion}

\subsubsection{Connection to nature in a business context}

Both Chapters 2 and 3 found a positive association between a greater connection to nature in New Zealand business leaders and the expression of pro-environmental behaviours in their businesses. These findings reinforce the association between a connection to nature and pro-environmental behaviours that has been found at an individual level in international literature (Mayer, 2004; Nisbet et al., 2009; Stern, 2000). The two studies extend on these findings by providing compelling evidence that indicates the importance of this association in a business context.

In Chapter 2, more frequent pro-environmental behaviour uptake was associated with a higher overall nature relatedness score (Nisbet et al., 2009). However, when nature relatedness was deconstructed into three individual dimensions (affective, experiential, and cognitive) the cognitive connection to nature was not significantly different between business leaders who undertake pro-environmental behaviours more or less frequently. Insights from the interviews with business leaders help to explain why this might be the case. All of the business leaders revealed cognitive awareness to environmental issues, sustainable practices, and environmental responsibility as a business. However, this cognitive awareness did not always translate into pro-environmental behaviours for several different reasons including various barriers to adopting pro-environmental behaviours, proenvironmental behaviours being identified as not relevant to the business, and perceptions of being unable to contribute directly to solving the environmental issue. Previous studies have addressed the gap between attitudes and actions finding that environmental awareness does not necessarily lead to pro-environmental behaviour uptake (Kollmuss \& Agyeman, 2002; Zsóka, 2005). Findings in this study support this hypothesis and contributes knowledge into why a cognitive connection to nature in a business context might not result in the uptake of pro-environmental behaviours in businesses.

Findings from Chapter 2 also showed that an affective and experiential connection to nature was higher in business leaders who undertake pro-environmental behaviours more 
frequently. Chapter 3 supports this result; when discussing why business leaders adopt certain pro-environmental behaviours in their businesses, environmental values and interactions with the natural environment were common themes that were shared. Most commonly, an affinity with and experiential connection to nature was described over time, from when business leaders were growing up through to how they currently perceive and experience the natural environment. These findings suggest that an affective and experiential connection to nature are deeply personal and change over time, which may explain why affective and experiential dimensions are significantly associated with more frequent pro-environmental behaviours. Findings from this study support previous research that shows that an affective and experiential connection to nature influences proenvironmental behaviour (Hinds \& Spark, 2008; Mayer \& Frantz, 2004; Pereira \& Forster, 2015).

Efforts that increase a business leader's connection to nature, specifically their affective and experiential connection may influence further pro-environmental behaviour uptake in their business (Pensini et al., 2016). My research shows that business leaders are cognitively aware of environmental issues; therefore, further information about these issues may not be significant enough reason for business leaders to undertake more frequent proenvironmental behaviours. Encouraging business leaders to personally connect with and experience their natural environments may be a more successful approach that motivates further pro-environmental behaviour uptake in businesses.

\subsubsection{Pro-environmental behaviours in a business context}

Both chapters explored pro-environmental behaviours in a business context to understand how these behaviours might contribute to positive environmental and biodiversity outcomes. In Chapter 2, I showed that business leaders most frequently undertake recycling, purchasing of sustainable products, and conservation of electricity, results that support findings in previous studies (Milfont \& Duckitt, 2010; Schultz \& Zelezny, 1998). These proenvironmental behaviours in businesses may have some positive indirect environmental outcomes but will not necessarily have direct effects on conserving biodiversity. In Chapter 3, I was able to unpack some of the decision-making around what behaviours business 
leaders promoted in their companies. Specifically, they reported undertaking a variety of individual lifestyle pro-environmental behaviours because they were identified as being environmentally-friendly, aligning with the businesses' values, or helping to reduce business operating expenses. Conservation pro-environmental behaviours were more often described as aspirational behaviours rather than being a part of the daily running of the business. This suggests interventions that support pro-environmental initiatives in businesses may be most effective if they have a highly targeted approach that suits the business in question, but also supports business leaders in understanding how they can directly improve biodiversity outcomes in their area.

Existing studies into pro-environmental behaviours are predominantly quantitative in the scientific literature (Dietz et al., 2005; Hinds \& Sparks, 2008; Nisbet et al., 2009). These studies focus on measuring a select set of pro-environmental behaviours identified by the researchers. In this study, conducting interviews allowed business leaders to freely share the types of pro-environmental behaviours that they are currently undertaking in the context of their connection to nature and businesses. Business leaders reported undertaking a wide variety of different pro-environmental behaviours that are specifically related to their businesses and industries; for example, waste management practices associated with production, sourcing local ingredients for products, digital delivery of content, utilising virtual teams, and taking advantage of fertiliser runoff. My qualitative study identified a number of specific and meaningful pro-environmental behaviours that are rarely, if ever, measured in quantitative studies (Clark et al., 2003; Kals et al., 1999; Milfont \& Duckitt, 2010). This finding expands societal understanding of what role the business sector might play in achieving environmental outcomes for New Zealand. In practice, the findings may be useful for business leaders to improve their understanding around what pro-environmental behaviours they could incorporate into the daily running of their businesses-if they are to achieve environmental objectives.

\subsubsection{Complexity of terminology}

In the quantitative chapter, I constructed the survey based on terminology commonly used in the literature (Blake, 1999; Cooper et al., 2015; Kollmuss \& Agyeman, 2002; McMullin et 
al., 2007). The term pro-environmental behaviour was chosen because it has been defined as behaviours which aim to reduce the negative impacts of people's actions on the natural world (Stern, 2000). Additionally, the term connection to nature was chosen because it has been identified as an overarching term used to describe how humans connect with nature (Ives et al., 2017). Based on the approach of quantitative methods, participants were restricted to the terminology that I had used in the survey questions. In contrast, participants in the qualitative study were able to freely use their own words to describe their connection to nature and pro-environmental behaviours.

Responses from the qualitative study showed that business leaders were more familiar with the term 'sustainable' when describing behaviours that relate to the environment. Additionally, the terms 'environmentally-friendly' or 'green' were also used to describe behaviours. In the literature, researchers appear to choose and define terms carefully to construct shared meaning (Banwo \& Du, 2019). Conversely, in the interviews, business leaders interchanged different terminology when describing their behaviours. The difference in terminology may reflect some disconnect between how researchers frame behaviours that protect the environment and how business leaders adopt and perform these kinds of behaviours in practice. If we are to achieve biodiversity outcomes, then business leaders will need to understand what types of behaviours are the most effective (Rondinelli \& Berry, 2000; Studer et al., 2006). The quantitative chapter begins to quantify how many business leaders partake in conservation and lifestyle pro-environmental behaviours in their business, while the qualitative chapter captures what business leaders define as proenvironmental, sustainable, environmentally-friendly, or green behaviours. These findings help to establish a baseline understanding of how pro-environmental behaviours are defined in the literature and how they are implemented by business leaders.

\subsubsection{Value of a mixed methods approach}

Through adopting a mixed method approach, this research benefitted from strengths associated with qualitative and quantitative methodologies. Specifically, the quantitative approach allowed me to establish that there is an association between a connection to nature and pro-environmental behaviours in business, while the qualitative approach enabled me 
to explore this more deeply in the context of the individual business leader's connection to nature and business. This approach is valuable because the findings from each chapter strengthen and build upon each other. By following quantitative methods outlined in Chapter 2, I was able to quantify the connection to nature of business leaders, frequency of proenvironmental behaviour uptake in businesses, and barriers to adopting pro-environmental behaviours, before providing insight on how these variables are associated using cluster analysis. While in Chapter 3, I was able to discuss pro-environmental behaviours and barriers in the context of each individual business leader, and unpack pro-environmental behaviours that were not revealed in the quantitative work. The interviews in Chapter 3 added richness to the conclusions from the quantitative chapter by grounding the findings in the business leaders' own experiences and responses.

Overall, following a mixed methods approach provides quantitative and qualitative evidence that current New Zealand business leaders across different industries are undertaking pro-environmental behaviours in their businesses that are related to their connection to nature and the primary objectives of their businesses. These findings provide insight into how business leaders are currently contributing to environmental outcomes through the daily running of their businesses. Both studies suggest that a connection to nature is an important influencer on business leaders when undertaking and enforcing proenvironmental behaviours in their businesses.

\subsubsection{Limitations}

While findings from this study indicate an association between individual connection to nature and the expression of pro-environmental behaviours, business leaders in reality are influenced by many different factors which this study does not address directly. For example, sustainable business decisions might be influenced by economic, social, technological, ethical, media, political, and legal factors (Baughn et al., 2007; Clegg, 2011; Hargreaves, 2011). In the quantitative chapter, these factors were considered outside the scope of the study because the aims focussed on identifying what pro-environmental behaviours are currently being undertaken, and establishing associations between connection to nature, pro-environmental behaviours, and barriers. In the qualitative chapter, some of these other 
influencing factors did get mentioned by business leaders; however, the scope of the analysis focussed on the relationship between individual connection to nature and proenvironmental behaviour. The findings from the qualitative chapter do indicate that some of these different factors are potentially important when business leaders adopt proenvironmental behaviours. For example, business leaders mentioned financial factors that either prompted them to adopt pro-environmental behaviours (e.g. reducing packaging to save on costs), or not to adopt pro-environmental behaviours (e.g. not purchasing an electric vehicle due to costs). Having a connection to nature is just one of many factors that may influence business leaders to adopt pro-environmental behaviours because decision-making in business is complex and dependent on many factors.

Another limitation relates to the sample of business leaders included in this research. Business leaders have very busy schedules and often face extreme internal and external pressures to perform in their businesses (Bruch \& Ghoshal, 2002); therefore, they may not have the time to participate in voluntary surveys. The generalisability of findings from the quantitative chapter are limited by the sample size $(n=216)$. Considering the vast number of small to medium-sized business leaders in New Zealand who could have participated in the survey, this study is unlikely to capture the views of all New Zealand business leaders fully and accurately. Additionally, while Denzin and Lincoln (2008), conclude that six participants are more than enough for qualitative interviews, the interview sample size of 10 is still unable to represent the views of all business leaders in New Zealand. The findings from both chapters can, however, provide a detailed snapshot of an actively engaged sample of New Zealand business leaders who were interested in this research, demonstrate a connection to nature, and undertake pro-environmental behaviours.

An additional limitation relates to the sampling methods used to survey business leaders. During the data collection phase, business networks were targeted because they were an appropriate and accessible group of business leaders to contact for this research. Business leaders in a business network are likely to share similar values, objectives, and purposes, which may not be representative of all business leaders in New Zealand who are not in a network. Additionally, the sampling methods targeted businesses who already 
display values and actions related to protecting the environment because these businesses were most likely to have business leaders who would be interested in participating in this research. Findings reflect actively interested business leaders who have volunteered time to partake in research about connection to nature and pro-environmental behaviours; therefore, consideration is needed when extrapolating these results to a broader sample. Future research might aim to focus on business leaders who are not already actively engaged in protecting the environment to determine if findings from this study are transferable to different samples of business leaders.

I undertook numerous steps during the construction and distribution of the survey to try and encourage business leaders to participate in the study. For example, the survey was kept short, included brief and succinct questions without jargon, and utilised ticking measures. When distributing the survey, emails were targeted directly to the business leader using their name (where possible) and personal phone calls were made with business network leaders asking them to distribute my survey to their members. While these steps helped to increase the sample size, future studies might consider surveying methods other than an online survey, to fully sample and represent business leaders, e.g., phone interviews or targeted workshops. Future studies might also include incentives (financial or otherwise) to further motivate business leaders to participate.

\subsubsection{Future research directions}

This research focussed on business leaders within New Zealand. Two notable areas for future research that stem from this thesis are: 1) research into how the barriers to undertaking pro-environmental behaviours can be mitigated to enable business leaders to undertake as much as they would like to for the environment; and 2) research into encouraging business leaders to adopt pro-environmental behaviours that have direct biodiversity outcomes. A focus on these two areas will provide real advancements for expanding the role of businesses in achieving biodiversity conservation. Research into the first area is important because the results from this study indicate that business leaders are facing similar barriers when trying to adopt pro-environmental behaviours in their businesses. By understanding how to mitigate even some of these barriers, business leaders 
will become more capable in being able to contribute to positive biodiversity outcomes. Research into the second area is strongly recommended because findings from this study indicate that business leaders more frequently undertake pro-environmental behaviours in their businesses that may not have direct biodiversity conservation outcomes. Further research will help to educate and empower business leaders to undertake proenvironmental behaviours that have direct impacts on conserving biodiversity.

Other research opportunities that would contribute and extend our understanding of connection to nature and pro-environmental behaviour in a business context could include: surveying a larger sample of New Zealand business leaders; conducting the same survey with business leaders from different countries; further research into understanding how other influencing factors affect business leaders when choosing to perform pro-environmental behaviours; and following different methods such as an observational study to assess how connection to nature translates into pro-environmental behaviours in practice, or a longitudinal study to determine how connection to nature and pro-environmental behaviours change over time. Knowledge gained through these studies will help increase theoretical knowledge and shape the role of businesses in realising connection to nature proenvironmental behaviours.

\subsection{Conclusion}

This thesis explored how New Zealand business leaders perceive their connection to nature in a business context, to determine how they currently, and may in the future, contribute positively to environmental outcomes. Key findings from this research include: a significant association between undertaking pro-environmental behaviours more frequently and a higher connection to nature; business leaders face various barriers such as limited time and resources, and changing behaviours when trying to do as much as they can for the environment; and business leaders have aspirations to undertake more pro-environmental behaviours, and for future business leaders to express environmental values when they start new businesses. It is hoped that findings from this research will provide insights into how business leaders might be further supported to express their connection to nature through 
pro-environmental behaviours in their businesses, and to help decision makers make informed decisions on how to further engage businesses with nature. 


\section{Appendix 1: Connection to nature survey}

\section{Business characteristics}

1. Do you currently hold a leadership role in a New Zealand business? (select one of these options-if 'no' is selected then the survey ends, if 'yes' is selected the survey continues)

- Yes

- No

2. What industry best describes your business? (select one of these options)

- Agriculture, Forestry and Fishing

- Mining

- Manufacturing

- Electricity, Gas, Water and Waste Services

- Construction

- Wholesale Trade

- Retail Trade and Accommodation

- Transport, Postal and Warehousing

- Information Media and Telecommunications

- Financial and Insurance Services

- Rental, Hiring and Real Estate Services

- Professional, Scientific, Technical, Administrative and Support Services

- Public Administration and Safety

- Education and Training

- Health Care and Social Assistance

- Arts, Recreation and Other Services

- Other (please mention)

3. What is the postcode for where your business is predominantly located? (type postcode)

4. Please estimate how many employees your business has (select one of these options)

- $1-5$

- $6-19$

- $20-49$

- $50-99$

- $100+$

5. How long has your business been operating for? (select one of these options)

- Less than 1 year

- 1 - 5 years

- 6 - 10 years

- More than 10 years 
6. How is your business structured? (select one of these options)

- Sole trader

- Company

- Partnership

- Other, please detail

7. Is your business a part of a business network? (select one of these options)

- No

- Yes, please list

8. Does your business have any accreditation or certificates related to protecting the environment? (select one of these options)

- No

- Yes, please list

\section{Nature relatedness questions}

The following questions are about you as an individual and your relationship with the environment.

1. Please indicate how strongly you agree or disagree with the following statements.

\begin{tabular}{|c|c|c|c|c|c|}
\hline & Agree strongly & Agree & $\begin{array}{l}\text { Neither agree } \\
\text { nor disagree }\end{array}$ & Disagree & $\begin{array}{l}\text { Disagree } \\
\text { strongly }\end{array}$ \\
\hline $\begin{array}{l}\text { My connection to nature and } \\
\text { the environment is a part of } \\
\text { my spirituality }\end{array}$ & 0 & 0 & 0 & 0 & 0 \\
\hline $\begin{array}{l}\text { My relationship to nature is } \\
\text { an important part of who I } \\
\text { am }\end{array}$ & 0 & 0 & 0 & 0 & 0 \\
\hline $\begin{array}{l}\text { I feel very connected to all } \\
\text { living things and the earth }\end{array}$ & O & 0 & 0 & 0 & 0 \\
\hline $\begin{array}{l}\text { I am not separate from } \\
\text { nature, but a part of nature }\end{array}$ & O & 0 & $\mathrm{O}$ & 0 & 0 \\
\hline $\begin{array}{l}\text { I always think about how my } \\
\text { actions affect the } \\
\text { environment }\end{array}$ & 0 & 0 & 0 & 0 & 0 \\
\hline $\begin{array}{l}\text { I am very aware of } \\
\text { environmental issues }\end{array}$ & O & O & O & O & O \\
\hline $\begin{array}{l}\text { I think a lot about the } \\
\text { suffering of animals }\end{array}$ & O & O & O & O & 0 \\
\hline $\begin{array}{l}\text { Even in the middle of the } \\
\text { city, I notice nature around } \\
\text { me }\end{array}$ & 0 & 0 & 0 & 0 & 0 \\
\hline $\begin{array}{l}\text { My feelings about nature do } \\
\text { not affect how I live my life }\end{array}$ & 0 & 0 & 0 & 0 & 0 \\
\hline
\end{tabular}


2. Please indicate how strongly you agree or disagree with the following statements.

\begin{tabular}{|c|c|c|c|c|c|}
\hline & Agree strongly & Agree & $\begin{array}{c}\text { Neither agree } \\
\text { nor disagree }\end{array}$ & Disagree & $\begin{array}{l}\text { Disagree } \\
\text { strongly }\end{array}$ \\
\hline $\begin{array}{l}\text { Humans have the right to } \\
\text { use natural resources any } \\
\text { way we want }\end{array}$ & $\mathrm{O}$ & $\mathrm{O}$ & $\mathrm{O}$ & 0 & 0 \\
\hline $\begin{array}{l}\text { Conservation is unnecessary } \\
\text { because nature is strong } \\
\text { enough to recover from any } \\
\text { human impact }\end{array}$ & $\mathrm{O}$ & 0 & 0 & 0 & 0 \\
\hline $\begin{array}{l}\text { Animals, birds and plants } \\
\text { have fewer rights than } \\
\text { humans }\end{array}$ & 0 & 0 & 0 & 0 & 0 \\
\hline $\begin{array}{l}\text { Some species are just meant } \\
\text { to die out or become extinct }\end{array}$ & $\mathrm{O}$ & 0 & $\mathrm{O}$ & 0 & 0 \\
\hline $\begin{array}{l}\text { Nothing I do will change } \\
\text { problems in other places on } \\
\text { the planet }\end{array}$ & $\mathrm{O}$ & 0 & 0 & 0 & 0 \\
\hline $\begin{array}{l}\text { The state of nonhuman } \\
\text { species is an indicator of the }\end{array}$ & 0 & 0 & 0 & 0 & 0 \\
\hline
\end{tabular}

future for humans

3. Please indicate how strongly you agree or disagree with the following statements.

\begin{tabular}{|c|c|c|c|c|c|}
\hline & Agree strongly & Agree & $\begin{array}{c}\text { Neither agree } \\
\text { nor disagree }\end{array}$ & Disagree & $\begin{array}{l}\text { Disagree } \\
\text { strongly }\end{array}$ \\
\hline $\begin{array}{l}\text { The thought of being deep in } \\
\text { the bush, away from } \\
\text { civilization, is frightening }\end{array}$ & O & $\mathrm{O}$ & $\mathrm{O}$ & $\mathrm{O}$ & 0 \\
\hline $\begin{array}{l}\text { Conservation is unnecessary } \\
\text { because nature is strong } \\
\text { enough to recover from any } \\
\text { human impact }\end{array}$ & 0 & 0 & $\mathrm{O}$ & $\mathrm{O}$ & $\mathrm{O}$ \\
\hline $\begin{array}{l}\text { My ideal vacation spot } \\
\text { would be a remote, } \\
\text { wilderness area }\end{array}$ & 0 & 0 & 0 & 0 & 0 \\
\hline $\begin{array}{l}\text { I enjoy being outdoors, even } \\
\text { in unpleasant weather }\end{array}$ & $\mathrm{O}$ & 0 & 0 & $\mathrm{O}$ & 0 \\
\hline I don't often go out in nature & O & O & $\bigcirc$ & O & $\bigcirc$ \\
\hline $\begin{array}{l}\text { I take notice of wildlife } \\
\text { wherever I am }\end{array}$ & $\bigcirc$ & O & $\mathrm{O}$ & $\bigcirc$ & 0 \\
\hline
\end{tabular}




\section{Pro environmental behaviours}

The following questions are about your business and pro-environmental behaviours.

1. Below are pro-environmental behaviours. How often does your business undertake these actions to protect the environment?

\begin{tabular}{|c|c|c|c|c|c|c|}
\hline & Never & Rarely & Occasionally & Often & Very often & Don't know \\
\hline Conserving electricty & 0 & $\mathrm{O}$ & 0 & 0 & $\mathrm{O}$ & $\mathrm{O}$ \\
\hline $\begin{array}{l}\text { Purchasing sustainable } \\
\text { products }\end{array}$ & O & $\bigcirc$ & $\bigcirc$ & $\bigcirc$ & $\bigcirc$ & $\bigcirc$ \\
\hline Habitat enhancement & 0 & 0 & 0 & 0 & 0 & 0 \\
\hline $\begin{array}{l}\text { Donating to conservation } \\
\text { groups }\end{array}$ & 0 & $\bigcirc$ & 0 & 0 & O & 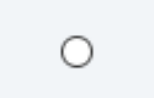 \\
\hline $\begin{array}{l}\text { Contacting government } \\
\text { agencies about } \\
\text { environmental issues }\end{array}$ & 0 & 0 & 0 & O & 0 & 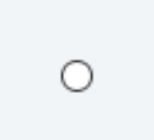 \\
\hline $\begin{array}{l}\text { Reading and watching } \\
\text { material related to protecting } \\
\text { the environment }\end{array}$ & 0 & 0 & 0 & $\bigcirc$ & 0 & O \\
\hline Supporting green policies & 0 & 0 & 0 & 0 & 0 & 0 \\
\hline $\begin{array}{l}\text { Joining environmental } \\
\text { groups }\end{array}$ & $\bigcirc$ & 0 & $\bigcirc$ & $\bigcirc$ & $\bigcirc$ & $\bigcirc$ \\
\hline Growing native plants & $\bigcirc$ & $\bigcirc$ & $\bigcirc$ & $\bigcirc$ & $\bigcirc$ & $\bigcirc$ \\
\hline Conserving water & O & 0 & 0 & 0 & 0 & 0 \\
\hline $\begin{array}{l}\text { Volunteering for } \\
\text { conservation }\end{array}$ & 0 & 0 & 0 & 0 & 0 & 0 \\
\hline Picking up litter & $\bigcirc$ & $\bigcirc$ & $\bigcirc$ & $\bigcirc$ & $\bigcirc$ & $\bigcirc$ \\
\hline Composting & $\bigcirc$ & $\bigcirc$ & $\bigcirc$ & $\bigcirc$ & $\bigcirc$ & $\bigcirc$ \\
\hline Recycling & $\bigcirc$ & 0 & $\bigcirc$ & 0 & 0 & $\bigcirc$ \\
\hline Pest control & 0 & $\bigcirc$ & $\bigcirc$ & $\bigcirc$ & $\bigcirc$ & $\bigcirc$ \\
\hline Having a green supply chain & $\bigcirc$ & $\bigcirc$ & $\bigcirc$ & $\bigcirc$ & $\bigcirc$ & $\bigcirc$ \\
\hline Using public transport & O & 0 & $\bigcirc$ & 0 & 0 & $\bigcirc$ \\
\hline
\end{tabular}

2. List any other pro-environmental behaviours that your business undertakes. 
3. To what extent do you think these barriers prevent your business from undertaking as much as you would like for the environment?

\begin{tabular}{l|cccccc} 
& Never & Rarely & Occasionally & Often & Very often & Don't know \\
\hline Lack of interest & 0 & 0 & 0 & 0 & 0 & 0 \\
Lack of resources/ costs & 0 & 0 & 0 & 0 & 0 & 0 \\
Availability of time & 0 & 0 & 0 & 0 & 0 & 0 \\
Lack of information & 0 & 0 & 0 & 0 & 0 & 0 \\
Lack of encouragement & 0 & 0 & 0 & 0 & 0 & 0 \\
Lack of opportunity & 0 & 0 & 0 & 0 & 0 & 0 \\
Other, please specify & 0 & 0 & 0 & 0 & 0 & 0 \\
& & & & & &
\end{tabular}

\section{Individual characteristics}

1. What age bracket do you belong to? (select one of these options)

- less than 20 years

- 20 - 24 years

- 25 - 29 years

- 30 - 34 years

- 35 - 39 years

- 40 - 44 years

- 45 - 49 years

- 50 - 54 years

- 55 - 59 years

- more than 60 years

2. What is your gender? (select one of these options)

- Female

- Male

- Other

- Prefer not to say

\section{Further comments}

1. As you reach the conclusion of the survey, do you have any further comments you would like to share about nature connection or pro-environmental behaviours?

\section{Thank you and further participation}

Thank you for taking the time to complete the survey. If you are a business leader, I would like to invite you to participate in an individual interview to discuss your connection to nature and business's pro-environmental behaviours in more detail. The interview will take approximately one hour.

If you are interested in being contacted further, please provide your contact details through the following survey link.

Please provide your contact details here (linked to contact survey).

You will be asked to provide your name, email address and mobile number. 
REFERENCES

\section{References}

Adams, M., \& Hardwick, P. (1998). An analysis of corporate donations: United Kingdom evidence. Journal of management Studies, 35(5), 641-654.

Albertini, E. (2013). Does environmental management improve financial performance? A meta-analytical review. Organization \& Environment, 26(4), 431-457.

Albudaiwi, D. (2017). Survey: Open-ended questions. The SAGE encyclopedia of communication research methods (1716-1717). SAGE.

Allen, M. W., \& Spialek, M. L. (2018). Young millennials, environmental orientation, food company sustainability, and green word-of-mouth recommendations. Journal of food products marketing, 24(7), 803-829.

Alsaawi, A. (2014). A critical review of qualitative interviews. European Journal of Business and Social Sciences, 3(4).

Amaladoss, M. X., \& Manohar, H. L. (2013). Communicating corporate social responsibilityA case of CSR communication in emerging economies. Corporate Social Responsibility and Environmental Management, 20(2), 65-80.

Ambert, A. M., Adler, P. A., Adler, P., \& Detzner, D. F. (1995). Understanding and evaluating qualitative research. Journal of Marriage and the Family, 879-893.

Amel, E., Manning, C., Scott, B., \& Koger, S. (2017). Beyond the roots of human inaction: Fostering collective effort toward ecosystem conservation. Science, 356(6335), 275279.

Ammenberg, J., Hjelm, O., \& Quotes, P. (2002). The connection between environmental management systems and continual environmental performance improvements. Corporate Environmental Strategy, 9(2), 183-192.

Aragón-Correa, J. A., Hurtado-Torres, N., Sharma, S., \& García-Morales, V. J. (2008). Environmental strategy and performance in small firms: A resource-based perspective. Journal of environmental management, 86(1), 88-103. 
REFERENCES

Armstrong, J. S., \& Overton, T. S. (1977). Estimating nonresponse bias in mail surveys. Journal of marketing research, 14(3), 396-402.

Ashrafi, M., Magnan, G. M., Adams, M., \& Walker, T. R. (2020). Understanding the conceptual evolutionary path and theoretical underpinnings of corporate social responsibility and corporate sustainability. Sustainability, 12(3), 760.

Attride-Stirling, J. (2001). Thematic networks: an analytic tool for qualitative research. Qualitative research, 1(3), 385-405.

Babiak, K., \& Trendafilova, S. (2011). CSR and environmental responsibility: motives and pressures to adopt green management practices. Corporate social responsibility and environmental management, 18(1), 11-24.

Bahari, S. F. (2010). Qualitative versus quantitative research strategies: contrasting epistemological and ontological assumptions. Sains Humanika, 52(1).

Balmer, J. M. (1995). Corporate branding and connoisseurship. Journal of General management, 21(1), 24-46.

Balmer, J. M., Fukukawa, K., \& Gray, E. R. (2007). The nature and management of ethical corporate identity: A commentary on corporate identity, corporate social responsibility and ethics. Journal of business ethics, 76(1), 7-15.

Banwo, A. O., \& Du, J. (2019). Workplace pro-environmental behaviors in small and mediumsized enterprises: an employee level analysis. Journal of Global Entrepreneurship Research, 9(1), 1-20.

Barbiero, G. (2011). Biophilia and Gaia. Two hypothesis for an affective ecology. Journal of Bio-Urbanism, 1, 11-27.

Baughn, C. C., Bodie, N. L., \& McIntosh, J. C. (2007). Corporate social and environmental responsibility in Asian countries and other geographical regions. Corporate social responsibility and environmental management, 14(4), 189-205.

Bell, C. (2008). 100\% PURE New Zealand: Branding for back-packers. Journal of Vacation Marketing, 14(4), 345-355. 
Benn, S., Edwards, M., \& Williams, T. (2014). Organizational change for corporate sustainability. Routledge.

Berg, N. (2005). Non-response bias. Encyclopedia of Social Measurement, 2(1), 865-873.

Berman, M. G., Jonides, J., \& Kaplan, S. (2008). The cognitive benefits of interacting with nature. Psychological science, 19(12), 1207-1212.

Bernstein, R. J. (1983). Beyond Objectivism and Relativism: Science. Hermeneutics, and Praxis, 223.

Berry, M. A., \& Rondinelli, D. A. (1998). Proactive corporate environmental management: A new industrial revolution. Academy of Management Perspectives, 12(2), 38-50.

Biodiversity. (2019). Ministry for the Environment. https://www.mfe.govt.nz/more/biodiversity/about-biodiversity/biodiversity-newzealand

Blake, J. (1999). Overcoming the 'value-action gap'in environmental policy: Tensions between national policy and local experience. Local environment, 4(3), 257-278.

Bleicher, J. (2017). Contemporary hermeneutics: Hermeneutics as method, philosophy and critique (Vol. 2). Routledge.

Blok, V., Wesselink, R., Studynka, O., \& Kemp, R. (2015). Encouraging sustainability in the workplace: a survey on the pro-environmental behaviour of university employees. Journal of cleaner production, 106, 55-67.

Blundel, R., Monaghan, A., \& Thomas, C. (2013). SMEs and environmental responsibility: a policy perspective. Business Ethics: A European Review, 22(3), 246-262.

Bögeholz, S. (2006). Nature experience and its importance for environmental knowledge, values and action: Recent German empirical contributions. Environmental education research, 12(1), 65-84. 
REFERENCES

Boiral, 0. (2005). The impact of operator involvement in pollution reduction: Case studies in Canadian chemical companies. Business Strategy and the Environment, 14(6), 339360.

Boiral, O.(2009). Greening the corporation through organizational citizenship behaviors. Journal of Business Ethics, 87(2), 221-236.

Boiral, O., Talbot, D., \& Paillé, P. (2015). Leading by example: A model of organizational citizenship behavior for the environment. Business Strategy and the Environment, 24(6), 532-550.

Braun, V., \& Clarke, V. (2006). Using thematic analysis in psychology. Qualitative research in psychology, 3(2), 77-101.

Bringslimark, T., Hartig, T., \& Patil, G. G. (2009). The psychological benefits of indoor plants: A critical review of the experimental literature. Journal of Environmental Psychology, 29(4), 422-433.

Brown, M. (2008). Outdoor education: Opportunities provided by a place based approach. New Zealand Journal of Outdoor Education, 2(3), 7-25

Brown, T. J., \& Dacin, P. A. (1997). The company and the product: Corporate associations and consumer product responses. Journal of marketing, 61(1), 68-84.

Bruch, H., \& Ghoshal, S. (2002). Beware the busy manager. Harvard Business Review, 80(2), 62-69.

Bryman, A. (2016). Social research methods. Oxford university press.

Buijs, A. E. (2009). Lay people's images of nature: Comprehensive frameworks of values, beliefs, and value orientations. Society and Natural Resources, 22(5), 417-432.

Cambra-Fierro, J., Polo-Redondo, Y., \& Wilson, A. (2008). The influence of an organisation's corporate values on employees personal buying behaviour. Journal of Business Ethics, 81(1), 157-167. 
Carmi, N., Arnon, S., \& Orion, N. (2015). Transforming environmental knowledge into behavior: The mediating role of environmental emotions. The Journal of Environmental Education, 46(3), 183-201.

Ceballos, G., Ehrlich, P. R., \& Dirzo, R. (2017). Biological annihilation via the ongoing sixth mass extinction signaled by vertebrate population losses and declines. Proceedings of the national academy of sciences, 114(30), E6089-E6096.

Chan, K. M., Balvanera, P., Benessaiah, K., Chapman, M., Díaz, S., Gómez-Baggethun, E., ... \& Luck, G. W. (2016). Opinion: Why protect nature? Rethinking values and the environment. Proceedings of the national academy of sciences, 113(6), 1462-1465.

Chang, C. Y., \& Chen, P. K. (2005). Human response to window views and indoor plants in the workplace. HortScience, 40(5), 1354-1359.

Chen, Y. S., Chang, C. H., \& Wu, F. S. (2012). Origins of green innovations: the differences between proactive and reactive green innovations. Management Decision.

Cheng, J. C. H., \& Monroe, M. C. (2012). Connection to nature: Children's affective attitude toward nature. Environment and Behavior, 44(1), 31-49.

Child, J., \& Tsai, T. (2005). The dynamic between firms' environmental strategies and institutional constraints in emerging economies: Evidence from China and Taiwan. Journal of Management studies, 42(1), 95-125.

Chowdhury, M. F. (2014). Interpretivism in aiding our understanding of the contemporary social world. Open Journal of Philosophy, 2014.

Clark, C. F., Kotchen, M. J., \& Moore, M. R. (2003). Internal and external influences on proenvironmental behavior: Participation in a green electricity program. Journal of environmental psychology, 23(3), 237-246.

Clayton, R., Thomas, C., \& Smothers, J. (2015). How to do walking meetings right. Harvard Business Review. 
REFERENCES

Clayton, S. (2003). Environmental identity: A conceptual and operational definition. In S. Clayton \& S. Opotow (Eds.), Identity and the natural environment. The psychology of nature (pp. 45-65). Cambridge, MA: MIT Press.

Clegg, B. (2011). Sustainable Business. Financial Times Prentice Hall.

Colléony, A., Prévot, A. C., Saint Jalme, M., \& Clayton, S. (2017). What kind of landscape management can counteract the extinction of experience?. Landscape and Urban Planning, 159, 23-31.

Collins, E., Lawrence, S., Pavlovich, K., \& Ryan, C. (2007). Business networks and the uptake of sustainability practices: the case of New Zealand. Journal of cleaner production, 15(8-9), 729-740.

Collins, E., Roper, J., \& Lawrence, S. (2010). Sustainability practices: trends in New Zealand businesses. Business Strategy and the Environment, 19(8), 479-494.

Corbin, J., \& Morse, J. M. (2003). The unstructured interactive interview: Issues of reciprocity and risks when dealing with sensitive topics. Qualitative inquiry, 9(3), 335-354.

Cosquer, A., Raymond, R., \& Prevot-Julliard, A. C. (2012). Observations of everyday biodiversity: a new perspective for conservation?. Ecology and Society, 17(4).

Crane, A. (2000). Corporate greening as amoralization. Organization Studies, 21(4), 673-696.

Creswell, J. W., \& Poth, C. N. (2016). Qualitative inquiry and research design: Choosing among five approaches. Sage publications.

Dahlmann, F., Branicki, L., \& Brammer, S. (2019). Managing carbon aspirations: The influence of corporate climate change targets on environmental performance. Journal of business ethics, 158(1), 1-24.

Daily, B. F., Bishop, J. W., \& Govindarajulu, N. (2009). A conceptual model for organizational citizenship behavior directed toward the environment. Business \& Society, 48(2), 243256. 
REFERENCES

Dean, J. H., Shanahan, D. F., Bush, R., Gaston, K. J., Lin, B. B., Barber, E., ... \& Fuller, R. A. (2018). Is nature relatedness associated with better mental and physical health?. International journal of environmental research and public health, 15(7), 1371.

Dean, T. J., \& McMullen, J. S. (2007). Toward a theory of sustainable entrepreneurship: Reducing environmental degradation through entrepreneurial action. Journal of business venturing, 22(1), 50-76.

Denzin, N. K., \& Lincoln, Y. S. (2008). Strategies of qualitative inquiry (Vol. 2). Sage.

Department of Conservation. (2020). Te Mana o te Taiao-Aotearoa New Zealand Biodiversity Strategy 2020. ISBN 978-0-9951392-1-3 (online).

DesJardins, J. (1998). Corporate environmental responsibility. Journal of business ethics, $17(8), 825-838$.

DiCicco-Bloom, B., \& Crabtree, B. F. (2006). The qualitative research interview. Medical education, $40(4), 314-321$.

Diekmann, A., \& Preisendörfer, P. (1998). Environmental behavior: Discrepancies between aspirations and reality. Rationality and society, 10(1), 79-102.

Dietz, T., Fitzgerald, A., \& Shwom, R. (2005). Environmental values. Annu. Rev. Environ. Resour., 30, 335-372.

Doh, J. P., Tashman, P., \& Benischke, M. H. (2019). Adapting to grand environmental challenges through collective entrepreneurship. Academy of Management Perspectives, 33(4), 450-468.

Dravigne, A., Waliczek, T. M., Lineberger, R. D., \& Zajicek, J. M. (2008). The effect of live plants and window views of green spaces on employee perceptions of job satisfaction. HortScience, 43(1), 183-187.

Dunlap, R. E., Van Liere, K. D., Mertig, A. G., \& Jones, R. E. (2000). New trends in measuring environmental attitudes: measuring endorsement of the new ecological paradigm: a revised NEP scale. Journal of social issues, 56(3), 425-442. 
Dutcher, T. S., Finley, J. C., Luloff, A. E., \& Johnson, J. B. (2007). Connectivity with nature as a measure of environmental values. Environment and Behavior, 39(4), 474-493.

Easton, K. L., McComish, J. F., \& Greenberg, R. (2000). Avoiding common pitfalls in qualitative data collection and transcription. Qualitative health research, 10(5), 703-707.

Ekwueme, C. M., Egbunike, C. F., \& Onyali, C. I. (2013). Benefits of triple bottom line disclosures on corporate performance: An exploratory study of corporate stakeholders. J. Mgmt. \& Sustainability, 3, 79.

Elkington, J. (2004). Enter the triple bottom line. The triple bottom line: Does it all add up, 11(12), 1-16.

Ewert, A., Place, G., \& Sibthorp, J. (2005). Early-life outdoor experiences and an individual's environmental attitudes. Leisure Sciences, 27(3), 225-239.

Ferdig, M. A. (2007). Sustainability leadership: Co-creating a sustainable future. Journal of Change Management, 7(1), 25-35.

Finger, M. (1994). From knowledge to action? Exploring the relationships between environmental experiences, learning, and behavior. Journal of social issues, 50(3), 141-160.

Fraj, E., Martínez, E., \& Matute, J. (2011). Green marketing strategy and the firm's performance: the moderating role of environmental culture. Journal of Strategic Marketing, 19(4), 339-355.

Gadamer, H. (1998). Truth and Method (2nd ed.). New York, NY: Continuum.

Gardner, G. T., \& Stern, P. C. (1996). Environmental problems and human behavior. Allyn \& Bacon.

Garvare, R., \& Johansson, P. (2010). Management for sustainability-a stakeholder theory. Total quality management, 21(7), 737-744.

Gebhard, U. (1994). Kind und Natur [Child and nature]. Opladen: WestdeutscherVerlag. 
REFERENCES

Gerstenfeld, A., \& Roberts, H. (2000). Size matters: barriers and prospects for environmental management in small and medium-sized enterprises. Small and medium-sized enterprises and the environment, 106-119.

Gill, P., Stewart, K., Treasure, E., \& Chadwick, B. (2008). Methods of data collection in qualitative research: interviews and focus groups. British dental journal, 204(6), 291295.

Glavas, A., \& Mish, J. (2015). Resources and capabilities of triple bottom line firms: going over old or breaking new ground?. Journal of Business Ethics, 127(3), 623-642.

Goldsmith, R. E. (1997). Reputation: realizing value from the corporate image. The Service Industries Journal, 17(2), 354.

Gray, E. R., \& Balmer, J. M. (1998). Managing corporate image and corporate reputation. Long range planning, 31(5), 695-702.

Green, J., \& Thorogood, N. (2018). Qualitative methods for health research. sage.

Gruen, L. (2009). Attending to nature: Empathetic engagement with the more than human world. Ethics \& the Environment, 14(2), 23-38.

Guba, E. G., \& Lincoln, Y. S. (1994). Competing paradigms in qualitative research. Handbook of qualitative research, 2(163-194), 105.

Hahn, E. R., \& Garrett, M. K. (2017). Preschoolers' moral judgments of environmental harm and the influence of perspective taking. Journal of environmental psychology, 53, 1119.

Hahn, R., \& Kühnen, M. (2013). Determinants of sustainability reporting: a review of results, trends, theory, and opportunities in an expanding field of research. Journal of cleaner production, 59, 5-21.

Handelman, J. M. (2006). Corporate identity and the societal constituent. Journal of the Academy of Marketing Science, 34(2), 107-114. 
REFERENCES

Hanelt, A., Busse, S., \& Kolbe, L. M. (2017). Driving business transformation toward sustainability: exploring the impact of supporting IS on the performance contribution of eco-innovations. Information Systems Journal, 27(4), 463-502.

Hargreaves, T. (2011). Practice-ing behaviour change: Applying social practice theory to proenvironmental behaviour change. Journal of consumer culture, 11(1), 79-99.

Headd, B., \& Saade, R. (2008). Do business definition decisions distort small business research results?. Available at SSRN 1228536.

Heikkurinen, P. (2011). Environmental strategy and sustainability. In Theory and Practice of Corporate Social Responsibility (pp. 123-140). Springer, Berlin, Heidelberg.

Hemingway, C. A., \& Maclagan, P. W. (2004). Managers' personal values as drivers of corporate social responsibility. Journal of business ethics, 50(1), 33-44.

Hidayati, N. D. (2011). Pattern of corporate social responsibility programs: a case study. Social Responsibility Journal.

Hinds, J., \& Sparks, P. (2008). Engaging with the natural environment: The role of affective connection and identity. Journal of Environmental Psychology, 28, 109-120.

Hirsh, J. B. (2010). Personality and environmental concern. Journal of Environmental Psychology, 30(2), 245-248.

Hirsh, J. B., \& Dolderman, D. (2007). Personality predictors of consumerism and environmentalism: A preliminary study. Personality and individual differences, 43(6), 1583-1593.

Hollender, J., \& Breen, B. (2010). The responsibility revolution: How the next generation of businesses will win. John Wiley \& Sons.

Hoogendoorn, B., Guerra, D., \& van der Zwan, P. (2015). What drives environmental practices of SMEs?. Small Business Economics, 44(4), 759-781. 
REFERENCES

Howell, A. J., Dopko, R. L., Passmore, H. A., \& Buro, K. (2011). Nature connectedness: Associations with well-being and mindfulness.Personality and individual differences, 51(2), 166-171.

Ives, C. D., Abson, D. J., von Wehrden, H., Dorninger, C., Klaniecki, K., \& Fischer, J. (2018). Reconnecting with nature for sustainability. Sustainability science, 13(5), 1389-1397.

Ives, C. D., Giusti, M., Fischer, J., Abson, D. J., Klaniecki, K., Dorninger, C., ... \& Raymond, C. M. (2017). Human-nature connection: a multidisciplinary review. Current Opinion in Environmental Sustainability, 26, 106-113.

Jakobsen, M., \& Jensen, R. (2015). Common method bias in public management studies. International Public Management Journal, 18(1), 3-30.

Jamshed, S. (2014). Qualitative research method-interviewing and observation. Journal of basic and clinical pharmacy, 5(4), 87.

Jones, J., Jackson, J., Tudor, T., \& Bates, M. (2012). Strategies to enhance waste minimization and energy conservation within organizations: a case study from the UK construction sector. Waste management \& research, 30(9), 981-990.

Kalamas, M., Cleveland, M., \& Laroche, M. (2014). Pro-environmental behaviors for thee but not for me: Green giants, green Gods, and external environmental locus of control. Journal of Business Research, 67(2), 12-22.

Kalliath, T., Kalliath, P., \& Kossek, E. E. (2012). Achieving employee wellbeing in a changing work environment. International Journal of Manpower.

Kals, E. (2014). Affective connection to nature. Encyclopedia of quality of life and well-being research, 83-88.

Kals, E., Schumacher, D., \& Montada, L. (1999). Emotional affinity toward nature as a motivational basis to protect nature. Environment and Behavior, 31(2), 178-202.

Kals, E., Schumacher, D., \& Montada, L. (1999). Sustainable development and emotions. In P. Schmuck \& W. P. Schultz (Eds.), Psychology of sustainable development (pp. 97-122). Norwell, MA: Kluwer Academic Publishers. 
REFERENCES

Kempton, W., Boster, J. S., \& Hartley, J. A. (1995). Environmental values in American culture. mit Press. Lumber R. Contact, emotion, meaning, compassion and beauty as pathways to nature connectedness. PhD (dissertation). Derby, The University of Derby; 2017.Unpublished.

Ketchen, D. J., \& Shook, C. L. (1996). The application of cluster analysis in strategic management research: an analysis and critique. Strategic management journal, 17(6), 441-458.

Khanna, M., Deltas, G., \& Harrington, D. R. (2009). Adoption of pollution prevention techniques: the role of management systems and regulatory pressures. Environmental and Resource Economics, 44(1), 85-106.

Kiesling, F. M., \& Manning, C. M. (2010). How green is your thumb? Environmental gardening identity and ecological gardening practices.Journal of Environmental Psychology, 30(3), 315-327.

Kirk, D. (1995). Environmental management in hotels. International journal of contemporary hospitality management.

Kirkwood, J., \& Walton, S. (2014). How green is green? Ecopreneurs balancing environmental concerns and business goals. Australasian Journal of Environmental Management, 21(1), 37-51.

Klassen, R. D., \& McLaughlin, C. P. (1996). The impact of environmental management on firm performance. Management science, 42(8), 1199-1214.

Koch, T. (1999). An interpretive research process: Revisiting phenomenological and hermeneutical approaches. Nurse Researcher (through 2013), 6(3), 20.

Koenig-Lewis, N., Palmer, A., Dermody, J., \& Urbye, A. (2014). Consumers' evaluations of ecological packaging-Rational and emotional approaches. Journal of environmental psychology, 37, 94-105. 
Kollmuss, A., \& Agyeman, J. (2002). Mind the gap: why do people act environmentally and what are the barriers to pro-environmental behavior?. Environmental education research, 8(3), 239-260.

Krakoff, S. (2003). Mountains without Handrails-Wilderness without Cellphones. Harv. Envtl. L. Rev., 27, 417.

Kudłak, R., \& Low, K. Y. (2015). Special issues dedicated to CSR and corporate sustainability: A review and commentary. Long Range Planning, 48(3), 215-227.

Kurasaki, K. S. (2000). Intercoder reliability for validating conclusions drawn from openended interview data. Field methods, 12(3), 179-194.

Kvale, S. (1994). Ten standard objections to qualitative research interviews. Journal of phenomenological psychology, 25(2), 147-173.

Larson, L. R., Whiting, J. W., \& Green, G. T. (2011). Exploring the influence of outdoor recreation participation on pro-environmental behaviour in a demographically diverse population. Local Environment, 16(1), 67-86.

Lawrence, E. K. (2012). Visitation to natural areas on campus and its relation to place identity and environmentally responsible behaviors. The Journal of Environmental Education, 43(2), 93-106.

Lee, C. J. G. (2012). Reconsidering constructivism in qualitative research. Educational Philosophy and theory, 44(4), 403-412.

Lee, S. Y. (2008). Drivers for the participation of small and medium-sized suppliers in green supply chain initiatives. Supply chain management: an international journal.

Lee, S. Y., \& Klassen, R. D. (2008). Drivers and enablers that foster environmental management capabilities in small-and medium-sized suppliers in supply chains. Production and Operations management, 17(6), 573-586.

Lent, T., \& Wells, R. P. (1992). Corporate environmental management study shows shift from compliance to strategy. Environmental Quality Management, 1(4), 379-394. 
Lepoutre, J., \& Heene, A. (2006). Investigating the impact of firm size on small business social responsibility: A critical review. Journal of business ethics, 67(3), 257-273.

Lewis, K., \& Cassells, S. (2010). Barriers and drivers for environmental practice uptake in SMEs: A New Zealand perspective. International Journal of Business Studies: A Publication of the Faculty of Business Administration, Edith Cowan University, 18(1), 7.

Lin, B. B., Fuller, R. A., Bush, R., Gaston, K. J., \& Shanahan, D. F. (2014). Opportunity or orientation? Who uses urban parks and why. PLoS one, 9(1).

Loder, A. (2014). 'There's a meadow outside my workplace': A phenomenological exploration of aesthetics and green roofs in Chicago and Toronto. Landscape and urban planning, 126, 94-106.

Longhurst, R. (2003). Semi-structured interviews and focus groups. Key methods in geography, 3(2), 143-156.

Lottrup, L., Grahn, P., \& Stigsdotter, U. K. (2013). Workplace greenery and perceived level of stress: Benefits of access to a green outdoor environment at the workplace. Landscape and Urban Planning, 110, 5-11.

Lozano, R. (2015). A holistic perspective on corporate sustainability drivers. Corporate social responsibility and environmental management, 22(1), 32-44.

Lucas, K., Brooks, M., Darnton, A., \& Jones, J. E. (2008). Promoting pro-environmental behaviour: existing evidence and policy implications. Environmental Science \& Policy, 11(5), 456-466.

Maas, K., \& Rosendaal, S. (2016). Sustainability targets in executive remuneration: Targets, time frame, country and sector specification. Business Strategy and the Environment, 25(6), 390-401.

Mackay, C. M., \& Schmitt, M. T. (2019). Do people who feel connected to nature do more to protect it? A meta-analysis. Journal of Environmental Psychology, 65, 101323.

MacLean, L. M., Meyer, M., \& Estable, A. (2004). Improving accuracy of transcripts in qualitative research. Qualitative health research, 14(1), 113-123. 
REFERENCES

Madsen, H., \& Ulhøi, J. P. (2001). Integrating environmental and stakeholder management. Business strategy and the environment, 10(2), 77-88.

Maduenyi, S., Oke, A. O., Fadeyi, O., \& Ajagbe, A. M. (2015). Impact of organisational structure on organisational performance.

Malik, M. (2015). Value-enhancing capabilities of CSR: A brief review of contemporary literature. Journal of Business Ethics, 127(2), 419-438.

Malterud, K. (2016). Theory and interpretation in qualitative studies from general practice: why and how?. Scandinavian Journal of Public Health, 44(2), 120-129.

Mayer, F. S., \& Frantz, C. M. (2004). The connectedness to nature scale: A measure of individuals' feeling in community with nature. Journal of environmental psychology, 24(4), 503-515.

McCaffrey, G., Raffin-Bouchal, S., \& Moules, N. J. (2012). Hermeneutics as research approach: A reappraisal. International Journal of Qualitative Methods, 11(3), 214-229.

McCullough, B. P., \& Cunningham, G. B. (2010). A conceptual model to understand the impetus to engage in and the expected organizational outcomes of green initiatives. Quest, 62(4), 348-363.

McCunn, L. J., \& Gifford, R. (2012). Do green offices affect employee engagement and environmental attitudes?. Architectural Science Review, 55(2), 128-134.

McCusker, K., \& Gunaydin, S. (2015). Research using qualitative, quantitative or mixed methods and choice based on the research. Perfusion, 30(7), 537-542.

McEwen, T. (2013). Ecopreneurship as a solution to environmental problems: implications for college level entrepreneurship education. International Journal of Academic Research in Business and Social Sciences, 3(5), 264.

Menon, A., \& Menon, A. (1997). Enviropreneurial marketing strategy: the emergence of corporate environmentalism as market strategy. Journal of marketing, 61(1), 51-67. 
REFERENCES

Metcalfe, C. E. (1998). The stakeholder corporation. Business Ethics: A European Review, 7(1), 30-36.

Milena, Z. R., Dainora, G., \& Alin, S. (2008). Qualitative research methods: A comparison between focus-group and in-depth interview. Annals of the University of Oradea, Economic Science Series, 17(4), 1279-1283.

Miles, M. P., \& Covin, J. G. (2000). Environmental marketing: A source of reputational, competitive, and financial advantage. Journal of business ethics, 23(3), 299-311.

Milfont, T. L., \& Duckitt, J. (2010). The environmental attitudes inventory: A valid and reliable measure to assess the structure of environmental attitudes. Journal of environmental psychology, 30(1), 80-94.

Miller, J. R. (2006). Restoration, reconciliation, and reconnecting with nature nearby. Biological conservation, 127(3), 356-361.

Miller, N., Pogue, D., Gough, Q., \& Davis, S. (2009). Green buildings and productivity. Journal of Sustainable Real Estate, 1(1), 65-89.

Montabon, F., Sroufe, R., \& Narasimhan, R. (2007). An examination of corporate reporting, environmental management practices and firm performance. Journal of operations management, 25(5), 998-1014.

Montiel, I. (2008). Corporate social responsibility and corporate sustainability: Separate pasts, common futures. Organization \& Environment, 21(3), 245-269.

Müller, M., Kals, E., \& Pansa, R. (2009). Adolescents' emotional affinity towards nature: A cross-societal study. Special Issue: Children and Nature. Journal of Developmental Processes, 4, 59-69.

Nawrocka, D., \& Parker, T. (2009). Finding the connection: environmental management systems and environmental performance. Journal of cleaner production, 17(6), 601607.

Nisbet, E. K., \& Zelenski, J. M. (2013). The NR-6: a new brief measure of nature relatedness. Frontiers in psychology, 4, 813. 
Nisbet, E. K., Zelenski, J. M., \& Murphy, S. A. (2009). The nature relatedness scale: Linking individuals' connection with nature to environmental concern and behavior. Environment and behavior, 41(5), 715-740.

Noble, H., \& Smith, J. (2015). Issues of validity and reliability in qualitative research. Evidence-based nursing, 18(2), 34-35.

Nord, M., Luloff, A. E., \& Bridger, J. C. (1998). The association of forest recreation with environmentalism. Environment and behavior, 30(2), 235-246.

OECD. (2017). Enhancing the contributions of SMEs in a global and digitalized economy. Paris: Meeting of the OECD Council at Ministerial Level.

OECD. (2019). OECD SME and Entrepreneurship. Outlook 2019. OECD Publishing, Paris.

Olson, E. G. (2008). Creating an enterprise-level "green” strategy. Journal of business strategy.

Orts, E. W., \& Strudler, A. (2002). The ethical and environmental limits of stakeholder theory. Business Ethics Quarterly, 215-233.

Otubanjo, O. (2013). Theorising the interconnectivity between corporate social responsibility (CSR) and corporate identity. J. Mgmt. \& Sustainability, 3, 74.

Paterson, M., \& Higgs, J. (2005). Using hermeneutics as a qualitative research approach in professional practice. The Qualitative Report, 10(2), 339-357.

Pensini, P., Horn, E., \& Caltabiano, N. J. (2016). An exploration of the relationships between adults' childhood and current nature exposure and their mental well-being. Children, Youth and Environments, 26(1), 125-147.

Pereira, M., \& Forster, P. (2015). The relationship between connectedness to nature, environmental values, and pro-environmental behaviours. Reinvention: An international journal of undergraduate research, 8(2).

Perron, G. M., Côté, R. P., \& Duffy, J. F. (2006). Improving environmental awareness training in business. Journal of Cleaner Production, 14(6-7), 551-562. 
REFERENCES

Phillips, R. A., \& Reichart, J. (2000). The environment as a stakeholder? A fairness-based approach. Journal of business ethics, 23(2), 185-197.

Podsakoff, P. M., \& Organ, D. W. (1986). Self-reports in organizational research: Problems and prospects. Journal of management, 12(4), 531-544.

Pooley, J. A., \& O’Connor, M. (2000). Environmental education and attitudes: Emotions and beliefs are what is needed. Environment and behavior, 32(5), 711-723.

Poortinga, W., Steg, L., \& Vlek, C. (2004). Values, environmental concern, and environmental behavior: A study into household energy use. Environment and behavior, 36(1), 7093.

Porter, M. E., \& Kramer, M. R. (2006). The link between competitive advantage and corporate social responsibility. Harvard Business Review, 84(12), 78-92.

Prior, M. T. (2018). Accomplishing "rapport" in qualitative research interviews: Empathic moments in interaction. Applied Linguistics Review, 9(4), 487-511.

Rezapouraghdam, H., Alipour, H., \& Arasli, H. (2018). Workplace spirituality and organization sustainability: a theoretical perspective on hospitality employees' sustainable behavior. Environment, Development and Sustainability, 1-19.

Ristovska, M. (2010). The Role Of The Business Sector In Promoting A Greener Future. International Business \& Economics Research Journal (IBER), 9(4).

Robertson, J. L., \& Barling, J. (2013). Greening organizations through leaders' influence on employees' pro-environmental behaviors. Journal of organizational behavior, 34(2), 176-194.

Rondinelli, D. A., \& Berry, M. A. (2000). Environmental citizenship in multinational corporations: social responsibility and sustainable development. European Management Journal, 18(1), 70-84.

Rosa, C. D., \& Collado, S. (2019). Experiences in nature and environmental attitudes and behaviors: Setting the ground for future research. Frontiers in psychology, 10, 763. 
REFERENCES

Rosen, C. M. (2005). The business-environment connection. Environmental History, 10(1), 77-79.

Ruepert, A., Keizer, K., Steg, L., Maricchiolo, F., Carrus, G., Dumitru, A., \& Moza, D. (2016). Environmental considerations in the organizational context: A pathway to proenvironmental behaviour at work. Energy Research \& Social Science, 17, 59-70.

Russell, S., \& Griffiths, A. (2008). Chapter 4 The role of emotions in driving workplace proenvironmental behaviors. Emotions, Ethics and Decision-Making (Research on Emotion in Organizations, Volume 4), 83-107.

Rutherfoord, R., Blackburn, R. A., \& Spence, L. J. (2000). Environmental management and the small firm. International Journal of Entrepreneurial Behavior \& Research.

Ryan, R. M., Weinstein, N., Bernstein, J., Brown, K. W., Mistretta, L., \& Gagne, M. (2010). Vitalizing effects of being outdoors and in nature.Journal of Environmental Psychology, 30(2), 159-168.

Sadovnikova, A., \& Pujari, A. (2017). The effect of green partnerships on firm value. Journal of the Academy of Marketing Science, 45(2), 251-267.

Saifulina, N., \& Carballo-Penela, A. (2017). Promoting sustainable development at an organizational level: An analysis of the drivers of workplace environmentally friendly behaviour of employees. Sustainable Development, 25(4), 299-310.

Salzmann, O., Ionescu-Somers, A., \& Steger, U. (2005). The business case for corporate sustainability: literature review and research options. European Management Journal, 23(1), 27-36.

Saunders, M., Lewis, P., \& Thornhill, A. (2009). Research methods for business students. Pearson education.

Schaltegger, S. (2002). A framework for ecopreneurship. Greener management international, (38).

Schick, H., Marxen, S., \& Freimann, J. (2002). Sustainability Issues for Start-up Entrepreneurs. Greener management international, (38). 
Schultz, P. W. (2001). The structure of environmental concern: Concern for self, other people, and the biosphere. Journal of environmental psychology, 21(4), 327-339.

Schultz, P. W., \& Zelezny, L. C. (1998). Values and proenvironmental behavior: A five-country survey. Journal of cross-cultural psychology, 29(4), 540-558.

Schuttler, S. G., Sorensen, A. E., Jordan, R. C., Cooper, C., \& Shwartz, A. (2018). Bridging the nature gap: can citizen science reverse the extinction of experience?. Frontiers in Ecology and the Environment, 16(7), 405-411.

Schwandt, T. A. (1994). Constructivist, interpretivist approaches to human inquiry. Handbook of qualitative research, 1, 118-137.

Shanahan, D. F., Fuller, R. A., Bush, R., Lin, B. B., \& Gaston, K. J. (2015). The health benefits of urban nature: how much do we need?. BioScience, 65(5), 476-485.

Sharma, S. (2002). Research in corporate sustainability: What really matters. Research in corporate sustainability: The evolving theory and practice of organizations in the natural environment, 1-29.

Shibata, S., \& Suzuki, N. (2004). Effects of an indoor plant on creative task performance and mood. Scandinavian journal of psychology, 45(5), 373-381.

Smith, J., \& Noble, H. (2014). Bias in research. Evidence-based nursing, 17(4), 100-101.

Snep, R. P., WallisDeVries, M. F., \& Opdam, P. (2011). Conservation where people work: A role for business districts and industrial areas in enhancing endangered butterfly populations?. Landscape and Urban Planning, 103(1), 94-101.

Starik, M. (1995). Should trees have managerial standing? Toward stakeholder status for non-human nature. Journal of business ethics, 14(3), 207-217.

Stern, P. C. (2000). New environmental theories: toward a coherent theory of environmentally significant behavior. Journal of social issues, 56(3), 407-424.

Stern, P. C. (2000). Towards a coherent theory of environmentally significant behavior. Journal of Social Issues, 56(3), 407-424. 
Stern, P. C., Dietz, T., \& Guagnano, G. A. (1995). The new environmental paradigm in social psychological perspective. Environment and Behavior, 27(6), 723-745.

Stubbs, W., \& Cocklin, C. (2008). Conceptualizing a "sustainability business model". Organization \& environment, 21(2), 103-127.

Stuckey, H. (2014). The first step in data analysis: Transcribing and managing qualitative research data. Journal of Social Health and Diabetes, 2(1), 6-6.

Studer, S., Welford, R., \& Hills, P. (2006). Engaging Hong Kong businesses in environmental change: drivers and barriers. Business Strategy and the Environment, 15(6), 416-431.

Sugiarto, A., Suharti, L., \& Dwiatmadja, C. (2019). Building Green Behavior as a Corporate Sustainability Strategy Study on a Green Company in Indonesia. Quality-Access to Success, 20(172).

Supporting SME's. (2020). Ministry of Foreign Affairs \& Trade. https://www.mfat.govt.nz/en/trade/free-trade-agreements/free-tradeagreements-in-force/cptpp/supporting-smes/

Sutton, J., \& Austin, Z. (2015). Qualitative research: Data collection, analysis, and management. The Canadian journal of hospital pharmacy, 68(3), 226.

Tam, K. P. (2013). Concepts and measures related to connection to nature: Similarities and differences. Journal of environmental psychology, 34, 64-78.

Taylor, M. C. (2005). Interviewing. Qualitative research in health care, 39-55.

Tehseen, S., Ramayah, T., \& Sajilan, S. (2017). Testing and controlling for common method variance: A review of available methods. Journal of Management Sciences, 4(2), 142168.

Tkaczynski, A. (2017). Segmentation using two-step cluster analysis. In Segmentation in social marketing (pp. 109-125). Springer, Singapore. 
REFERENCES

Tudor, T. L., Barr, S. W., \& Gilg, A. W. (2007). Strategies for improving recycling behaviour within the Cornwall National Health Service (NHS) in the UK. Waste management \& research, 25(6), 510-516.

Utting, P. (2005). Corporate responsibility and the movement of business. Development in practice, $15(3-4), 375-388$.

Van Birgelen, M., Semeijn, J., \& Keicher, M. (2009). Packaging and proenvironmental consumption behavior: Investigating purchase and disposal decisions for beverages. Environment and Behavior, 41(1), 125-146.

Vazquez, D. A., \& Liston-Heyes, C. (2008). Corporate discourse and environmental performance in Argentina. Business Strategy and the Environment, 17(3), 179-193.

Veríssimo, D. (2013). Influencing human behaviour: an underutilised tool for biodiversity management. Conservation Evidence, 10(1), 29-31.

Vermeulen, W. J., \& Witjes, S. (2016). On addressing the dual and embedded nature of business and the route towards corporate sustainability. Journal of Cleaner Production, 112, 2822-2832.

Vernon, J., Essex, S., Pinder, D., \& Curry, K. (2003). The 'greening'of tourism microbusinesses: outcomes of focus group investigations in South East Cornwall. Business strategy and the environment, 12(1), 49-69.

Viswanathan, L., \& Varghese, G. (2018). Greening of business: A step towards sustainability. Journal of Public Affairs, 18(2), e1705.

Wagner, B., \& Svensson, G. (2014). A framework to navigate sustainability in business networks. European Business Review.

Wang, Y., Shi, S., Chen, Y., \& Gursoy, D. (2019). An examination of market orientation and environmental marketing strategy: the case of Chinese firms. The Service Industries Journal, 39(15-16), 1046-1071.

Weber, M. (2008). The business case for corporate social responsibility: A company-level measurement approach for CSR. European Management Journal, 26(4), 247-261. 
REFERENCES

Wendler T., Gröttrup S. (2016) Cluster Analysis. In: Data Mining with SPSS Modeler. Springer, Cham. https://doi.org/10.1007/978-3-319-28709-6_7

Whelan, T., \& Fink, C. (2016). The comprehensive business case for sustainability. Harvard Business Review, 21, 2012.

Whitburn, J., Linklater, W. L., \& Milfont, T. L. (2019). Exposure to urban nature and tree planting are related to pro-environmental behavior via connection to nature, the use of nature for psychological restoration, and environmental attitudes. Environment and Behavior, 51(7), 787-810.

Wilson, D. (2002). This juvenile posturing is for punks. The Guardian, 8.

Yaffe, T., \& Kark, R. (2011). Leading by example: the case of leader OCB. Journal of Applied Psychology, 96(4), 806.

York, J. G. (2009). Pragmatic sustainability: Translating environmental ethics into competitive advantage. Journal of Business Ethics, 85(1), 97-109.

Zientara, P., \& Zamojska, A. (2018). Green organizational climates and employee proenvironmental behaviour in the hotel industry. Journal of Sustainable Tourism, 26(7), 1142-1159.

Zinkhan, G. M., Ganesh, J., Jaju, A., \& Hayes, L. (2001). Corporate image: a conceptual framework for strategic planning. In American Marketing Association. Conference Proceedings (Vol. 12, p. 152). American Marketing Association.

Zsóka, Á. (2005). Consistency and awareness gaps in pro-environmental organisational behaviour (Doctoral dissertation, Doctoral dissertation. Corvinus University of Budapest).

Zsóka, Á., Szerényi, Z. M., Széchy, A., \& Kocsis, T. (2013). Greening due to environmental education? Environmental knowledge, attitudes, consumer behavior and everyday pro-environmental activities of Hungarian high school and university students. Journal of Cleaner Production, 48, 126-138. 
Zu, L. (2019). Purpose-driven leadership for sustainable business: From the Perspective of Taoism. International Journal of Corporate Social Responsibility, 4(1), 1-31. 